Portland State University

PDXScholar

$3-11-2021$

\title{
Short-term and Long-term Effects of New Light Rail Transit Service on Transit Ridership and Traffic Congestion at Two Geographical Levels
}

Huajie Yang

Portland State University

Follow this and additional works at: https://pdxscholar.library.pdx.edu/open_access_etds

Part of the Transportation Commons, and the Urban Studies Commons Let us know how access to this document benefits you.

\section{Recommended Citation}

Yang, Huajie, "Short-term and Long-term Effects of New Light Rail Transit Service on Transit Ridership and Traffic Congestion at Two Geographical Levels" (2021). Dissertations and Theses. Paper 5658.

https://doi.org/10.15760/etd.7530

This Dissertation is brought to you for free and open access. It has been accepted for inclusion in Dissertations and Theses by an authorized administrator of PDXScholar. Please contact us if we can make this document more accessible: pdxscholar@pdx.edu. 
Short-term and Long-term Effects of New Light Rail Transit Service on Transit Ridership and Traffic Congestion at Two Geographical Levels

by

Huajie Yang

A dissertation submitted in partial fulfillment of the requirements for the degree of

Doctor of Philosophy

in

Urban Studies

Dissertation Committee:

Liming Wang, Chair

Jennifer Dill

Aaron Golub

Wayne Wakeland

Portland State University

2021 
(C) 2021 Huajie Yang 


\begin{abstract}
This dissertation quantitatively examines the effect of new Light Rail Transit (LRT) services on transit ridership and traffic congestion over time at two different geographical levels: at the corridor level, this study conducts case studies of two LRT lines in the Portland, Oregon region; at the regional level, this study uses a synthetic control method to construct a "synthetic" control Urbanized Areas (UA) that closely approximates the counterfactual transit ridership and traffic congestion scenario in the absence of light rail project in three UAs across America. The results of the corridor-level study suggest that both LRT lines increased transit ridership in the short- and long-term and relieved traffic congestion in the short-term, while having no statistically significant effect on traffic congestion in the long-term, likely due to induced traffic demand. Results of the regional-level study suggest that, while new LRT services contributed to transit ridership in most UAs, they did relieve traffic congestion in a limited number of UAs, and that the effect changed over time and varied across UAs. The comprehensively temporal and geographical analysis will provide a better understanding of the impacts of new LRT services on transit ridership and traffic congestion, and hence provides policy makers insightful suggestions for building LRT projects to be more sustainable and to more effectively attract riders from former auto drivers.
\end{abstract}




\section{Acknowledgements}

I am grateful to many individuals for the completion of this dissertation. Without the generous support from my adviser, teachers, and mentors along the way, I could not have turned the research ideas into established research products. As my dissertation advisor, Dr. Liming Wang, provides enormous support and valuable suggestions. In the past seven years, he offered me many opportunities to participate in his cutting-edge research projects. The seven years working with him have been wonderful. I not only have got comprehensive academic training from him, and also have learned how to be a rigorous scholar and how to be a good man. He generously shared his time and data and provided extraordinary patience and guidance to improve my research. I would also like to send my appreciation to the other professors on my dissertation committee. I would like to express my gratitude to Dr. Jennifer Dill. It is lucky to take four transportation courses taught by her. These courses opened the door to the transportation problems and policies world for me. For my dissertation and field papers, she always gave me very insightful comments on how to improve. I also want to thank Dr. Aaron Golub. His past and present research was and continues to be an inspiration for this dissertation. My discussions with him deepen my understanding of transit and help me to write an academic paper in a coherent and concise way. I also want to thank Wayne Wakeland. My discussions with Dr. Wayne Wakeland help me to refine this research and consolidate the conceptual framework of this research. He also taught me agent-based simulation. 
I would also like to thank many other people at PSU. As a field exam committee member, Dr.Kuan-Pin Lin helped much on the methodologies. He shared the synthetic control method with me. I would like to thank Dr. Yiping Fang. She always encouraged and helped me. I shared an office with Dr. Joseph Broach for years and we worked on one research project. No matter when I have a question and no matter what the question is, he always could find a solution. He taught me many software techniques and research skills. I also learned how to do rigorous research from him. For all my peer Ph.D. Students at the Toulan School of Urban Studies and Planning, thank you for all the years we have spent together.

Finally, this dissertation is dedicated to my beloved family. I would like to thank my parents, Ms. Tianhua Lou and Mr. Gaolin Yang, and my elder sister, Ms. Huahui Yang. Thank you for providing patience, support, and belief in what I was doing. I am truly grateful. Your full support kept me going through many crises and all-nighters. 


\section{Table of Contents}

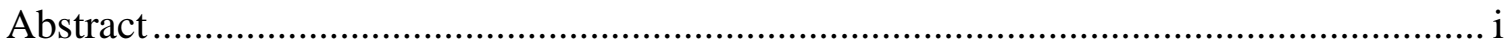

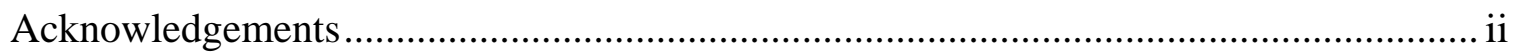

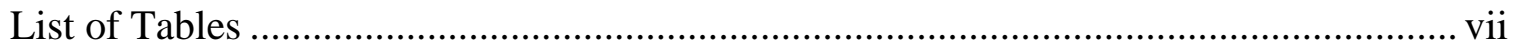

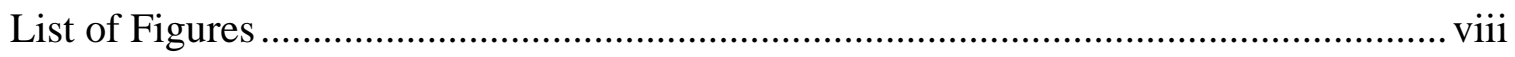

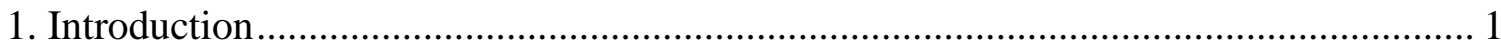

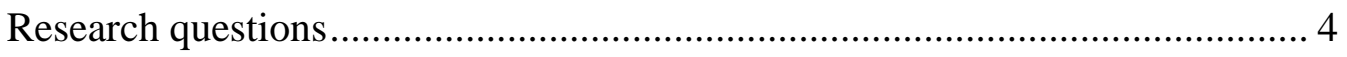

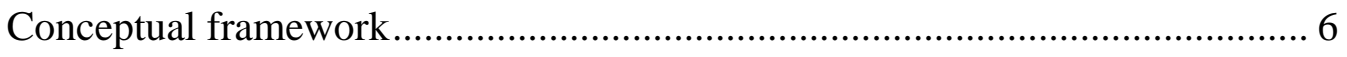

2. Literature review ....................................................................................... 14

2.1 Effect of light rail transit service on transit ridership ........................... 14

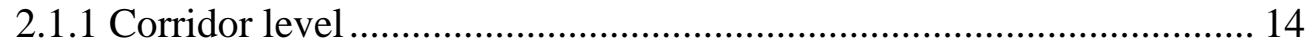

2.1.2 Regional level ................................................................... 17

2.2 Effect of new transit service on traffic congestion .............................. 17

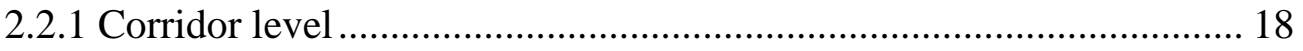

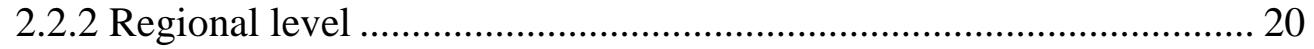

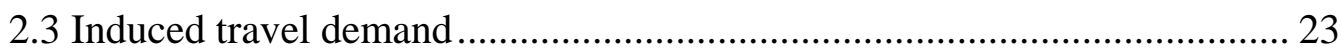

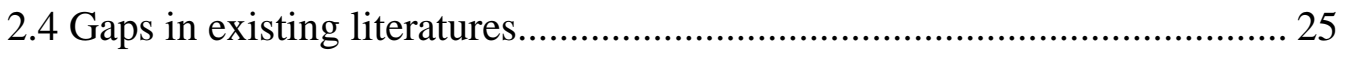

3. Effect of new LRT service on transit ridership and traffic congestion at the corridor

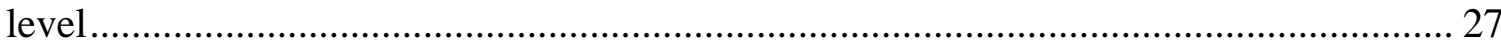


Research Design

Data

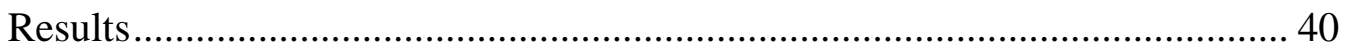

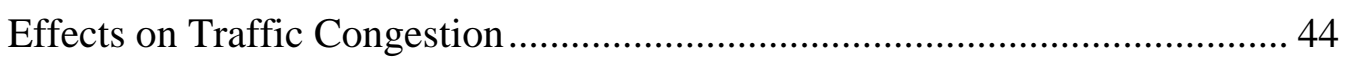

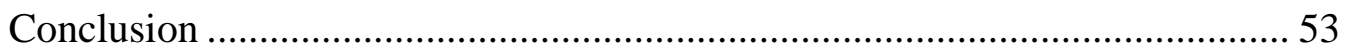

4. Effect of new LRT service on transit ridership and traffic congestion at the regional

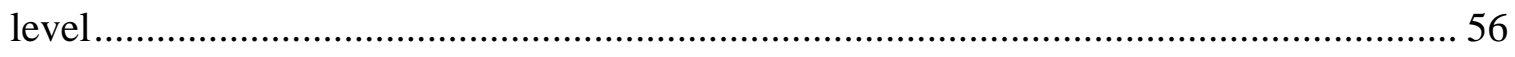

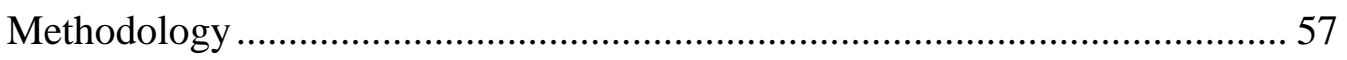

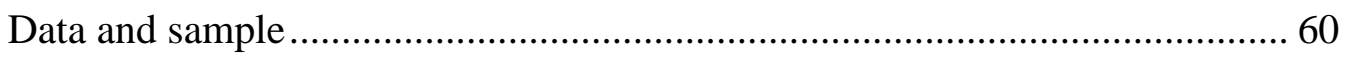

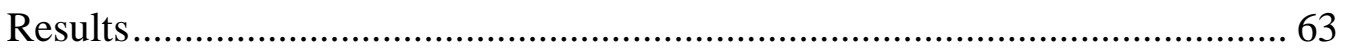

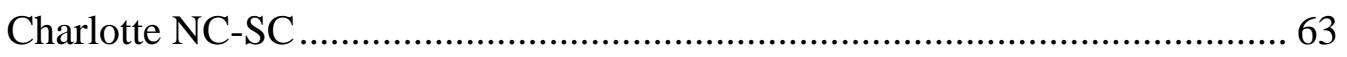

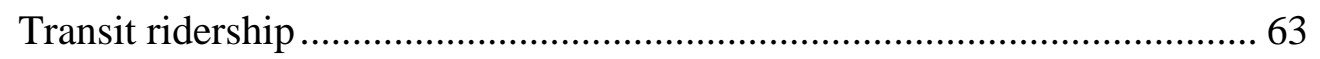

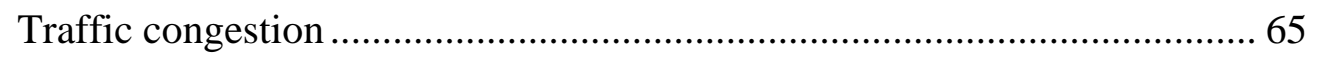

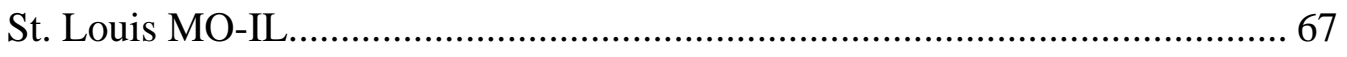

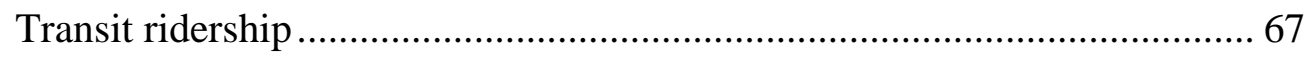

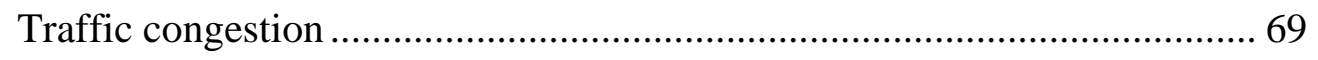

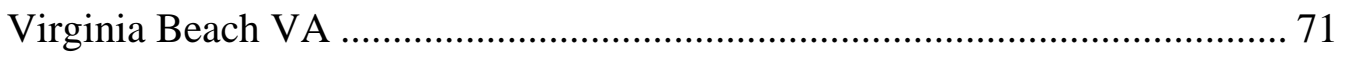

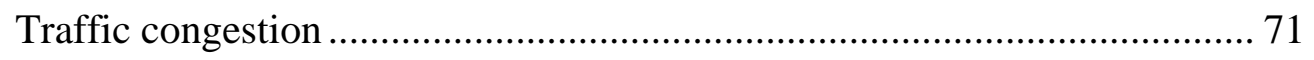

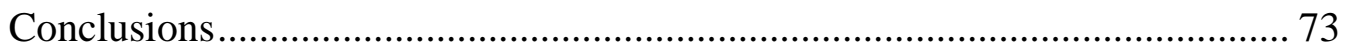




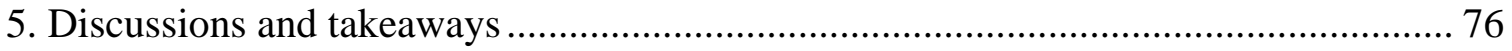

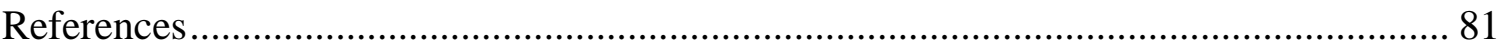




\section{List of Tables}

Table 2. 1 Empirical studies on the effect of LRT on transit ridership ..........................16

Table 2. 2 Corridor studies of transit effect on traffic congestion ................................19

Table 2. 3 Regional studies of transit effect on traffic congestion ................................22

Table 3. 1 Transit ridership DID regression models ...................................................42

Table 3. 2 Crosstab of boardings within the experimental and control corridors.............43

Table 3. 3 The difference-in-difference base regression models on the speed effect of the

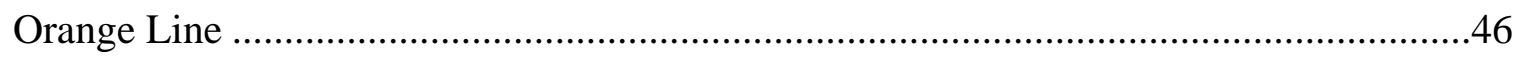

Table 3. 4 The difference-in-difference base regression models on the speed effect of the

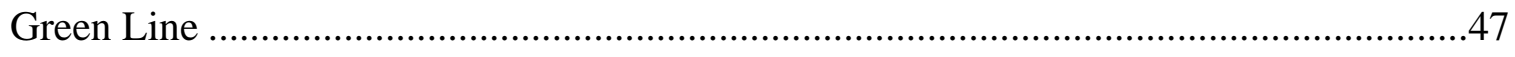

Table 3. 5 Travel Speed Difference-in-Difference Regression Models with Multiple

Time periods on the speed effect of the Orange Line ................................................50

Table 3. 6 Results of Travel Speed Difference-in-Difference Regression Models with multiple time periods of the Green Line Case .....................................................52

Table 4. 1 Control urban areas ..........................................................................61

Table 4. 2 Selected Treated UAs .....................................................................63

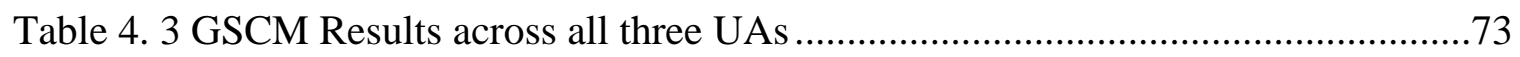




\section{List of Figures}

Figure 1. 1 Conceptual framework of LRT effects on ridership and congestion ...............

Figure 1. 2 The evolution of effect of new LRT service on traffic congestion ..................

Figure 3. 1 Routes and stations of the MAX Light Rail system in Portland, Oregon

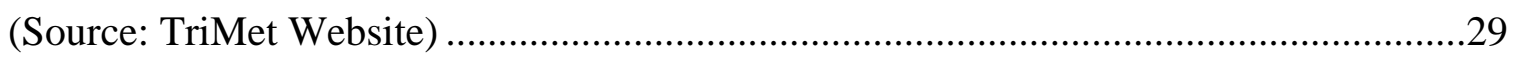

Figure 3. 2 Causal effects in the Difference in Difference model ..................................30

Figure 3. 3 Experimental and control corridor for the Green Line ............................... 31

Figure 3. 4 Experimental and control corridor for the Orange Line ................................31

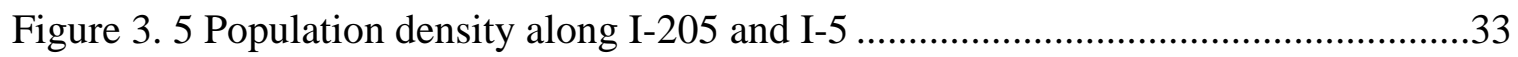

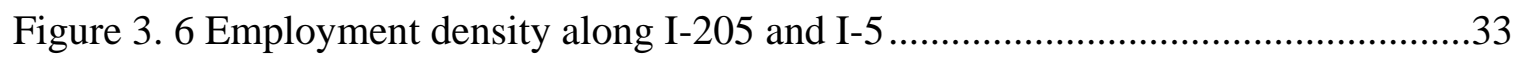

Figure 3. 7 Population density along SE McLoughlin Blvd and Powell Blvd ..................35

Figure 3. 8 Employment density along SE McLoughlin Blvd and Powell Blvd..............36

Figure 3. 9 The change in the average weekday boardings at all bus and rail stops located within the experimental and control corridors over time ........................................40

Figure 3. 10 The Difference-in-Differences effects of boardings................................42

Figure 3. 11 The trends of the boardings and alightings at bus stops located within a quarter-mile radius of the Green and Orange line stations over time ...........................43

Figure 3.12 The weekday peak periods speed comparison between experimental corridor (McLoughlin Blvd) and control corridor (Powell Blvd) for the Orange line .45

Figure 3.13 The weekday peak periods speed comparison between experimental corridor (I-205) and control corridor (I-5) for the Green line. 
Figure 3. 14 The estimated speed based on the DID base models for the Orange line during weekday peak periods.

Figure 3. 15 The estimated speed based on the DID base models for the Green line during weekday peak periods

Figure 3. 16 Predicted speed based on the DID models with multiple time periods for the Orange line during weekday peak periods.

Figure 3. 17 Predicted Average Travel Speed Based on the DID models with multiple

time periods for the Green Line Case

Figure 4. 1 TTI in Seattle WA and control UAs.

Figure 4. 2 PTAUPT per PPT in Charlotte NC-SC 64

Figure 4. 3 TTI in Charlotte NC-SC .66

Figure 4. 4 PTAUPT per PPT in St. Louis Mo-IL....................................................68

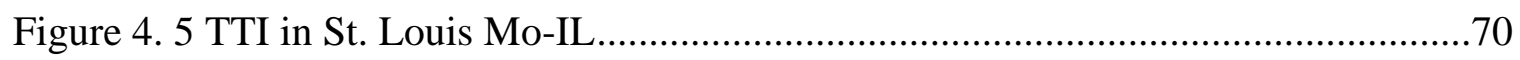

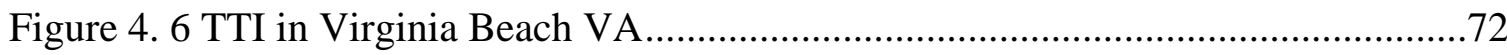




\section{Introduction}

Over the past decades, there have been a continuing increase in private vehicle usage and an overall decline in the use of public transit in the United States. The interesting thing is that, despite the fact that private vehicles are increasingly widely used with the decline of gasoline price and vehicle production costs, more cities are investing in costly new public transit systems. In 2015 , for example, the total operating expense for transit was $\$ 45.3$ billion with over 58.6 billion passenger miles traveled in the U.S. (APTA, 2017). The main end of public transit is to induce more people transfer their travel mode from driving to riding transit, and to provide the urban poor easy access to quality life and job opportunities. Some researchers also suggest mass transit (hereafter referred to simply as transit) as an effective means to reduce auto dependence and relieve traffic congestion. Bhattacharjee et al. (2012) found that in Denver, the light rail transit generally lowered the increase of traffic in the influenced highway zone. Anderson (2013) found that Los Angeles transit provided more congestion relief benefits than what previously believed.

Although there are continuous large investments in transit, there is a continuing debate over its effectiveness in relieving traffic congestion. Proponents of building more transit argue that transit is more efficient than private vehicles and can reduce auto dependency and relieve congestion. Opponents of building more transit, however, claim that transit cannot fulfill these benefits, because it cannot attract enough riders in automobile-oriented areas and transit accounts for a small share of commuting trips in most American cities. In addition, transit may potentially increase congestion because 
bus vehicles take up roadway space and interfere with the traffic due to their frequent stops. Correspondingly, the findings from a large and growing body of studies examining the effect of transit on transit ridership and traffic congestion have been inconsistent.

The aim of this study is to provide additional in-depth understanding of the shortterm and long-term effect of new light rail transit (LRT) service on transit ridership and traffic congestion and explain the conflicting empirical results of existing research. LRT is a kind of transit mode that lies between subway and bus/streetcar. LRT serves fewer people than the subway does per ride, but it is less expensive and easier to access than the subway. Compared with buses, LRT is comfortable and speedy, containing more passengers per ride. Its unique attributes make LRT a mode of choice for many cities. This study will estimate the effect of new LRT service on transit ridership and traffic congestion at the corridor and regional levels, and keep track of the changes of these effects over time. This study focuses on LRT. A primary reason is that transit with a separate right-of-way is likely to relieve traffic congestion. Downs (2005) contends that transit can reduce traffic congestion only when the vast majority of peak-hour commuters take transit with separate right-of-way. Litman (2014) noted less congestion delay in American cities with a high share of grade-separated transit as compared to cities without a high share of gradeseparated transit. Another reason is that many cities in the U.S. and elsewhere have tilted their investment in LRT despite its substantially higher cost compared with other transportation infrastructure. From 1999 to 2017, nationwide vehicle revenue hours of LRT service have increased from 3.1 million to 7.5 million (NTD, 2000, 2018), which makes LRT deserved to be separately explored and evaluated quantitatively. 
The paper is geographically focused on two different perspectives. At the corridor level, the MAX Green Line and Orange Line in Portland, OR region are selected as case studies. For each line, using a quasi-experiment design and transportation data before and after the operation of new LRT service, this study examines the changes in transit ridership and speed in a view of relatively long time horizon, which may provide marginal meaningful enlightenment for existing documents. Specifically, I take the following steps. First, before/after comparisons are conducted. Then, difference-indifference (DID) regression models are estimated for each line to evaluate the effect of new LRT service on ridership and traffic congestion. Thirdly, the difference in the effects between these two lines is discussed.

At the regional level, this study investigates the effect of New Starts LRT projects on transit ridership and traffic congestion in large and very large Urbanized Areas (UAs) in the U.S. From 1998 to 2015, 60 New Starts LRT projects began operation across 27 UAs, but little is known about the effect of these projects on transit ridership and traffic congestion. This study conducts empirical analyses of the effect of these projects on transit ridership and traffic congestion. To build up the comparable "counterfactual" scenario, I use Synthetic Control Method (SCM), initially introduced by Abadie and Gardeazabal (2003), to examine what the transit ridership and traffic congestion would have been in the absence of light rail projects. 


\section{Research questions}

This study attempts to quantify the effects of new LRT service on transit ridership and traffic congestion at the corridor and regional levels, and the changes of such effects over time. Specifically, this study aims to tackle the following questions:

1. What is the effect of new light rail transit service on transit ridership and traffic congestion at the corridor level?

2. What is the effect of new light rail transit service on transit ridership and traffic congestion at the regional level?

3. How does the effect of new light rail transit service on transit ridership and traffic congestion change over time at the corridor and regional levels?

The first research question investigates the effects of new LRT service on ridership and congestion at the corridor level. The operation of new LRT service is expected to improve the level of transit service and accessibility, therefore it is likely to increase transit ridership, and eventually relieve traffic congestion by attracting former drivers to transit. But such effects are likely subject to the condition of local transportation and land use systems, and the attributes of the LRT project. The effects of new LRT service highly depend on people's choice faced with the new launch of transit option: for one thing, the transit may attract some portion of people living near the corridor to change travel mode from driving personally to public transit, which may contribute to the increase of ridership and decline of traffic congestion; for the other, 
people living outside of the corridor zone may choose to change their routes(in the shortterm) or to move to reside near the corridor(in the long-term), and in these cases, congestion may not be relieved even though the ridership is boosted.

The second question investigates the effects at the regional level. A significant effect at the corridor level does not guarantee a significant effect at the regional level. On the one hand, the effect of a single LRT line at the regional level is likely to be small, because the new LRT service only constitutes a marginal change of overall transportation supply at the regional level. On the other, a new LRT line may catalyst changes to a region's transportation investment priority toward LRT in particular and transit in general, which may improve the region's overall transport efficiency. The literature in the regional perspective is rare. If a region is undergoing an economic boom, resulting in an influx of both capital and population, its traffic conditions in the short and middle term are probably unsatisfactory. The launch of new transit may be able to solve part of the problem, but the average mitigation effect may not be as significant as that in corridor. In a city where traffic congestion is getting worse, a new transit option may improve corridor traffic condition.

The third question explores the changes of these effects over time at the corridor and regional levels. At the corridor level, induced travel demand may play a role in the changes of the effects of LRT on ridership and traffic congestion. At the regional level, induced travel demand may be less detectable, because the effect of the New Starts LRT project is more likely to take place within localized area. The trends at both corridor and regional levels are deserved to be discussed, because the comparison of corridor and 
regional results of certain districts will make the picture clearer. For the region of metropolitan, it is believed that in the long term, only building up extensive and highquality of LRT network through continuous investments in LRT may fundamentally change travel behavior, lowering auto ownership, making transit become the dominant travel mode, reducing traffic delay.

\section{Conceptual framework}

This study follows the conceptual framework shown in Figure 1.1. The short-term and long-term effects of LRT service on transit ridership and traffic congestion can be different due to induced travel demand. Pickerell (2001) defines "short-term" as "the period during which a household's residential locations as well as the spatial distribution of economic activity and thus of employment remain fixed". In other words, I take the location adjustment of household, employment and activity as long-term induced travel demand that is different from short-term induced travel demand (e.g. people's travel route adjustment without destination change). In the framework as pictured, the residential location and economic activities spatial distribution are vital to explain the long-term trends of transit ridership and traffic congestion, so the long-term picture may be significantly different from the short-term. 


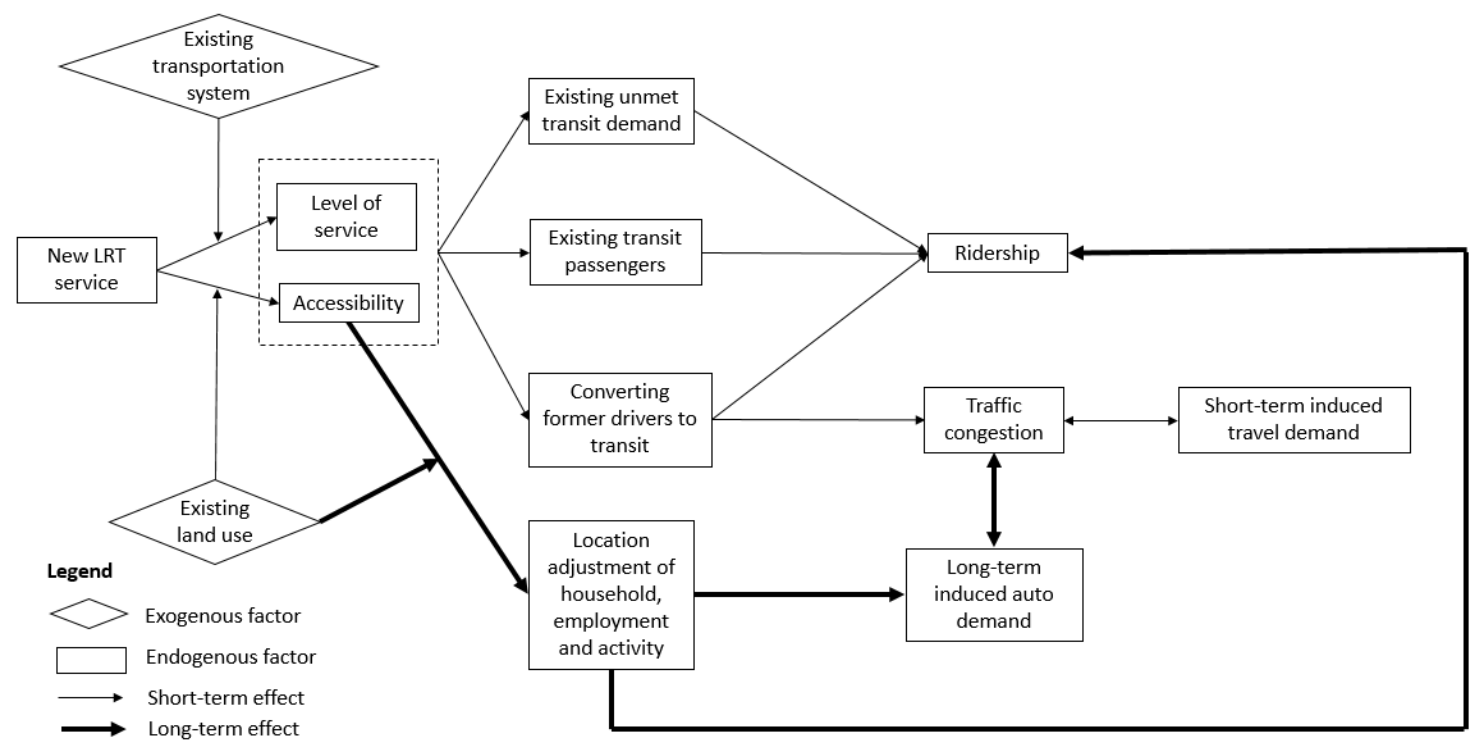

Figure 1. 1 Conceptual framework of LRT effects on ridership and congestion

In the short-term, new LRT service may increase transit ridership and relieve traffic congestion at the corridor level. New LRT service typically replaces existing bus service and tends to improve accessibility and the level of transit service along the corridor, and the extent of such improvement is subject to existing transportation and land use systems. The improved accessibility and level of transit service attract transit ridership from three sources: existing unmet transit demand, former transit passengers, and former drivers. The ridership from former transit passengers has no net effect on transit ridership and traffic congestion. Ridership from existing unmet transit demand leads to increased transit ridership but does not affect traffic congestion. Ridership from former drivers increases transit ridership and relieves traffic congestion. However, improved traffic conditions are likely to evoke induced travel demand and reduce the initial benefit to traffic. As illustrated by Pickerell (2001), "short-term induced traffic" 
includes diverted traffic that changes its route onto the improved facility, rescheduled traffic that previously used the facility at a different time, shifts from other modes and so on.

Figure 1.2 shows the possible changes of the effects of LRT service over time. Because it takes time for travelers to switch to the new LRT service, the ridership from former drivers remains small immediately after the opening of the new LRT service. After a period of time, ridership from former drivers increases, which reduces traffic congestion. With the increase of ridership from former drivers, the traffic congestion will be relieved correspondingly. Then, the improved traffic condition may evoke the shortterm induced travel demand: trips from other routes, modes and other time are diverted to the roadway with improved traffic conditions; people living along the roadway are likely to take new or longer trips because of the improved traffic condition. Such induced travel demand will increase traffic on the roadway, which gradually offsets the congestion reduction benefits until traffic condition reaches a new equilibrium. Theoretically, shortterm induced travel demand does not lead to worse traffic congestion than it was before the operation of new LRT service, because trips will not be diverted to the roadway, and people will not take new or longer trips once the traffic congestion relief benefit disappears. 


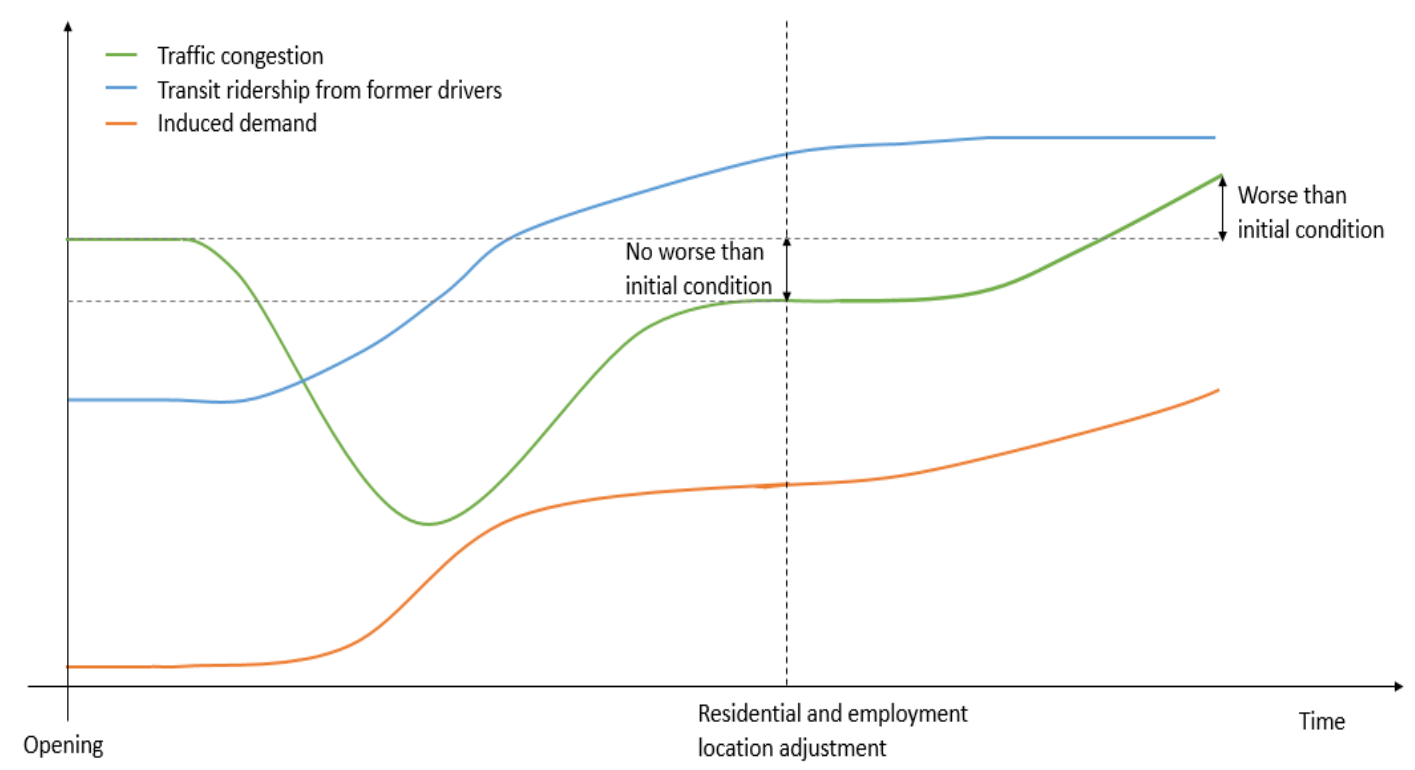

Figure 1.2 The evolution of effect of new LRT service on traffic congestion

In the long-term, new LRT service may increase ridership but worsen traffic congestion. As mentioned earlier, the operation of new LRT service improves accessibility along the LRT corridor. The improved accessibility will attract households, employments, and activities to locate near the LRT stations, leading to increased overall travel demand. Based on the definition by Pickerell (2001), the induced travel demand resulting from location adjustment is the long-term induced travel demand. The increased overall travel demand resulting from long-term induced travel demand may further boost transit ridership and offset congestion relief benefits or even make traffic conditions worse than the initial condition.

The effects of new LRT service on transit ridership and congestion are expected to vary by geographical levels. In the short-term, new LRT service usually constitutes a marginal change of overall transportation supply at the regional level. Thus, it is expected 
to exert little influence on transit ridership and traffic congestion at the regional level. In the long-term, a LRT project may catalyst improvement to the transit system and attract residents and employments to locate near LRT stations, and eventually leads to detectable changes in transit ridership and traffic at the regional level. At the regional level, with the continuing construction of LRT projects, an extensive and high-quality LRT network may lead to fundamental changes in travel behavior, reducing car ownership and making transit become the dominant commuting mode, which increases transit ridership, reduces auto dependence and relieves the traffic congestion at the regional level.

\section{Hypotheses:}

1. The effects of new LRT service on transit ridership and traffic congestion at the corridor level vary by local context.

- The effects of new LRT service on transit ridership and traffic congestion rely on improving the level of transit service and accessibility along the transit corridor. The extent of such improvement is subject to existing transportation and land use system, and existing transportation and land use system determines transit demand and the extent of current congestion.

If the new LRT service primarily attracts ridership from existing transit riders, it does not affect transit ridership and traffic congestion. If the new LRT service attracts transit demand that is not met before the operation of new LRT service, it increases transit ridership and has no effect on traffic 
congestion. If the new LRT service attracts substantial ridership from former drivers, which depends on the attractiveness of new LRT service over driving, it will increase ridership and relieve traffic congestion.

2. The effects of new LRT service on transit ridership and traffic congestion at the corridor level change over time.

- In the short-term, it takes time for travelers to switch from driving to riding transit, which may improve traffic condition; then the improved traffic condition may evoke induced travel demand: trips are diverted from other routes, modes and times; people living along the corridor take new or longer trips.

- In the long-term, both people and employment may be attracted to locate near new LRT stations and land use changes may occur along the LRT corridor due to improved level of transit service and accessibility, which further increases transit ridership and worsens traffic congestion

3. The effects of new LRT service on transit ridership and traffic congestion at the regional level may vary by region.

○ Regional socioeconomic factors, state of the economy, and existing transportation and land use system are all likely to influence the effects at the regional level. 
- The effects of new LRT service depend on its scale relative to the existing system. Single LRT generally has little effect on transit ridership and traffic congestion at the regional level, because the new LRT service only constitutes a marginal change of overall transportation supply at the regional level. An extensive and high-quality LRT network may lead to fundamental changes in travel behavior, reducing car ownership and making transit become the dominant commuting mode, and thus can increase transit ridership and relieve traffic congestion at the regional level.

4. The effect of new LRT service on transit ridership and traffic congestion at the regional level changes over time.

○ In the short-term, a single LRT project only has little detectable effects on transit supply, so it has little effect on transit ridership and traffic congestion at the regional level.

- In the long-term, a LRT project may catalyst improvement to the transit system and attract residents and employments to locate near transit station, and eventually leads to detectable changes in transit ridership and traffic at the regional level. In addition, the construction of extensive and high-quality LRT network may increase transit mode share and reduce auto dependence and, therefore, reduce traffic congestion. However, for the region, decent infrastructure may be accompanied by economic 
flourish, which probably gives rise to huge marginal traffic demand and worsens local traffic condition. 


\section{Literature review}

The effects of transit include direct effect - transit ridership, and indirect effect, including traffic congestion, land use, property value, etc. Transit ridership is "a necessary, but not sufficient condition for any of the indirect benefits ascribed to LRT investments" (Giuliano et al. 2015). Among the reasons the transit is built to attract ridership from auto drivers and reduce traffic congestion by virtue of having their rightsof-way.

\subsection{Effect of light rail transit service on transit ridership}

As LRT plays an increasingly important role in daily travel, a considerable amount of studies has examined the effects of new LRT service on transit ridership. In this review, these studies are grouped by geographical levels: corridor and regional. Table 2.1 summarizes the literature, especially the findings and limitations.

\subsubsection{Corridor level}

At the corridor level, a stream of studies uses residents as the unit of analysis. Most of these studies use cross-sectional data, so they only investigate transit ridership at a single time point. Cervero (1994) examined the transit use of residents living in transitoriented development (TOD) areas in California. Results suggested that residents living close to rail stations were more likely to use transit for both commuting and noncommuting trips than the average residents in the region. Lund et al. (2006) re-evaluated the travel pattern of residents living in TOD areas in California and reached similar 
conclusions. They found that residents living in TOD areas were more likely to ride transit, especially for commuting, than those who did not live in TOD areas. These two studies provide evidence about transit usage for daily travel, but they did not use a quasiexperimental design or take into account residential self-selection (RSS), which might undermine the validity of their results.

Cao et al. (2014) used a quasi-experimental design and cross-sectional data to investigate the impact of LRT on transit use. Their analysis examined two urban corridors and two suburban corridors and used propensity score matching (PSM) to eliminate the residential self-selection effect on transit use. Results indicated that non-movers, namely residents living within the LRT corridor before the operation of the LRT, used transit more frequently than residents in urban control corridors, while movers used transit as frequently as residents in the urban control corridors. 
Table 2. 1 Empirical studies on the effect of LRT on transit ridership

\begin{tabular}{|c|c|c|c|c|c|c|}
\hline $\begin{array}{l}\text { Author/s } \\
\text { (years) }\end{array}$ & Location & $\begin{array}{l}\text { Unit of } \\
\text { analysis }\end{array}$ & Data & $\begin{array}{l}\text { Temporal } \\
\text { Dimension }\end{array}$ & Key findings & Limitations \\
\hline $\begin{array}{l}\text { Cervero } \\
\text { (1994) }\end{array}$ & $\begin{array}{l}\text { California, } \\
\text { USA }\end{array}$ & Resident & $\begin{array}{l}\text { Travel } \\
\text { diary } \\
\text { surveys of } \\
\text { targeted } \\
\text { population }\end{array}$ & $\begin{array}{l}\text { Single time } \\
\text { point, } 10 \\
\text { years after } \\
\text { transit } \\
\text { service }\end{array}$ & $\begin{array}{l}\text { Stations- } \\
\text { residents } \\
\text { ride rail } \\
\text { transit more } \\
\text { than the } \\
\text { average } \\
\text { residents in } \\
\text { the region }\end{array}$ & $\begin{array}{l}\text { No evidence of } \\
\text { the evolution of } \\
\text { transit ridership; } \\
\text { no quasi- } \\
\text { experimental } \\
\text { design; no RSS } \\
\text { adjustment }\end{array}$ \\
\hline $\begin{array}{l}\text { Lund et } \\
\text { al. (2006) }\end{array}$ & $\begin{array}{l}\text { California, } \\
\text { USA }\end{array}$ & Resident & $\begin{array}{l}\text { Travel } \\
\text { diary } \\
\text { surveys of } \\
\text { targeted } \\
\text { population }\end{array}$ & $\begin{array}{l}\text { Single time } \\
\text { point, } 21 \\
\text { years after } \\
\text { transit } \\
\text { service }\end{array}$ & $\begin{array}{l}\text { TOD } \\
\text { residents are } \\
\text { more likely } \\
\text { to use rail } \\
\text { transit than } \\
\text { non-TOD } \\
\text { residents. }\end{array}$ & $\begin{array}{l}\text { No evidence of } \\
\text { the evolution of } \\
\text { transit ridership; } \\
\text { no quasi- } \\
\text { experimental } \\
\text { design; No RSS } \\
\text { adjustment }\end{array}$ \\
\hline $\begin{array}{l}\text { Cao et al. } \\
\text { (2014) }\end{array}$ & $\begin{array}{l}\text { Minneapolis, } \\
\text { Minnesota, } \\
\text { USA }\end{array}$ & Resident & $\begin{array}{l}\text { Travel } \\
\text { diary } \\
\text { surveys of } \\
\text { targeted } \\
\text { population }\end{array}$ & $\begin{array}{l}\text { Single time } \\
\text { point, } 7 \\
\text { years after } \\
\text { transit } \\
\text { operation }\end{array}$ & $\begin{array}{l}\text { Non-movers } \\
\text { used transit } \\
\text { more } \\
\text { frequently } \\
\text { than } \\
\text { residents in } \\
\text { the control } \\
\text { corridors, } \\
\text { while } \\
\text { movers used } \\
\text { transit as } \\
\text { frequently as } \\
\text { residents in } \\
\text { the control } \\
\text { corridors }\end{array}$ & $\begin{array}{l}\text { No evidence of } \\
\text { the evolution of } \\
\text { transit ridership }\end{array}$ \\
\hline $\begin{array}{l}\text { Giuliano } \\
(2015)\end{array}$ & $\begin{array}{l}\text { Los Angeles, } \\
\text { California, } \\
\text { USA }\end{array}$ & Corridor & $\begin{array}{l}\text { Transit } \\
\text { ridership } \\
\text { from } \\
\text { transit } \\
\text { agency }\end{array}$ & $\begin{array}{l}\text { 3-month } \\
\text { periods } \\
\text { before and } \\
\text { after transit } \\
\text { service }\end{array}$ & $\begin{array}{l}\text { The Expo } \\
\text { Line has a } \\
\text { net increase } \\
\text { in transit } \\
\text { ridership }\end{array}$ & $\begin{array}{l}\text { Single light rail } \\
\text { line }\end{array}$ \\
\hline $\begin{array}{l}\text { Baum- } \\
\text { Snow \& } \\
\text { Kahn } \\
(2005)\end{array}$ & $\begin{array}{l}\text { Sixteen } \\
\text { American } \\
\text { cities }\end{array}$ & City & $\begin{array}{l}\text { Panel data } \\
\text { set of } 16 \\
\text { cities }\end{array}$ & $\begin{array}{l}\text { Time } \\
\text { series, } \\
1970-2000\end{array}$ & $\begin{array}{l}\text { Rail service } \\
\text { does not } \\
\text { increase } \\
\text { transit modal } \\
\text { share at the } \\
\text { regional } \\
\text { level }\end{array}$ & $\begin{array}{l}\text { An average } \\
\text { effect }\end{array}$ \\
\hline
\end{tabular}

Another line of studies uses the transit corridor as the unit of analysis. Giuliano et al. (2015) investigated the effect of Metro Exposition Line (Expo Line) on transit 
ridership in Los Angeles, California. Using a quasi-experimental design and a unique historical archive of high-resolution multimodal transportation data, they examined transit ridership within the experimental and control corridors before and after the operation of the Expo Line. Results indicated that the Expo Line increased weekday boarding of all bus and rail stops within the experimental corridor by approximately 7,000. This study examined only the immediate effects of a single light rail line.

\subsubsection{Regional level}

Studies examining transit ridership at the regional level are rare. Baum-Snow and Kahn (2005) examined the effects of rail transit capital investment on public transit ridership. They used a panel data set of sixteen cities with rail transit improvement between 1970 and 2000. They found that new rail transit service primarily attracted riders from bus passengers - not drivers and therefore did not increase transit mode share at the regional level. Although this study examined the effect of rail transit on ridership over time with panel data, the estimation is an average effect over time. It did not keep track of the change of the effect over time.

\subsection{Effect of new transit service on traffic congestion}

A growing body of studies has examined the effect of transit on traffic congestion, but the results of these studies are mixed. These studies are also reviewed by geographical levels: corridor and regional. 


\subsubsection{Corridor level}

There has been a considerable amount of literature on the effects of transit improvement on traffic congestion at the corridor level. The results of these studies are mixed partly because they are different in terms of measurement, method and time frame, shown in Table 2.2.

Bhattacharjee et al. (2012) investigated the effect of Denver light rail lines on traffic congestion from 1992 to 2008. They used Vehicle Miles Traveled (VMT), converted from Annual Average Daily Traffic (AADT), as traffic performance metric. Results suggested that light rail lines lowered the growth rate of VMT: the average VMT within the influence zone increased by $31 \%$ compared to $41 \%$ outside the influence zone. Ewing et al. (2014) examined the short-, medium- and long-term effects of the University of Utah's TRAX LRT line on traffic congestion. They used AADT as the measurement of traffic congestion and found that LRT reduced AADT in all three time frames. Both studies suggest that LRT has a congestion relief effect and that effect changes over time, but they have to approximate their congestion measure from AADT and do not capture daily or monthly variations in traffic.

In addition to examining transit ridership mentioned above, Giuliano et al. (2015) investigated the effect of the Los Angeles Metro Exposition Line (Expo Line) on traffic performance with high-resolution historical archival data. Their results indicated that, even though it increased transit ridership, it had no significant influence on traffic congestion. They attributed the insignificant effect on traffic congestion to the large induced travel demand within the congested corridor. Although this study had a rigorous 
research design and a sound dataset, a major limitation was that it only examined transportation performance shortly after the opening of the Expo Line. The Expo Line began operation in June 2012. They used data during November 2011-January 2012 (before) and November 2012-January 2013 (after) to control the seasonality in their data and did not examine the medium-and long-term effect.

Table 2. 2 Corridor studies of transit effect on traffic congestion

\begin{tabular}{|c|c|c|c|c|c|}
\hline $\begin{array}{l}\text { Author/s } \\
\text { (years) }\end{array}$ & Location & Measurement & $\begin{array}{l}\text { Temporal } \\
\text { Dimension }\end{array}$ & Key findings & Limitations \\
\hline $\begin{array}{l}\text { Bhattacharjee } \\
\text { et al. (2012) }\end{array}$ & $\begin{array}{l}\text { Denver, } \\
\text { Colorado, } \\
\text { USA }\end{array}$ & $\begin{array}{l}\text { VMT } \\
\text { converted } \\
\text { from AADT }\end{array}$ & $1992-2008$ & $\begin{array}{l}\text { LRT lines } \\
\text { decrease the } \\
\text { growth rate } \\
\text { of VMT } \\
\text { within the } \\
\text { influence } \\
\text { zone }\end{array}$ & $\begin{array}{l}\text { No quasi- } \\
\text { experiment; } \\
\text { approximate } \\
\text { measuremen } \\
\text { t of } \\
\text { congestion; } \\
\text { annual } \\
\text { measuremen } \\
\text { t }\end{array}$ \\
\hline $\begin{array}{l}\text { Giuliano et al. } \\
\text { (2015) }\end{array}$ & $\begin{array}{l}\text { Los } \\
\text { Angeles, } \\
\text { California, } \\
\text { USA }\end{array}$ & $\begin{array}{l}\text { Travel time } \\
\text { and travel time } \\
\text { reliability }\end{array}$ & $\begin{array}{l}\text { 3-month periods } \\
\text { before and after } \\
\text { transit service }\end{array}$ & $\begin{array}{l}\text { A net } \\
\text { increase in } \\
\text { transit } \\
\text { ridership; no } \\
\text { significant } \\
\text { influence on } \\
\text { traffic } \\
\text { congestion }\end{array}$ & $\begin{array}{l}\text { No } \\
\text { examination } \\
\text { of } \\
\text { transportatio } \\
n \\
\text { performance } \\
\text { immediately } \\
\text { before and } \\
\text { after the } \\
\text { opening of } \\
\text { the Expo } \\
\text { Line. }\end{array}$ \\
\hline $\begin{array}{l}\text { Ewing et al. } \\
(2014)\end{array}$ & $\begin{array}{l}\text { Salt Lake } \\
\text { City, Utah, } \\
\text { USA }\end{array}$ & AADT & $\begin{array}{l}\text { Short-run: } 1 \\
\text { year before and } \\
\text { after the } \\
\text { operation of } \\
\text { LRT in } 12 / 2001 \text {; } \\
\text { Medium-run: } \\
2001 \text { VS the } \\
\text { average of } \\
\text { 2006-2012; } \\
\text { Long-run: long- } \\
\text { run: } 1999 \text { VS } \\
2009\end{array}$ & $\begin{array}{l}\text { LRT reduces } \\
\text { AADT in all } \\
\text { three time } \\
\text { frames. }\end{array}$ & $\begin{array}{l}\text { Congestion } \\
\text { measure is } \\
\text { roughly } \\
\text { approximate } \\
\text { d from } \\
\text { AADT }\end{array}$ \\
\hline
\end{tabular}




\subsubsection{Regional level}

Regional studies on the effect of transit on traffic congestion either simulate the effect with regional travel models, or conduct empirical analysis of transit strike data or panel data, summarized in Table 2.3. Simulation studies largely build on the assumption that a subset of transit passengers will switch to driving when transit service is reduced or halts operation. Therefore, the results of these studies are sensitive to the assumed proportion of transit passengers switching to driving and all suggest that all types of transit services can relieve congestion. Nelson et al. (2007) used a regional strategic planning simulation model to estimate transit service benefits in the Washington, DC metropolitan area. They found that the transit system reduced a total of 184,000 personhours of driving per day, and that rail service generated a larger congestion relief benefit than bus service. Aftabuzzamand et al. (2010) utilized a regional travel demand model to estimate the effect of public transit on congestion in Melbourne, Australia. They converted $32.4 \%$ of the public transit trip matrix to the base car trip matrix to simulate a scenario in which the entire transit system was eliminated. The results indicated that congestion would increase by more than $150 \%$ when the entire transit system was not in operation.

Simulation studies provide counterfactual insights into what would have happened if all transit lines halt service, but such studies have pitfalls. The results are sensitive to the assumed proportion of transit passenger diverting to driving when transit is not in operation. 
Transit strike data provide another way to examine what happens when a transit system halts service Anderson (2013) used a regression discontinuity design to estimate travel delay with transit labor strike data in Los Angeles, California, and noted a 47\% increase in highway delay during the strike. According to his model, the effect of transit on traffic volume was minor, but it nevertheless had a large effect on traffic congestion. Lo and Hall (2006) calculated the average traffic speed during 20 consecutive working days before and during a transit strike using similar data,. They noted that the length of the rush period increased by up to $200 \%$. Although such studies provide sound evidence of the short-term effects of transit on traffic congestion, such studies may not provide good evidence of response to transit improvement, because travelers are likely to respond differently to transit improvement and transit cessation. More specifically, travelers must change travel behavior immediately if transit service is stopped, while travelers gradually change travel behavior if the level of transit service is improved. 
Table 2. 3 Regional studies of transit effect on traffic congestion

\begin{tabular}{|c|c|c|c|c|c|}
\hline Author/s (years) & Location & Methods & Time context & Key findings & Limitations \\
\hline $\begin{array}{l}\text { Nelson et al. } \\
(2007)\end{array}$ & $\begin{array}{l}\text { Washington, } \\
\text { DC, USA }\end{array}$ & $\begin{array}{l}\text { Simulation } \\
\text { with } \\
\text { strategic } \\
\text { planning } \\
\text { simulation } \\
\text { model }\end{array}$ & $\begin{array}{l}\text { Single time } \\
\text { point } \\
\text { (counterfactua } \\
1 \text { analysis ) }\end{array}$ & $\begin{array}{l}\text { Rail service } \\
\text { generates } \\
\text { larger } \\
\text { congestion } \\
\text { relief benefit } \\
\text { than bus } \\
\text { services }\end{array}$ & $\begin{array}{l}\text { Implications of } \\
\text { results are limited; } \\
\text { depends on the } \\
\text { proportion of } \\
\text { transit passengers } \\
\text { who convert to } \\
\text { driving; response } \\
\text { to transit cessation }\end{array}$ \\
\hline $\begin{array}{l}\text { Aftabuzzamand } \\
\text { et al. (2010) }\end{array}$ & $\begin{array}{l}\text { Melbourne, } \\
\text { Australia }\end{array}$ & $\begin{array}{l}\text { Simulation } \\
\text { with travel } \\
\text { demand } \\
\text { model }\end{array}$ & $\begin{array}{l}\text { Single time } \\
\text { point } \\
\text { (counterfactua } \\
\text { l analysis) }\end{array}$ & $\begin{array}{l}\text { Congestion } \\
\text { increased by } \\
\text { more than } \\
150 \% \text { when } \\
\text { the entire } \\
\text { transit } \\
\text { system was } \\
\text { terminated }\end{array}$ & $\begin{array}{l}\text { Implications of } \\
\text { their results are } \\
\text { limited; depends } \\
\text { on the proportion } \\
\text { of transit } \\
\text { passengers who } \\
\text { convert to driving; } \\
\text { response to transit } \\
\text { cessation }\end{array}$ \\
\hline $\begin{array}{l}\text { Anderson } \\
\text { (2013) }\end{array}$ & $\begin{array}{l}\text { Los Angeles, } \\
\text { California, } \\
\text { USA }\end{array}$ & $\begin{array}{l}\text { Regression } \\
\text { discontinui } \\
\text { ty }\end{array}$ & $\begin{array}{l}\text { 200-day } \\
\text { window } \\
\text { containing the } \\
\text { transit strike }\end{array}$ & $\begin{array}{l}\text { highway } \\
\text { delay } \\
\text { increased by } \\
47 \% \\
\end{array}$ & $\begin{array}{l}\text { Response to } \\
\text { transit cessation }\end{array}$ \\
\hline $\begin{array}{l}\text { Lo and Hall } \\
(2006)\end{array}$ & $\begin{array}{l}\text { Los Angeles, } \\
\text { California, } \\
\text { USA }\end{array}$ & $\begin{array}{l}\text { Comparati } \\
\text { ve analysis }\end{array}$ & $\begin{array}{l}20 \text { consecutive } \\
\text { working days } \\
\text { before and } \\
\text { after transit } \\
\text { strike }\end{array}$ & $\begin{array}{l}\text { the length of } \\
\text { the rush } \\
\text { period } \\
\text { increased up } \\
\text { to } 200 \%\end{array}$ & $\begin{array}{l}\text { Response to } \\
\text { transit cessation }\end{array}$ \\
\hline $\begin{array}{l}\text { Winston and } \\
\text { Langer (2006) }\end{array}$ & $\begin{array}{l}72 \text { UZAs in } \\
\text { the U.S. }\end{array}$ & $\begin{array}{l}\text { Semi- } \\
\text { logarithmic } \\
\text { regression } \\
\text { model }\end{array}$ & $\begin{array}{l}1982 \text { to } 1996 \\
\text { (Annual } \\
\text { longitudinal } \\
\text { analysis) }\end{array}$ & $\begin{array}{l}\text { Rail transit } \\
\text { system did } \\
\text { not relieve } \\
\text { congestion } \\
\text { and bus } \\
\text { transit } \\
\text { system } \\
\text { increased } \\
\text { congestion }\end{array}$ & $\begin{array}{l}\text { Estimates are } \\
\text { essentially an } \\
\text { average effect } \\
\text { over time }\end{array}$ \\
\hline $\begin{array}{l}\text { Beaudoin et al. } \\
\text { (2014) }\end{array}$ & $\begin{array}{l}96 \text { UZAs in } \\
\text { the U.S. }\end{array}$ & $\begin{array}{l}\text { Two-step } \\
\text { GMM }\end{array}$ & $\begin{array}{l}\text { 1991- } 2011 \\
\text { (Annual } \\
\text { longitudinal } \\
\text { analysis) }\end{array}$ & $\begin{array}{l}\text { A } 10 \% \\
\text { increase in } \\
\text { overall } \\
\text { transit } \\
\text { capacity } \\
\text { generated on } \\
\text { average } \\
\text { around } 0.8 \% \\
\text { congestion } \\
\text { reduction }\end{array}$ & $\begin{array}{l}\text { Estimations are } \\
\text { essentially an } \\
\text { average effect } \\
\text { over time }\end{array}$ \\
\hline
\end{tabular}


Another line of studies utilizes panel datasets to examine the effect of transit on traffic congestion. Winston and Langer (2006) investigated the effect of highway spending and transit capacity on VMT with a panel dataset of 72 UZAs over the period 1982 to 1996 . They found that rail transit service relieved congestion while bus transit service increased congestion. Beaudoin et al. (2014) used a two-step Generalized Method of Moments (GMM) method to examine the effects of transit capacity on traffic congestion in 96 UZAs across the U.S. from 1991 to 2011. Their results indicated that a $10 \%$ increase in overall transit capacity led to on average around $0.8 \%$ congestion reduction. These empirical studies provide weak evidence of the evolution of the effect of transit on traffic congestion over time, because these estimates with panel datasets are essentially an average effect over time.

\subsection{Induced travel demand}

Commonly, induced travel demand refers to the travel demand caused by the expanded roadway capacity. Many opponents of building more transit for relieving congestion claim that the addition of transit service also evokes induced travel demand. Consider a congested roadway. The operation of new transit service reduces the generalized cost of riding transit by reducing travel time cost, and therefore it may prompt some drivers to switch to riding transit, which may relieve traffic congestion. The relieved traffic congestion is expected to evoke induced travel demand at different time scales. 
In the short-term, people may take longer trips and/or travel more frequently taking advantage of the improved traffic, and travel from other routes, times, and modes may be diverted to the roadway with improved traffic conditions until reaching a new equilibrium. These induced travel will offset the congestion relief benefit of new transit service, while it possibly cannot lead to the same or worse traffic congestion than it was before the operation of new transit service, because travel will not be diverted to the roadway and people will not take new or longer trips as long as the traffic congestion relief effect disappear. These conclusions are based on the definition of "the short-term" as 'the period during which household's residential locations as well as the spatial distribution of economic activity and thus of employment remain fixed" (Pickerell, 2001).

In the long-term, induced travel demand can cause traffic condition to become worse than the initial condition. Households and employments are likely to relocate close to the transit corridor, which may add overall travel demand and make the traffic congestion worse than before the operation of transit service. An important factor that should be taken into consideration in the long-term is population growth. Giuliano (2004) claim that increased travel demand due to population growth is not induced demand.

There has been a large body of empirical studies examining induced travel demand. Most of these studies focus on the induced travel demand resulting from roadway capacity expansion (Cervero, 2002; Noland \& Lem, 2002). There are limited studies examining the induced travel demand due to new transit service. Small and Verhoef (2007, p. 174) noted that the induced auto demand offset the majority of traffic 
congestion relief benefits of Bay Area Rapid Transit (BART). The operation of BART attracted 8,750 auto trips to switch to riding transit, but the relieved traffic congestion evoked 7,000 new auto trips. Beaudoin and Lin (2018) used a panel dataset of 96 Urbanized Areas from 1991 to 2011 to examine the effect of transit supply on auto demand. Results indicated that the effect of public transit supply on driving demand change over time due to induced travel demand and substitution effect. A $10 \%$ percent increase in transit supply on average generated a $0.7 \%$ decrease in auto demand because of substitution effect in the short run. Due to induced auto demand offsetting the substitution effect, transit supply has no effect on auto demand in the medium run. A $10 \%$ increase in transit supply on average evoked a $0.4 \%$ increase in auto demand in the long run. They also noted that new transit service could not relieve traffic congestion if congestion level did not reach a threshold level.

These findings provide supportive evidence for Downs' (2005) claim that the traffic congestion relief effect of new transit service is a short-term effect because of induced travel demand. Induced travel demand resulting from improved traffic congestion will gradually fill up the roadway space left by auto drivers switching to riding transit.

\subsection{Gaps in existing literatures}

A few gaps can be identified in existing studies:

First, the results of existing studies are inconsistent. Several issues seem to contribute to these inconsistencies: different geographical scales, and variations in terms 
of data sources, approaches and time periods. The significant effect at the corridor level cannot guarantee significant effect at the regional level. As mentioned in the literature, studies using approximate congestion measurement find congestion relief effect while studies using direct congestion measurement fail to find evidence of congestion relief effect. Simulation studies indicate all types of transit can relieve traffic congestion, while empirical studies find conflicting results.

Second, existing studies rarely examine the changes in these effects over time. Studies using cross-sectional data examine travel behavior at a single time point and therefore cannot keep track of the changes in these effects over time. Neither can traditional linear panel data analysis, which estimates elasticities or average change over time. One exception (as mentioned earlier) is the study by Ewing et al. (2014). They examined the short-, medium- and long-term effects of LRT on traffic congestion, but they estimated the effect at three discrete time points rather than tracing the evolution of the effects. They had to approximate traffic measures from AADT.

Lastly, there are few comparative studies conducted at the regional level. Most comparative studies are conducted at the corridor level. Comparative analyses are scarce at the regional level studies probably because it is not easy to find similar control units for comparison. 


\section{Effect of new LRT service on transit ridership and traffic congestion at the corridor level}

Traffic congestion has become an urgent issue across urban areas in the U.S. due to its direct time and monetary costs and many indirect adverse effects. For instance, the cost of extra time and fuel due to congestion delay in 498 urban areas has increased from \$24 billion in 1982 to $\$ 166$ billion in 2017 (Schrank et al., 2019). Besides extra time and fuel costs, traffic congestion also worsens air quality that causes adverse health effects and emits additional carbon dioxide and other pollutants which contribute to climate change (Sun et al., 2019; Yu et al., 2020). To relieve traffic congestion and alleviate its adverse impacts, light rail transit (LRT), with its separate right-of-way, has been suggested as an effective means of attracting transit riders from auto drivers and achieving traffic congestion relief (Downs, 2005; Litman, 2014). So far it still is an ongoing debate regarding the effectiveness in fulfilling these potentials. Proponents have argued that it reduces auto dependency and relieving congestion, while opponents have claimed that LRT either cannot attract enough riders in many automobile-dependent U.S. cities to matter or, when it does, there is enough latent demand for driving to eliminate any intermediate effect on the traffic.

Considerable research efforts have been dedicated to examining the actual or potential effects of LRT on transit ridership and traffic congestion (Bhattacharjee \& Goetz, 2012; Cao \& Schoner, 2014b; Ewing et al., 2014; Giuliano, 2004; Litman, 2014). However, these studies have failed to systematically evaluate both short- and long-term effects, due to a lack of consistent high-resolution historical data. Partially due to this 
data limitation, most previous studies on this topic have employed methods strong on establishing associations; few of them have used methods supporting causal inference. The purpose of this study is to add to existing research a more in-depth understanding of the effects of new light rail transit (LRT) service in both short- and long-term timeframe with a rigorous method supporting causal inference. Through case studies of two LRT lines in Portland, Oregon, this study conducts two analyses: (1) before and after comparisons of the LRT opening and (2) the difference-in-difference regression models to quantify the effects of new LRT service on ridership and traffic congestion. Routelevel transit boarding data and high-resolution historical traffic information from archival databases and iPeMS enable us to do the analyses. This study expects that this research fills the research gaps and helps transportation planners, policymakers, and community members to better understand the effects of LRT on transit ridership and traffic congestion.

\section{Research Design}

\section{Study Area}

As the case studies, this study selects the Green Line and Orange Line in the Portland metropolitan area, where the 59.7-mile MAX light rail system has been built over three decades partly as a solution to alleviate the worsening traffic congestion.

Figure 3. 1 shows the routes and stations of the MAX light rail system. The two cases are selected due to the trend in transit ridership and traffic congestion, and the availability of current and historical ridership and travel speed data for analysis. The Green Line is a 15- 
mile LRT line opened on September 12, 2009. It extends transit service to the eastside Portland metropolitan area by connecting Clackamas, Happy Valley, and downtown Portland. The Orange Line is a 7.3-mile light rail line opened in September 2015, the latest addition to the MAX light rail system. It extends light rail service to Southeast Portland, connecting downtown Portland, Portland State University, and Park Avenue in South East Portland.

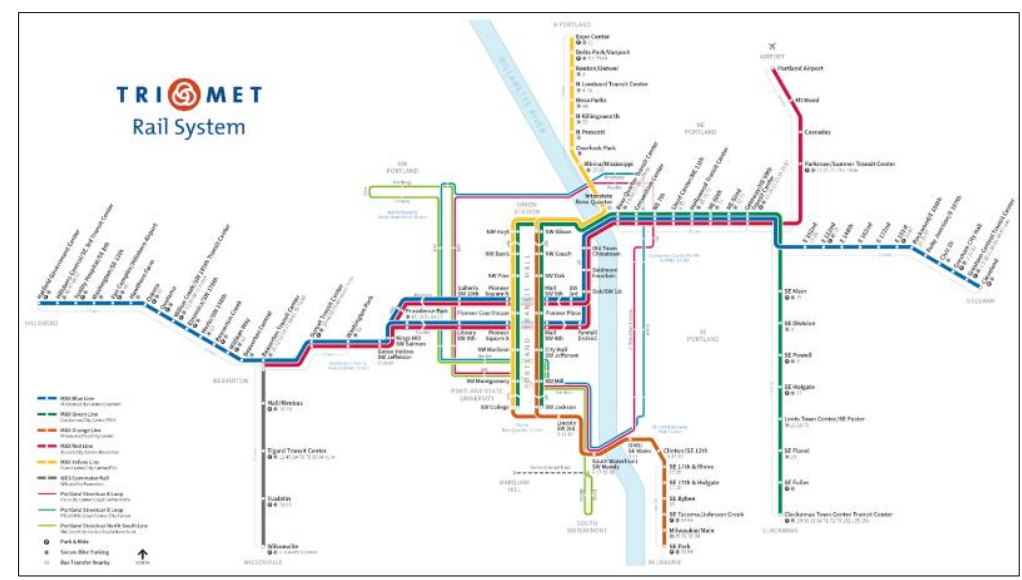

Figure 3. 1 Routes and stations of the MAX Light Rail system in Portland, Oregon (Source: TriMet Website)

\section{Methodology}

This study aims to quantify the effects of new LRT lines on transit ridership and traffic congestion at the corridor level and analyze the changes of these effects over time. This study uses a quasi-experimental design, and a difference-in-difference (DID) method with high temporal and spatial resolution data. The DID method is used to estimate group-level fixed effects of treatment (Figure 3.2) with an ability to correct 
group-level omitted variable bias. The following equation shows the classic DID regression model:

$$
y_{i t g}=\beta_{0}+\beta_{1} T+\beta_{2} G+\beta_{3} T G+\varepsilon
$$

where:

$y_{i t g}=$ outcome of interest (transit ridership and travel speed) on roadway segment i of group $g$

(experimental/control) during time period $\mathrm{t}$ (before/after)

$\mathrm{T}=$ dummy variable indicating time period (" 1 " for after the opening)

$\mathrm{G}=$ dummy variable indicating treated and control group (" 1 " for experimental group)

$\beta_{3}=$ the DID estimate

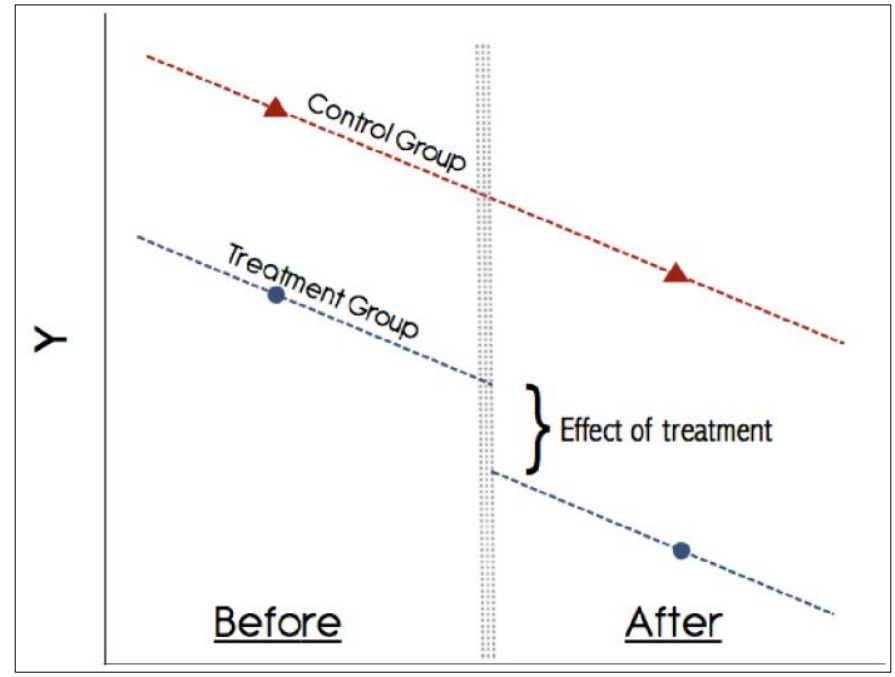

Figure 3. 2 Causal effects in the Difference in Difference model 


\section{Control and Experimental Groups}

This study chooses the corridors along a segment of the Green and Orange lines as experimental groups. This study then selects a control corridor for each line. Figure 3. 3 and Figure 3. 4 show the experimental and control corridors for the Green and Orange lines.

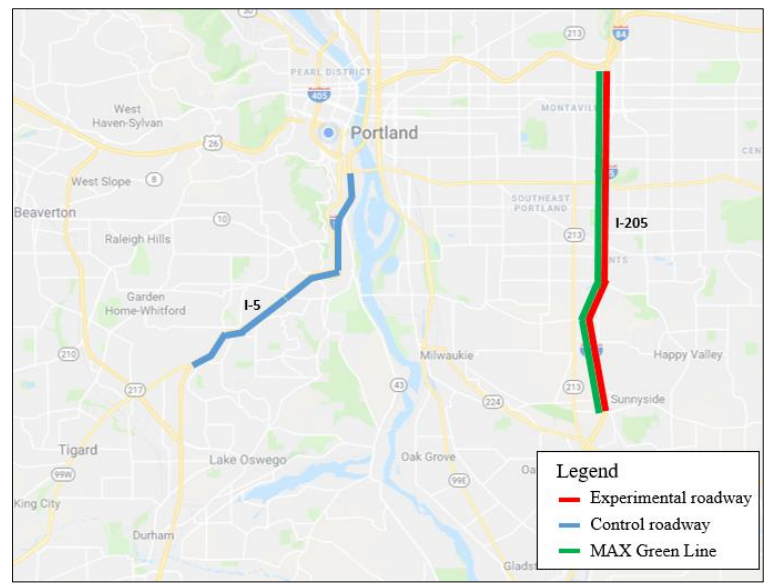

Figure 3. 3 Experimental and control corridor for the Green Line

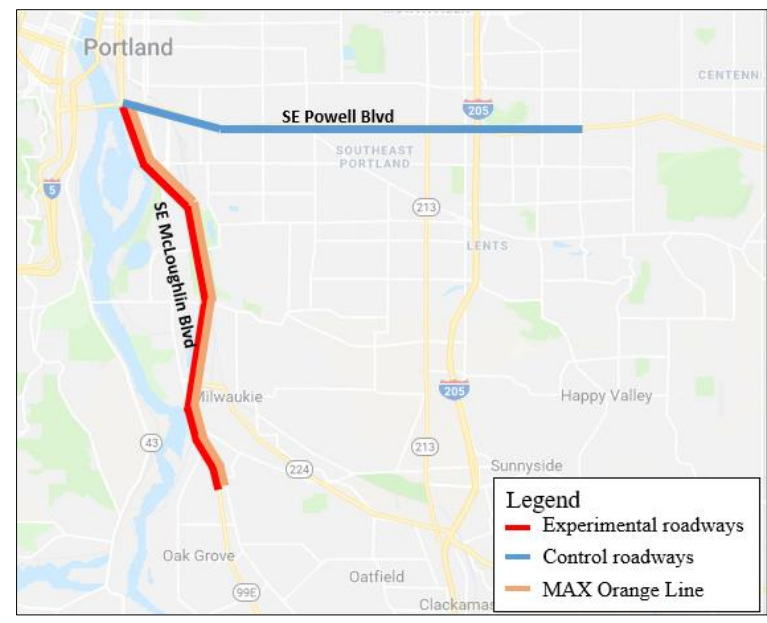

Figure 3. 4 Experimental and control corridor for the Orange Line 
The Green Line provides an additional travel mode between Clackamas and downtown Portland. This study focuses on the segment of the Green Line that stretches from Clackamas Town Center Station to SE Main St. Station. This segment of the Green Line is 7 miles long and runs close and parallel to I-205. After reviewing roadways profiles and traffic characteristics, I select the I-5 segment south of Downtown Portland as the control roadway, beginning at the interaction of I-5 with Ross Island Bridge to its intersection with Oregon Route 99. The Orange Line provides an alternative mode between downtown Portland and SE Portland.

The chosen I-5 segment and I-205 segment are comparable. I-5 is an interstate highway. I-205 is an auxiliary interstate highway, serving as a bypass route of I-5. The traffic volume of the two segments is similar, and they both serve the north-south traffic. From Clackamas Town Center to the North of Halsey Street, the selected I-205 segment travels through the eastern residential area of Portland, mainly including neighborhoods: Lents, Southgate, and West Mt. Scott. From its intersection with Oregon Route 99 to the north of Downtown Portland, the selected I-5 segment travels the southern residential area of Portland, mainly including neighborhoods: FAR Southwest, Crestwood, West Portland Park, Multnomah, Markham, South Burlingame, Hillsdale, and South Portland. Figure 3. 5 and Figure 3. 6 show that population density and employment density are similar along I-5 and I-205. Though the selected I-5 segment is a comparable control roadway, there are still some differences between I-5 and I-205. I-5 directly connects with Downtown Portland, while I-205 locates far away from the downtown area. The 
downtown area acts as an important employment center Portland Metropolitan Area.

Thus, there are probably differences in traffic patterns between I-5 and I-205.

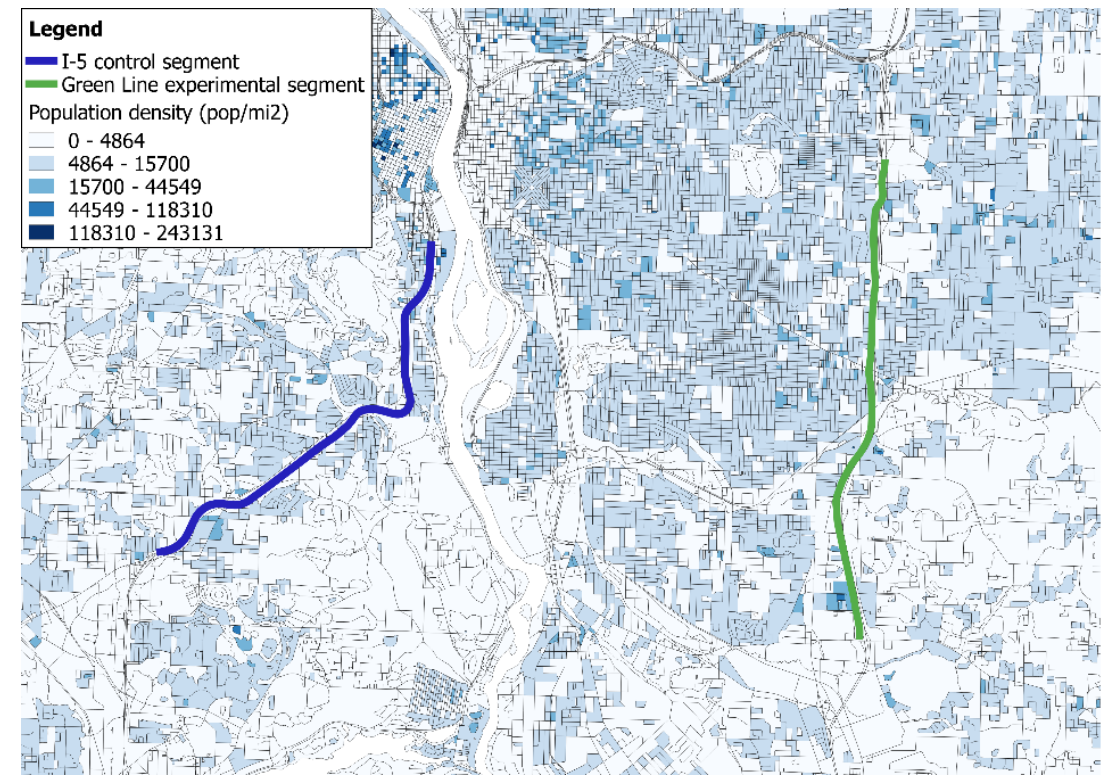

Figure 3. 5 Population density along I-205 and I-5

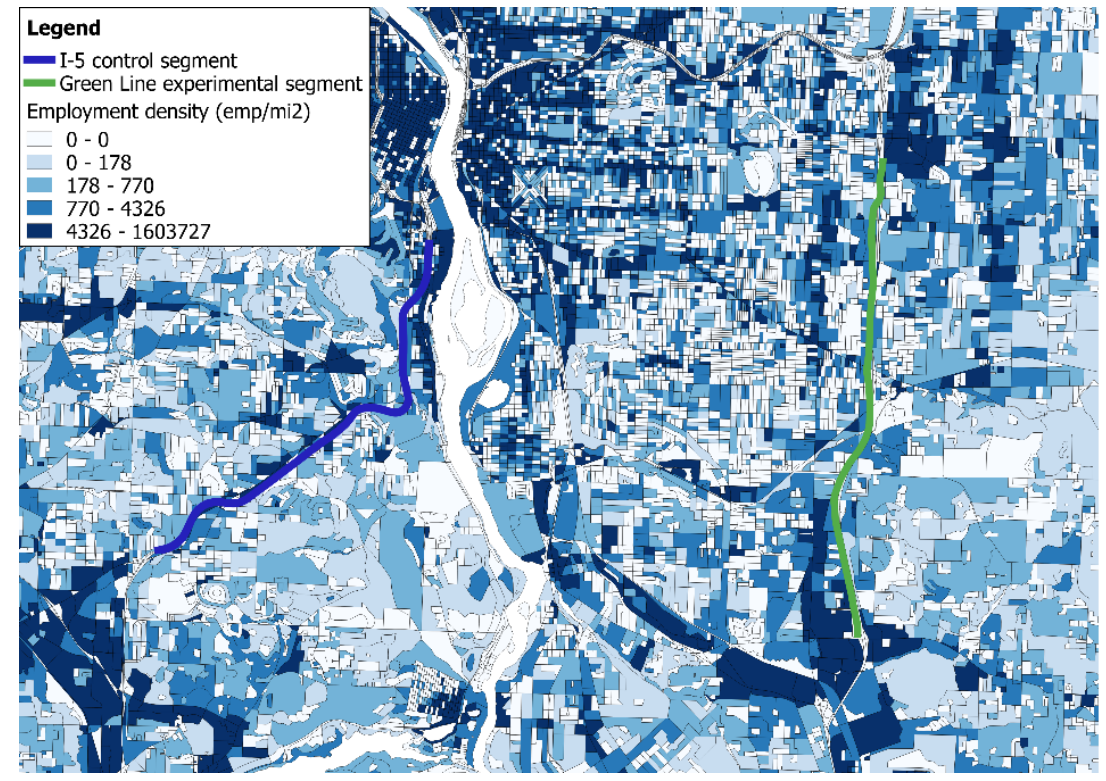

Figure 3. 6 Employment density along I-205 and I-5 
However, the selected I-5 highway segment is a better option as a control roadway after reviewing the other roadways in the area. An alternative of control roadway is Oregon Route $99 \mathrm{~W}$. It runs parallel to the I-5 highway. Since it is a statenumbered route, different from the experimental roadway, it is not selected. Another choice of control roadway is the I-5 segment from outside of downtown Portland northbound to Vancouver. However, from its intersection with N Columbia Blvd to Vancouver, the I-5 segment serves Delta Park, a recreational area. Thus, the I-5 segment from outside of downtown Portland northbound to Vancouver is not selected as a control roadway.

For the Orange Line, the experimental corridor is the area along the SE McLoughlin Blvd. From downtown Portland to Park Ave in SE Portland, most of SE McLoughlin Blvd is parallel and close to the Orange Line. The roadway segments within the experimental corridor include SE McLoughlin Blvd from its intersection with SE Franklin St to its intersection with SE Park Ave. After examining roadway profile and traffic characteristics, the control corridor is selected to be the SE Powell Blvd segment bounded by SE 122th Ave to the east and SE McLoughlin Blvd to the west. The control corridor is generally perpendicular to the Orange Line, and therefore should not be affected by the Orange Line.

The selected SE McLoughlin Blvd segment and SE Powell Blvd are comparable. The SE McLoughlin Blvd is an urban expressway, and it serves the southeastern residential area, mainly including neighborhoods: Hosford-Abernethy, Brooklyn and Sellwood-Moreland. SE Powell Blvd is an urban expressway, and it mainly serves the 
eastern residential area, including neighborhoods: Sullivan's Gulch, Kerns, North Tabor, Montavilla, and Centennial. The population density and employment density are similar along the selected SE McLoughlin Blvd segment and SE Powell Blvd, shown in Figure 3. 7 and Figure 3. 8. The selected SE McLoughlin Blvd segment and SE Powell Blvd are comparable in an overall sense. An alternative of the control roadway is Oregon Route 99E from North of NE Multnomah Street northbound to Vancouver. The Oregon Route 99E segment serves Delta Park, a recreation area, it is not finally selected.

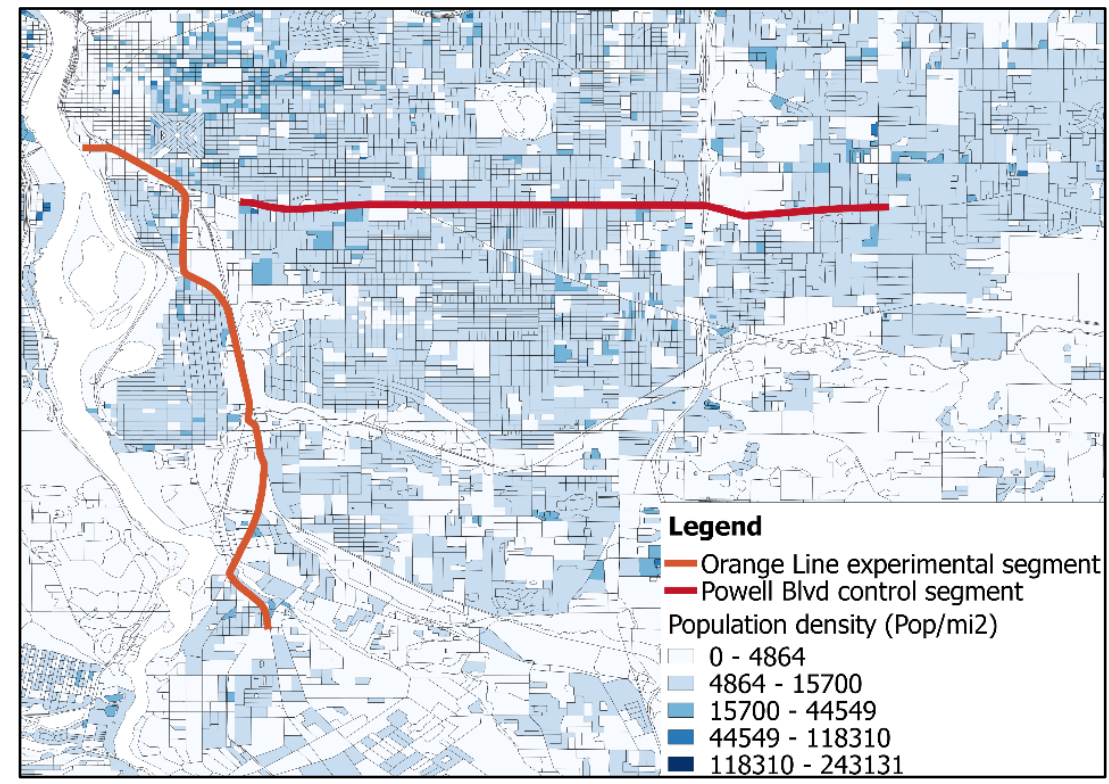

Figure 3. 72010 population density 2010 along treatment (SE McLoughlin Blvd) and control (Powell Blvd) 


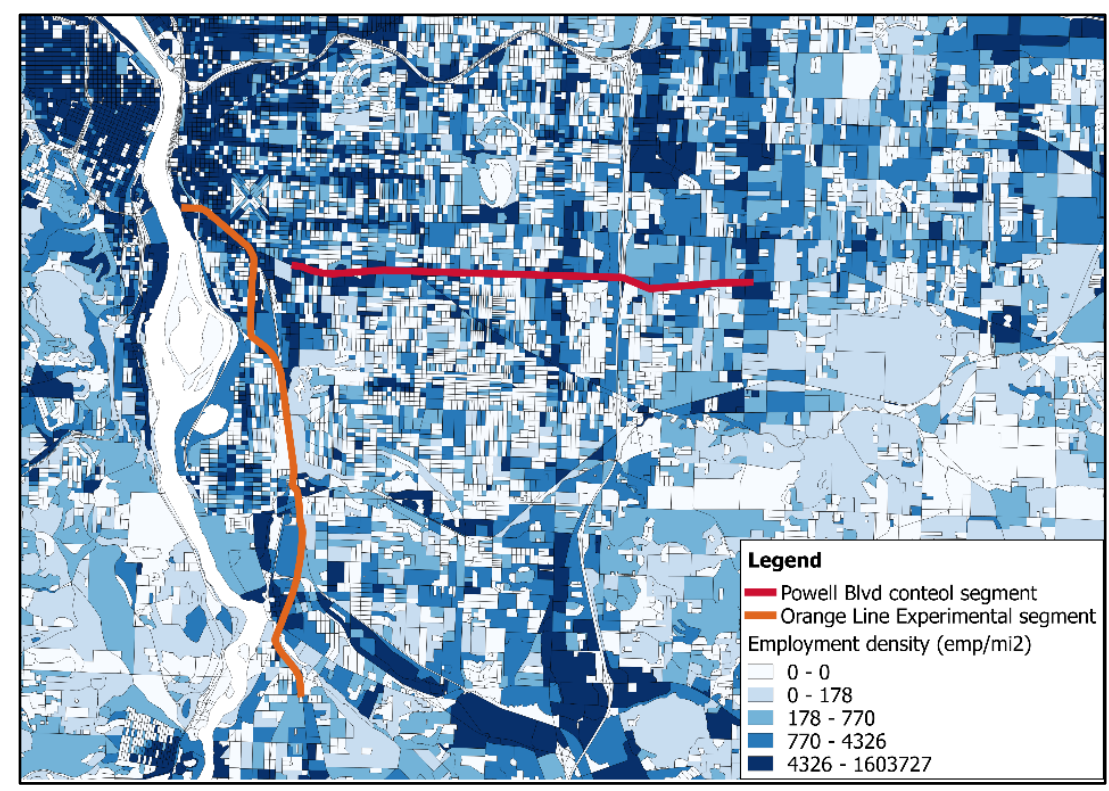

Figure 3. 82010 employment density along treatment (SE McLoughlin Blvd) and control (Powell Blvd)

Existing research has found the association between transit use and land use (Cervero, 1994; Ding et al., 2014; Ewing \& Cervero, 2010). The transit model would be improved after including land use variables. This study still does not include land use variables because of data availability at the corresponding temporal and spatial resolution. In the transit model, the ridership data are quarterly, while land use variables are annual. The temporal resolutions are different.

Population density is another variable that should be included in the transit model. This study does not include this variable due to two issues. The first issue is the temporal resolution of the population density variable. Population from U.S. Census Bureau is annual 5-year rolling data, while the transit ridership data are quarterly. The temporal resolutions are different. Second, in order to include population density in the transit 
model, it must be assumed that the population is equally distributed. This assumption does not reflect reality.

Because of lacking land use and population density variables, my estimation of the effect of the new LRT project on ridership is likely to be biased by overestimating the effect. Land use and population change are likely to contribute to ridership increase. In the regression model without land use and population variables, the impact of land use on ridership would be attributed to the new LRT project. Thus, the impact of the new LRT project on transit ridership would be overestimated because the coefficients include the effects resulting from land use and population changes.

Since population and land use changes are similar in the control and experimental corridors, the DID method used here may make up the impact of not including population and land use variables in the transit models because the selected control and experimental corridors are still comparable.

Other changes, such as ramp meters, that affect travel speed on the highway should also be considered when evaluating the impact of the new LRT project on congestion if they were implemented on the control or treatment corridor (but not both). The purpose of ramp meters is to reduce bottlenecks and improve the overall speed of traffic flow. By regulating vehicles entering a highway, ramp meters can avoid situations where a large number of vehicles move onto the highway at one time and lead to traffic congestion. Ramp meters also can improve travel speed by reducing crashes. If ramp meters are implemented before the operation of the new LRT project, it would not affect the impact of the new LRT project on traffic congestion. If ramp meters are implemented 
after the operation of the new LRT project, they will affect the impact of the new LRT project on traffic congestion. However, no information can be found on the implementation of such changes to the control or treatment corridor.

\section{Data}

This research focuses on the effects of LRT on both transit ridership and traffic congestion in that the transit ridership effect is a necessary, but not sufficient condition to explain indirect benefits ascribed to LRT (Giuliano et al., 2015). This study examines both effects by using transit boarding data and high-resolution historical traffic information from archival databases and iPeMS to comprehensively investigate the shortand long-term effects of LRT at the corridor level with case studies of two LRT lines in Portland, Oregon.

For traffic congestion data, this study uses route-level travel speed as a measure of traffic congestion. For the Green line case, this study employs the Transportation Data Archive for Portland-Vancouver (PORTAL) for travel speed data. PORTAL is a historical multi-modal transportation data archive, including historical weather data, incident data, transit data, and 20-second granularity loop detector data for the PortlandVancouver metropolitan region since July 2004 (Hansen et al., 2005). There are 13 and 11 loop detector stations in the experimental and control corridors, respectively. Each loop detector installed along the roadways generates a record including volume, speed, and occupancy for its corresponding lane every 20 seconds. Theoretically, each detector generates 4,320 records in a single day, but the actual number may be smaller due to non- 
reporting, which are excluded from this research. The 20-second granularity is sensitive to random noise, so this study aggregates the data into 5-minute granularity. This study then converts station-level data to route-level data. The final number of records for travel speed is 11,482 . Because the PORTAL data do not cover arterials, for the Orange line case, this study uses the iPeMS database for travel speed data, which is an online database tool provided by Iteris, Inc. The iPeMS database collects probe data from a sample of data collected from vehicle navigation systems, cell phone apps, and fleet vehicles. In iPeMS, users have access to statewide travel data from highways, principal arterials, minor arterials, and major collectors. Users can extract route-level travel data by assigning origination and destination only as far back as 2011, so it cannot be used for the Green Line case.

This study utilizes travel speed data collected before and after the operation of the LRT lines. The Orange Line began operation on September 12, 2015. The travel speed data were collected for the three year periods before (from September 12, 2012, to September 11, 2015) and after (from September 12, 2015, to September 11, 2018) the opening of the Orange Line. The Green Line began operation on September 12, 2009. The travel speed data were collected for the five-year periods before (from September 12, 2004, to September 11, 2009) and after (from September 12, 2009, to September 11, 2014) the Green Line opening.

This study obtains the data set from TriMet, the transit authority for the Portland, Oregon region, regarding transit ridership. The data includes boarding and alighting information by transit line, stop, time of day, and day of the week. The data has been 
collected by TriMet every three months. The time periods of transit ridership data used in this study are the same as travel speed data.

\section{Results}

\section{Effects on Transit Ridership}

Average weekday ridership

First, this study analyzes average weekday boardings at all bus and rail stops located within the experimental and control corridors before and after the operation of the two light rail transit lines. As shown in Figure 3. 9, the vertical dashed line indicates the date when the new light rail transit lines began operation. After the openings, boardings within each of the experimental corridors noticeably increased, while boardings within the control corridor decreased slightly for the Orange Line and remained nearly stable for the Green Line.

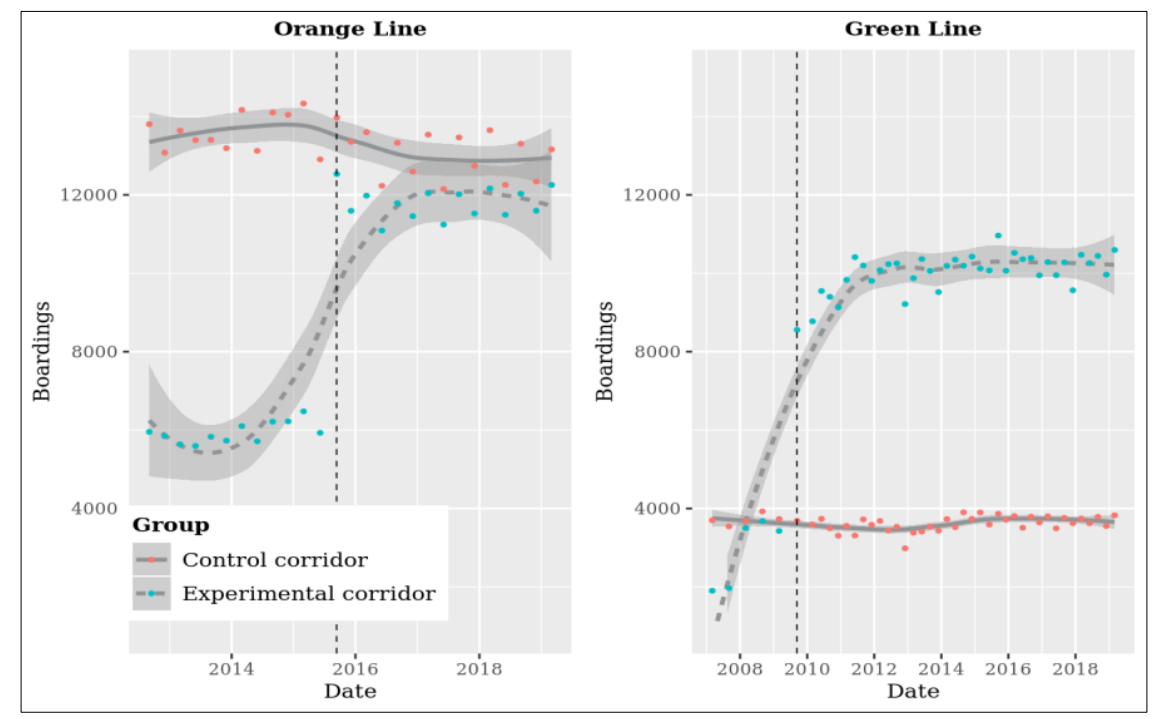

Figure 3.9 The change in the average weekday boardings at all bus and rail stops located within the experimental and control corridors over time 


\section{The difference-in-difference regression models}

This study then uses the DID regression models to examine the impacts on ridership. The DID estimators of base models were both statistically significant and positive, demonstrating that the average treatment effect of new LRT lines is 6,404 and 7,225 for the Orange Line and Green Line, respectively (Table 3. 1). That is, the Orange Line and Green Line contribute to an increase of 6,404 and 7,225 riders on average, respectively (Figure 3.10). Analyzing the ridership by each year after the operation of the Green Line, results indicate that there was an increase in ridership compared to the ridership in the control corridor (Table 3. 2). Table 3. 2 shows that ridership increased in the first year and then remained nearly stable after the first year for the Orange Line. For the Green Line, the ridership increased to about 9,000 from about 3,000 in the first year, and to about 9,500 in the second year, then kept relatively stable from the third year onward, and reached the maximum in the 7th year.

In sum, the DID estimators of both base models confirm the increase in transit ridership. More importantly, the two LRT lines lead to a large increase in transit ridership, particularly for the first few years of the operation of new LRT lines. This study also compares boardings and alightings at bus stops within a quarter-mile network distance of Orange Line stops before and after the Orange Line operation. The results also reveal that bus boardings and alightings both increased after the operation of both LRT lines (Figure 3. 11). 
Table 3. 1 Transit ridership DID regression models

\begin{tabular}{|c|c|c|}
\hline Variable & $\begin{array}{l}\text { Orange Line Base } \\
\text { model }\end{array}$ & $\begin{array}{l}\text { Green Line Base } \\
\text { model }\end{array}$ \\
\hline Time period (after $=1$ ) & $\begin{array}{l}-554.00^{* * *} \\
(179.00)\end{array}$ & $\begin{array}{l}-102.00^{* * * *} \\
(196.00)\end{array}$ \\
\hline Group (experimental group=1) & $\begin{array}{l}-7,662.00^{* * *} \\
(189.00)\end{array}$ & $\begin{array}{l}-821.00^{* * * *} \\
(260.00)\end{array}$ \\
\hline Time period*Group & $\begin{array}{l}6,404.00^{* * *} \\
(254.00)\end{array}$ & $\begin{array}{l}7,225.00^{* * *} \\
(277.00)\end{array}$ \\
\hline Constant & $\begin{array}{l}13,599.00^{* * *} \\
(134.00)\end{array}$ & $\begin{array}{l}3,716.00^{* * *} \\
(184.00)\end{array}$ \\
\hline Observations & 54 & 86 \\
\hline $\mathrm{R}^{2}$ & 0.98 & 0.985 \\
\hline Adjusted $\mathrm{R}^{2}$ & 0.98 & 0.984 \\
\hline Residual Std. Error & $\begin{array}{l}463.00 \\
(\mathrm{df}=50)\end{array}$ & $\begin{array}{l}411.00 \\
(\mathrm{df}=82)\end{array}$ \\
\hline F Statistic & $\begin{array}{l}712.00^{* * *} \\
(\mathrm{df}=3 ; 50)\end{array}$ & $\begin{array}{l}1,753.00^{* * * *} \\
(\mathrm{df}=3: 82)\end{array}$ \\
\hline
\end{tabular}

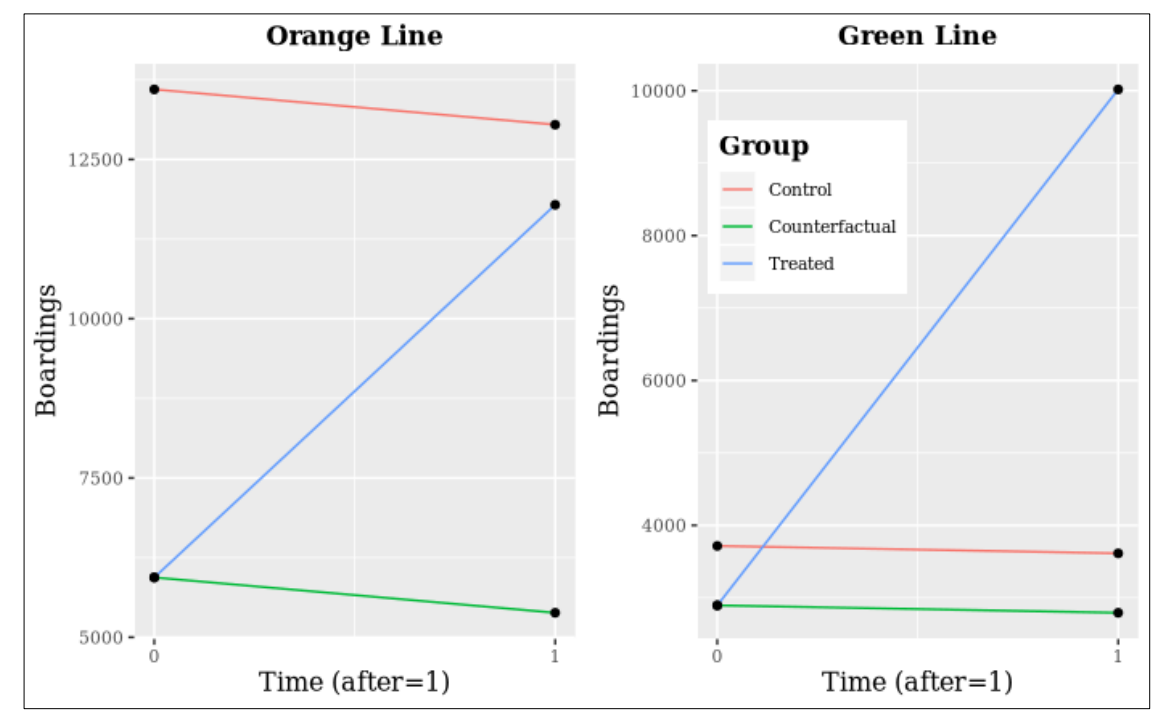

Figure 3. 10 The Difference-in-Differences effects of boardings 
Table 3. 2 Crosstab of boardings within the experimental and control corridors

\begin{tabular}{|l|l|l|l|l|}
\hline & \multicolumn{2}{|c|}{ Orange Line } & \multicolumn{2}{c|}{ Green Line } \\
\hline Time period & Control corridor & $\begin{array}{l}\text { Experimental } \\
\text { corridor }\end{array}$ & Control corridor & $\begin{array}{l}\text { Experimental } \\
\text { corridor }\end{array}$ \\
\hline Before & 13599 & 5938 & 3716 & 2895 \\
\hline $1^{\text {st }}$ year & 13289 & 11799 & 3671 & 8960 \\
\hline $2^{\text {nd }}$ year & 12902 & 11634 & 3417 & 9694 \\
\hline $3^{\text {rd }}$ year & 13028 & 11800 & 3606 & 10080 \\
\hline $4^{\text {th }}$ year & 12936 & 11961 & 3327 & 9926 \\
\hline $5^{\text {th }}$ year & & & 3556 & 10030 \\
\hline $6^{\text {th }}$ year & & & 3782 & 10204 \\
\hline $7^{\text {th }}$ year & & & 3724 & 10478 \\
\hline $8^{\text {th }}$ year & & & 3683 & 10144 \\
\hline $9^{\text {th }}$ year & & & 3689 & 10144 \\
\hline $10^{\text {th }}$ year & & & 3721 & 10334 \\
\hline
\end{tabular}

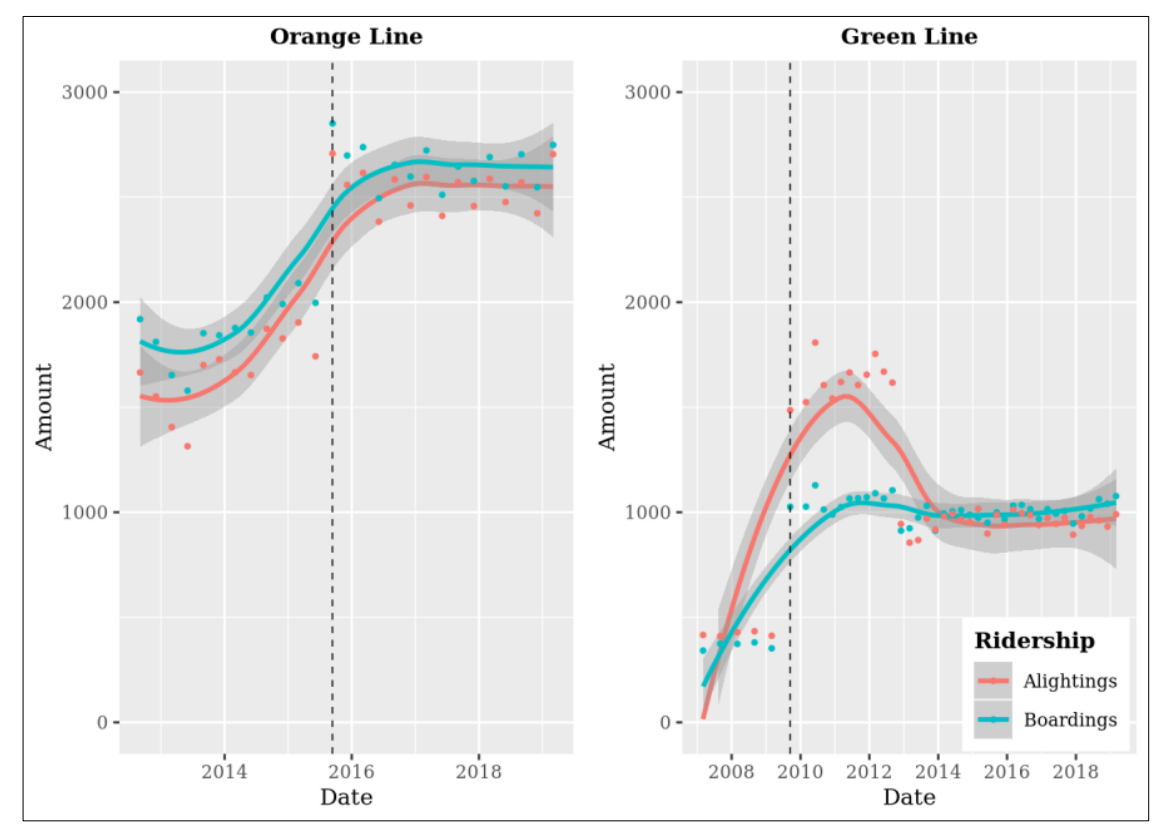

Figure 3. 11 The trends of the boardings and alightings at bus stops located within a quarter-mile radius of the Green and Orange line stations over time 


\section{Effects on Traffic Congestion}

This study focuses our study on the effects of LRT on traffic congestion on weekday peak periods when traffic volumes are considerably heavy and congestion more common: the AM peak between 7-10 AM, and the PM peak between 4-7 PM.

\section{Average speed}

This study, firstly, analyzes the average speed on experimental and control roadways by peak periods and directions (inbound to/outbound from downtown) for the Orange and Green lines (Figure 3. 12 and Figure 3. 13). For the Orange line case, as shown in Figure 3. 12, while the trend of average peak period travel speed on the experimental and control roadway segments was similar before the operation, average peak periods travel speed for both directions of the experimental corridor increased after the operation. The increase of speed for AM peak outbound from downtown was the largest, followed by PM peak inbound to downtown, that is, the directions with less congestion and higher speed to begin with. For the Green line case, shown in Figure 3. 13 , the average peak period travel speed on the experimental and control roadways was overall similar before the opening of the Green line. After its operation, the average speed on the experimental roadway saw little change. Also, note that there was a large variation in travel speed on the control roadway (I-5). 


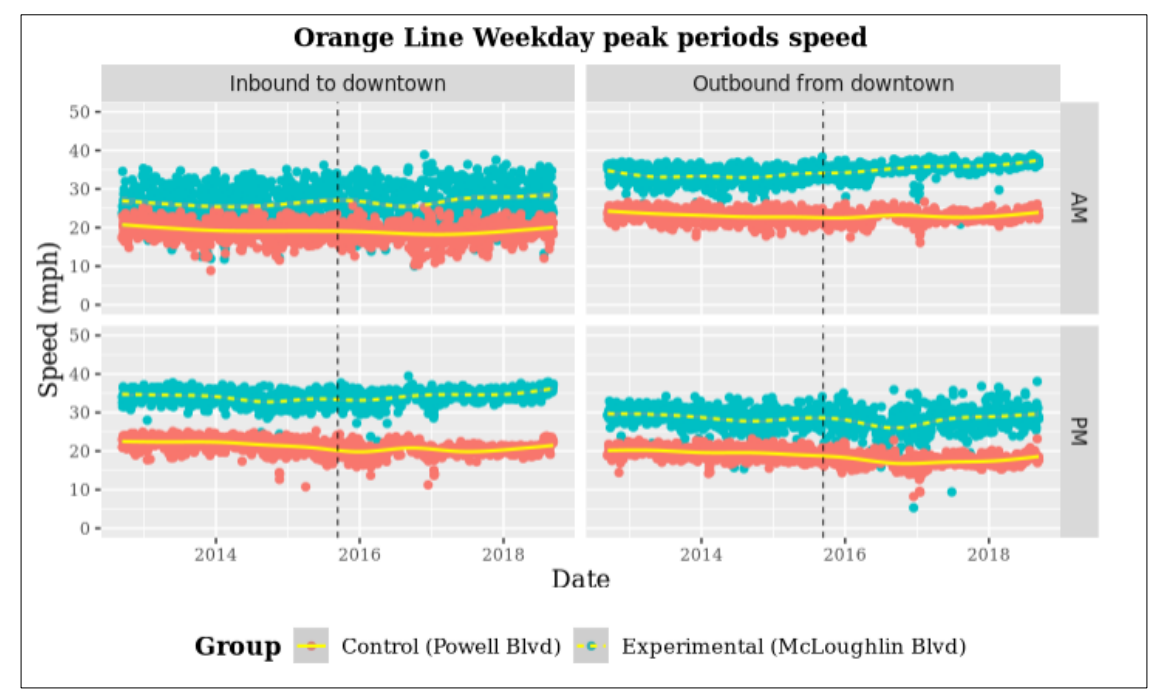

Figure 3. 12 The weekday peak periods speed comparison between experimental corridor (McLoughlin Blvd) and control corridor (Powell Blvd) for the Orange line

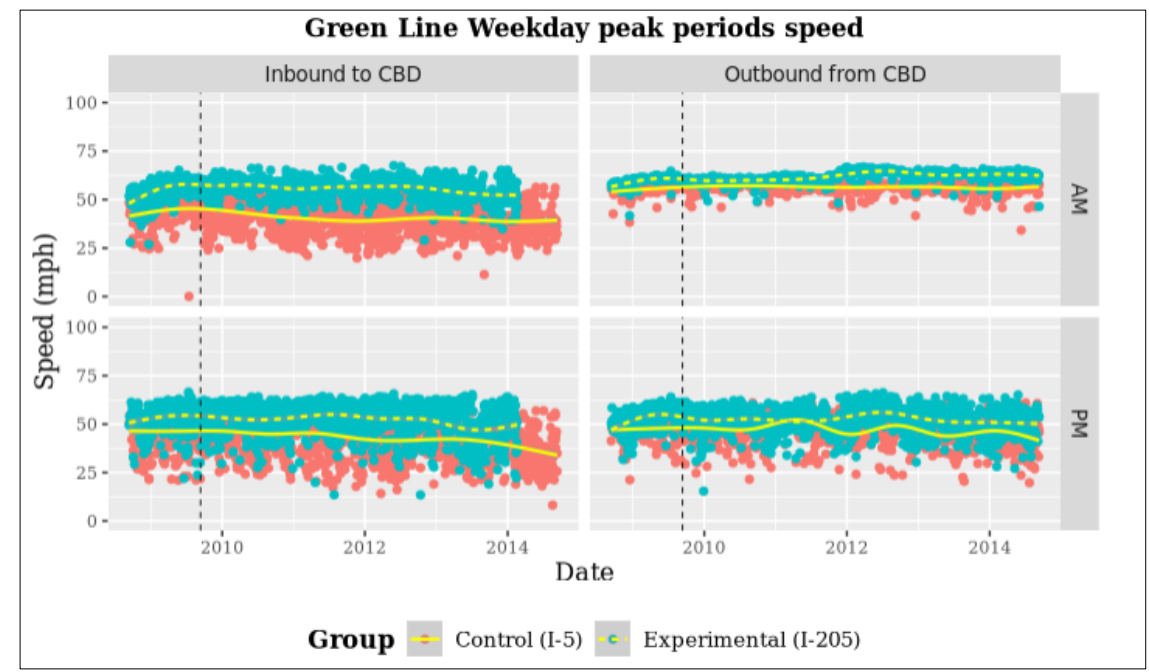

Figure 3. 13 The weekday peak periods speed comparison between experimental corridor (I-205) and control corridor (I-5) for the Green line 


\section{Difference-in-Difference base regression models}

For the Orange line case, the results in Table 3.3 show that each of the four models one for each period and direction combination, indicated a significant increase in the speed, ranging from $1.35 \mathrm{mph}$ to $2.35 \mathrm{mph}$ on average, of the experimental roadway in all cases. That is, our results suggest that the Orange Line has an effect on increasing travel speed on the experimental segment. The size of the impacts differed across the periods and directions.

Table 3. 3 The difference-in-difference base regression models on the speed effect of the Orange Line

\begin{tabular}{|l|l|l|l|l|}
\hline & AM Outbound & AM Inbound & PM Outbound & PM inbound \\
\hline $\begin{array}{l}\text { Time Period } \\
\text { (after }=1)\end{array}$ & $\begin{array}{l}-0.257^{* * *} \\
(0.077)\end{array}$ & $\begin{array}{l}-0.748^{* * *} \\
(0.180)\end{array}$ & $\begin{array}{l}-2.130^{* * *} \\
(0.100)\end{array}$ & $\begin{array}{l}-1.490^{* * * *} \\
(0.083)\end{array}$ \\
\hline $\begin{array}{l}\text { Group } \\
\text { (experimental } \\
\text { group }=1)\end{array}$ & $\begin{array}{l}10.300^{* * *} \\
(0.077)\end{array}$ & $\begin{array}{l}6.690^{* * *} \\
(0.180)\end{array}$ & $\begin{array}{l}9.090^{* * *} \\
(0.108)\end{array}$ & $\begin{array}{l}12.000^{* * *} \\
(0.083)\end{array}$ \\
\hline $\begin{array}{l}\text { Time period }{ }^{*} \\
\text { Group }\end{array}$ & $\begin{array}{l}2.350^{* * *} \\
(0.109)\end{array}$ & $\begin{array}{l}1.500^{* * *} \\
(0.255)\end{array}$ & $\begin{array}{l}1.350^{* * *} \\
(0.152)\end{array}$ & $\begin{array}{l}2.070^{* * *} \\
(0.117)\end{array}$ \\
\hline Constant & $23.200^{* * *}$ & $19.500^{* * *}$ & $19.700^{* * *}$ & $21.800^{* * *}$ \\
& $(0.055)$ & $(0.127)$ & $(0.076)$ & $(0.058)$ \\
\hline Observations & 3,129 & 3,130 & 3,128 & 3,128 \\
\hline $\mathrm{R}^{2}$ & 0.935 & 0.524 & 0.844 & 0.941 \\
\hline Adjusted $\mathrm{R}^{2}$ & 0.935 & 0.523 & 0.843 & 0.941 \\
\hline Residual Std. & $1.530(\mathrm{df}=$ & $3.570(\mathrm{df}=$ & $2.130(\mathrm{df}=$ & $1.630(\mathrm{df}=$ \\
Error & $3,125)$ & $3,126)$ & $3124)$ & $3124)$ \\
\hline F Statistic & $14,943.000^{* * *}$ & $1,146.000^{* * *}$ & $5,616.000^{* * *}$ & $16,664.000^{* * *}$ \\
& $(\mathrm{df}=3 ; 3125)$ & $(\mathrm{df}=3 ; 3126)$ & $(\mathrm{df}=3 ; 3124)$ & $(\mathrm{df}=3 ; 3124)$ \\
\hline
\end{tabular}

For the Green line case, as shown in Table 3. 4, each of the four models indicated a significant increase in travel speed of the experimental roadway in both directions during 
AM peak and PM Outbound, with the increase ranging from $1.12 \mathrm{mph}$ to $5.12 \mathrm{mph}$. There is no significant effect for the outbound direction during PM peak, as the coefficient from the DID estimator was negative, but not statistically significant.

Table 3. 4 The difference-in-difference base regression models on the speed effect of the Green Line

\begin{tabular}{|l|l|l|l|l|}
\hline & $\begin{array}{l}\text { AM } \\
\text { Outbound }\end{array}$ & AM Inbound & PM Outbound & PM inbound \\
\hline $\begin{array}{l}\text { Time Period (after } \\
=1)\end{array}$ & $\begin{array}{l}-4.580^{* * *} \\
(0.475)\end{array}$ & $\begin{array}{l}-3.380^{* * *} \\
(0.643)\end{array}$ & $\begin{array}{l}0.912^{* * *} \\
(0.163)\end{array}$ & $\begin{array}{l}-0.657 \\
(0.468)\end{array}$ \\
\hline $\begin{array}{l}\text { Group } \\
\text { (experimental } \\
\text { group }=1)\end{array}$ & $\begin{array}{l}10.500^{* * * *} \\
(0.611)\end{array}$ & $\begin{array}{l}7.270^{* * *} \\
(0.818)\end{array}$ & $\begin{array}{l}4.350^{* * *} \\
(0.210)\end{array}$ & $\begin{array}{l}5.400^{* * *} \\
(0.594)\end{array}$ \\
\hline $\begin{array}{l}\text { Time period * } \\
\text { Group }\end{array}$ & $\begin{array}{l}5.120^{* * *} \\
(0.674)\end{array}$ & $\begin{array}{l}2.25^{* * *} \\
(0.901)\end{array}$ & $\begin{array}{l}1.120^{* * *} \\
(0.229)\end{array}$ & $\begin{array}{l}-0.117 \\
(0.651)\end{array}$ \\
\hline Constant & $44.900^{* * *}$ & $46.000^{* * *}$ & $55.500^{* * *}$ & $47.700^{* * *}$ \\
& $(0.434)$ & $(0.589)$ & $(0.150)$ & $(0.430)$ \\
\hline Observations & 2,773 & 2,833 & 2,884 & 2,922 \\
\hline $\mathrm{R}^{2}$ & 0.549 & 0.208 & 0.586 & 0.143 \\
\hline Adjusted $\mathrm{R}^{2}$ & 0.549 & 0.208 & 0.586 & 0.142 \\
\hline Residual Std. Error & $\begin{array}{l}6.760 \\
(\mathrm{df}=2769)\end{array}$ & $\begin{array}{l}9.140 \\
(\mathrm{df}=2829)\end{array}$ & $\begin{array}{l}2.270 \\
(\mathrm{df}=2880)\end{array}$ & $\begin{array}{l}6.560 \\
(\mathrm{df}=2918)\end{array}$ \\
\hline F Statistic & $\begin{array}{l}1,124.000^{* * *} \\
(\mathrm{df}=3 ; 2769)\end{array}$ & $\begin{array}{l}248.000^{* * *} \\
(\mathrm{df}=3 ; 2829)\end{array}$ & $\begin{array}{l}1,361.000^{* * *} \\
(\mathrm{df}=3 ; 2880)\end{array}$ & $\begin{array}{l}162.000^{* * *} \\
(\mathrm{df}=3 ; 2918)\end{array}$ \\
\hline Note: ${ }^{*} \mathrm{p}<0.1 ;{ }^{* *} \mathrm{p}<0.05 ;{ }^{* * *} \mathrm{p}<0.01$ & & \\
\hline
\end{tabular}

Based on the results of the speed DID base models, Figure 3. 14 and Figure 3. 15 show the changes in average travel speed before and after the operation of the new LRT lines for both the experimental and control roadway segments, by directions and periods for the Orange Line and Green Line, respectively. The "counterfactual" line shows what would have happened in the absence of the operation of the Orange Line, assuming the 
change in travel speed on the experimental roadway segment would mirror the change in travel speed on the control roadway segment. For the Orange Line, the travel speed on the experimental roadway segment for after period is higher than that in the counterfactual scenario (Figure 3. 14). For the Green Line, the travel speed on the experimental roadway segment for the after-period was higher than that in the counterfactual scenario for the after-period, except in the case of the PM outbound (Figure 3. 15). I, thus, conclude that both LRT Lines have had a relief effect on travel speed on the experimental roadway segment.

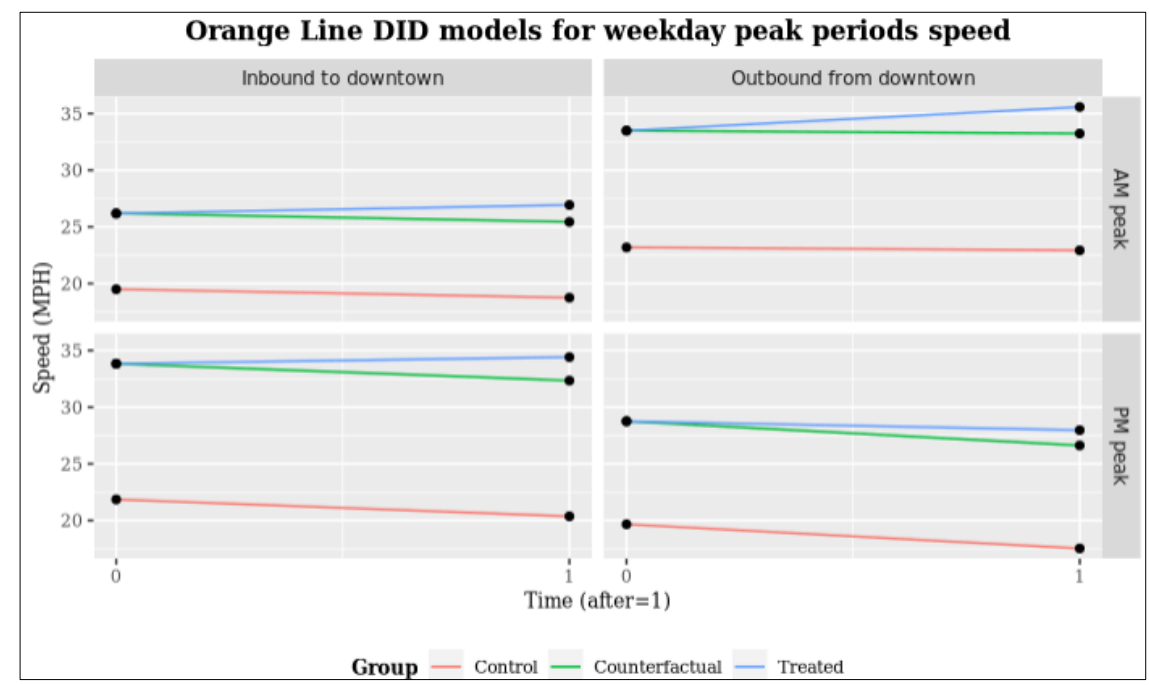

Figure 3. 14 The estimated speed based on the DID base models for the Orange line during weekday peak periods 


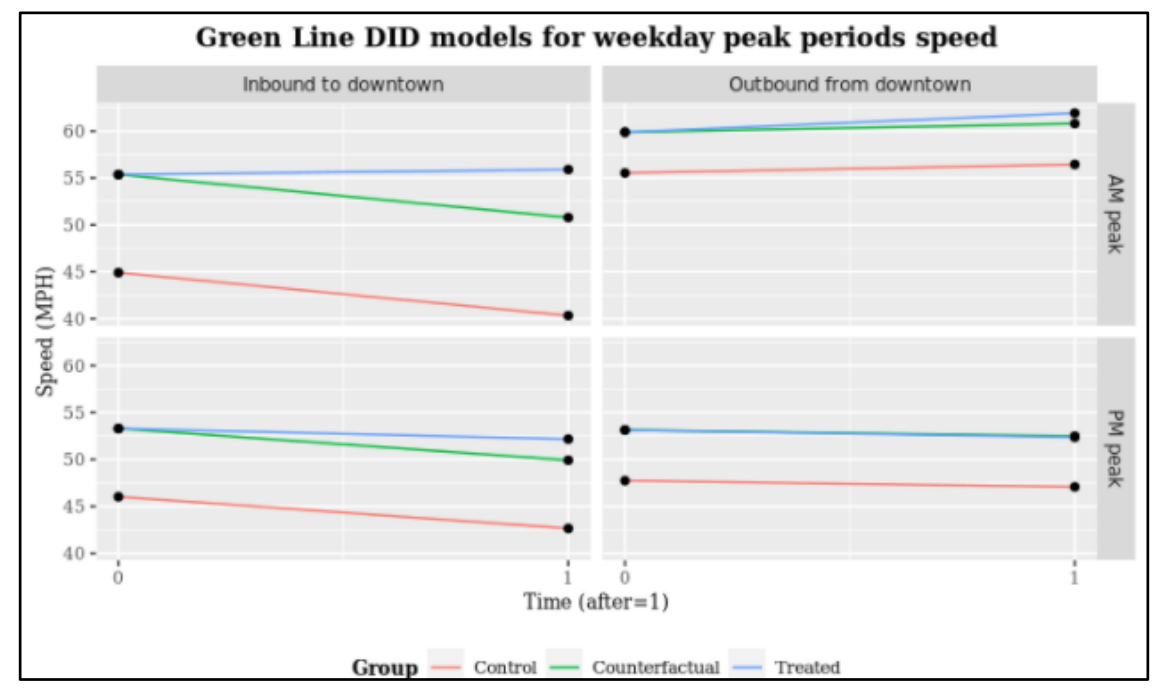

Figure 3. 15 The estimated speed based on the DID base models for the Green line during weekday peak periods

Difference-in-Difference regression models with multiple time periods

This study further investigates how the increase in travel speed changes over time by applying the DID regression models with multiple time periods. As predicted by the induced demand hypothesis, the increase in travel speed, if any, would diminish over time.

Table 3. 5 shows the results of the DID regression models with multiple time periods for the Orange Line case. The results of the DID estimators indicated that the increases in travel speed of the experimental roadway persist and improve over time, as most coefficients for Year * Group is significant with magnitude increasing from the 1 st to 2 nd and then 3 rd year. Two exceptions are the effect on the outbound direction for the PM period in the first year, which is negative but statistically insignificant, and on the inbound direction for the AM period for the 3rd year, which is almost the same as that for the 2nd year. 
Figure 3. 16 provides a more visual representation of this result. The horizontal dashed lines indicate the average treated effects for the corresponding period and direction. The line plot shows the evolution of the effects of new LRT lines on travel speed over the years, with the confidence intervals for each year also represented in the figure. It is clear in Figure 3. 16 that the size of the effect on travel speed varies by periods and directions, and for a given period and direction, the size of the effect generally increases over time.

Table 3. 5 Travel Speed Difference-in-Difference Regression Models with

Multiple Time periods on the speed effect of the Orange Line

\begin{tabular}{|c|c|c|c|c|}
\hline & AM Outbound & AM Inbound & PM Outbound & PM inbound \\
\hline $\begin{array}{l}\text { Group } \\
\text { (experimental } \\
\text { group=1) }\end{array}$ & $\begin{array}{l}10.300^{\text {*** }} \\
(0.075)\end{array}$ & $\begin{array}{l}6.690^{* * *} \\
(0.179)\end{array}$ & $\begin{array}{l}9.090^{* * * *} \\
(0.105)\end{array}$ & $\begin{array}{l}12.000^{* * *} \\
(0.081)\end{array}$ \\
\hline $1^{\text {st }}$ year & $\begin{array}{l}-0.315^{\text {*** }} \\
(0.106)\end{array}$ & $\begin{array}{l}-0.558^{* * *} \\
(0.254)\end{array}$ & $\begin{array}{l}-1.580^{\text {**** }} \\
(0.149)\end{array}$ & $\begin{array}{l}-1.490^{* * *} \\
(0.114)\end{array}$ \\
\hline $2^{\text {nd }}$ year & $\begin{array}{l}-0.380^{* * *} \\
(0.105)\end{array}$ & $\begin{array}{l}-1.380^{* * *} \\
(0.254)\end{array}$ & $\begin{array}{l}-2.830^{* * * *} \\
(0.148)\end{array}$ & $\begin{array}{l}-1.710^{* * * *} \\
(0.114)\end{array}$ \\
\hline $3^{\text {rd }}$ year & $\begin{array}{l}-0.076 \\
(0.105)\end{array}$ & $\begin{array}{l}-0.307 \\
(0.254)\end{array}$ & $\begin{array}{l}-1.990^{* * * *} \\
(0.148)\end{array}$ & $\begin{array}{l}-1.260^{* * * *} \\
(0.114)\end{array}$ \\
\hline $1^{\text {st }}$ year $*$ Group & $\begin{array}{l}1.320^{* * *} \\
(0.149)\end{array}$ & $\begin{array}{l}0.622^{*} \\
(0.359)\end{array}$ & $\begin{array}{l}-0.059 \\
(0.210)\end{array}$ & $\begin{array}{l}1.200^{* * * *} \\
(0.162)\end{array}$ \\
\hline $2^{\text {nd }}$ year*Group & $\begin{array}{l}2.710^{* * * *} \\
(0.149)\end{array}$ & $\begin{array}{l}1.970^{* * * *} \\
(0.359)\end{array}$ & $\begin{array}{l}1.760^{* * * *} \\
(0.210)\end{array}$ & $\begin{array}{l}2.460^{* * * *} \\
(0.162)\end{array}$ \\
\hline $3^{\text {rd }}$ year*Group & $\begin{array}{l}3.000^{* * * *} \\
(0.149)\end{array}$ & $\begin{array}{l}1.900^{* * * *} \\
(0.359)\end{array}$ & $\begin{array}{l}2.340^{* * * *} \\
(0.210)\end{array}$ & $\begin{array}{l}2.550^{* * * *} \\
(0.162)\end{array}$ \\
\hline Constant & $\begin{array}{l}23.2000^{* * *} \\
(0.053)\end{array}$ & $\begin{array}{l}19.500^{\text {**** }} \\
(0.127)\end{array}$ & $\begin{array}{l}19.700^{\text {*** }} \\
(0.074)\end{array}$ & $\begin{array}{l}21.800^{* * *} \\
(0.057)\end{array}$ \\
\hline Observations & 3,129 & 3,130 & 3,128 & 3,128 \\
\hline $\mathrm{R}^{2}$ & 0.939 & 0.529 & 0.852 & 0.944 \\
\hline Adjusted $\mathrm{R}^{2}$ & 0.939 & 0.528 & 0.852 & 0.944 \\
\hline $\begin{array}{l}\text { Residual Std. } \\
\text { Error }\end{array}$ & $\begin{array}{l}1.470(\mathrm{df}= \\
3121)\end{array}$ & $\begin{array}{l}3.550(\mathrm{df}= \\
3122)\end{array}$ & $\begin{array}{l}2.080(\mathrm{df}= \\
3120)\end{array}$ & $\begin{array}{l}1.600(\mathrm{df}= \\
3120)\end{array}$ \\
\hline F Statistic & $\begin{array}{l}6,916.000^{* * *} \\
(\mathrm{df}=7 ; 3121)\end{array}$ & $\begin{array}{l}502.000^{* * *}(\mathrm{df} \\
=7 ; 3122)\end{array}$ & $\begin{array}{l}2,564.000^{* * *} \\
(\mathrm{df}=7 ; 3120)\end{array}$ & $\begin{array}{l}7,479.000^{* * *} \\
(\mathrm{df}=7 ; 3120)\end{array}$ \\
\hline
\end{tabular}




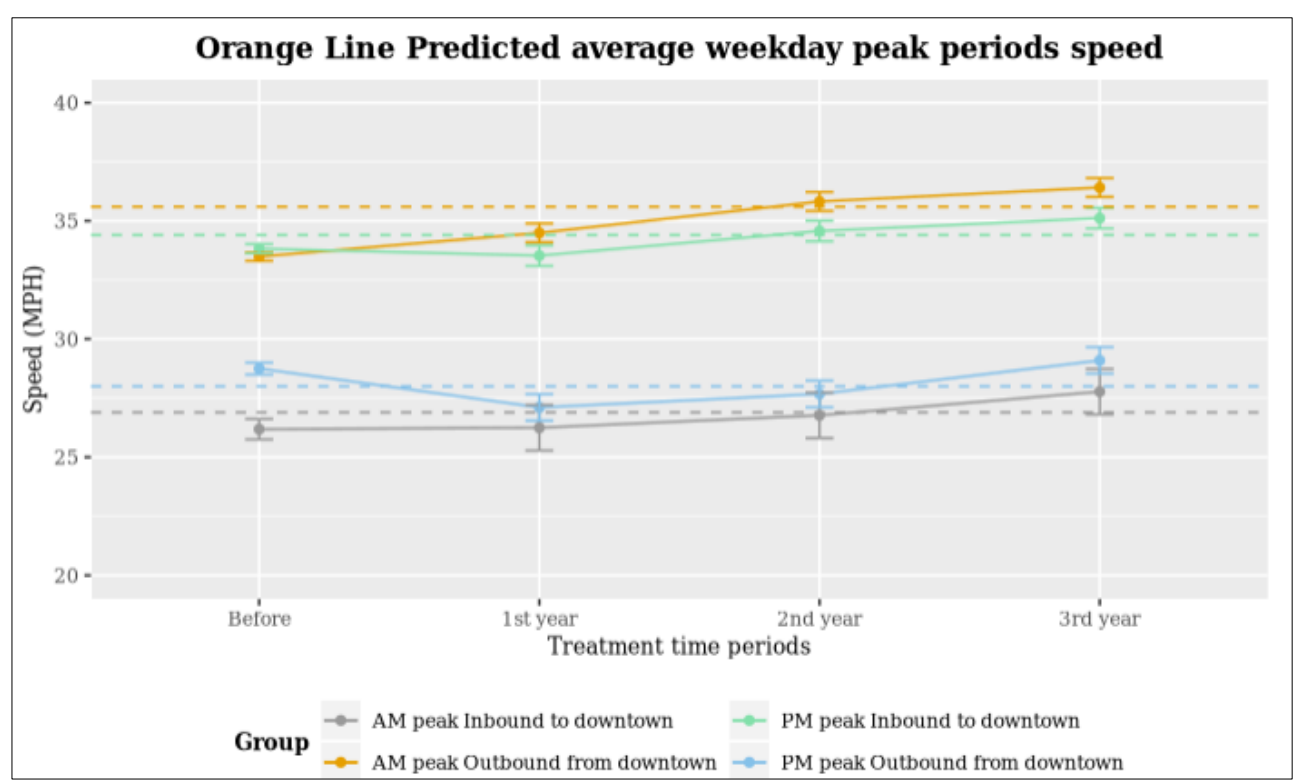

\section{Figure 3. 16 Predicted speed based on the DID models with multiple time periods for the Orange line during weekday peak periods}

For the Green line case, Table 3. 6 shows that most of the coefficients for Year * Group of the DID estimators were positive and statistically significant, indicating that there were increases in travel speed on the experimental roadway. The size of Year $*$ Group coefficients from the DID estimators were highest in the third year for all four models, but there is no clear pattern of how the effect changes over time. Figure 3.17 provides a visual representation of the result. As shown in Figure 3. 17, for a given period and direction, even though the point estimates of the effect differ from one year to the next, their confidence intervals largely overlap, indicating the differences in the effect size over the years are not statistically significant. 
Table 3. 6 Results of Travel Speed Difference-in-Difference Regression Models with multiple time periods of the Green Line Case

\begin{tabular}{|c|c|c|c|c|}
\hline & AM Outbound & AM Inbound & PM Outbound & PM inbound \\
\hline $\begin{array}{l}\text { Group } \\
\text { (experimental } \\
\text { group=1) }\end{array}$ & $\begin{array}{l}10.500^{* * * *} \\
(0.595)\end{array}$ & $\begin{array}{l}7.270^{* * * *} \\
(0.798)\end{array}$ & $\begin{array}{l}4.350^{* * * *} \\
(0.186)\end{array}$ & $\begin{array}{l}5.400^{* * * *} \\
(0.581)\end{array}$ \\
\hline $1^{\text {st }}$ year & $\begin{array}{l}-1.130^{* * * *} \\
(0.589)\end{array}$ & $\begin{array}{l}-0.480^{* * * *} \\
(0.799)\end{array}$ & $\begin{array}{l}1.400^{* * * *} \\
(0.183)\end{array}$ & $\begin{array}{l}-0.093^{* * *} \\
(0.580)\end{array}$ \\
\hline $2^{\text {nd }}$ year & $\begin{array}{l}-5.050^{* * * *} \\
(0.588)\end{array}$ & $\begin{array}{l}-0.777^{* * *} \\
(0.802)\end{array}$ & $\begin{array}{l}1.190^{* * * *} \\
(0.182)\end{array}$ & $\begin{array}{l}2.350^{* * * *} \\
(0.589)\end{array}$ \\
\hline $3^{\text {rd }}$ year & $\begin{array}{l}-5.740^{* * *} \\
(0.588)\end{array}$ & $\begin{array}{l}-4.600^{* * *} \\
(0.797)\end{array}$ & $\begin{array}{l}0.794^{* * *} \\
(0.183)\end{array}$ & $\begin{array}{l}-1.110^{* * *} \\
(0.577)\end{array}$ \\
\hline $4^{\text {th }}$ year & $\begin{array}{l}-4.830^{* * *} \\
(0.592)\end{array}$ & $\begin{array}{l}-3.630^{* * *} \\
(0.811)\end{array}$ & $\begin{array}{l}0.887^{* * *} \\
(0.184)\end{array}$ & $\begin{array}{l}-1.680^{* * *} \\
(0.583)\end{array}$ \\
\hline $5^{\text {th }}$ year & $\begin{array}{l}-6.550^{* * * *} \\
(0.625)\end{array}$ & $\begin{array}{l}-7.940^{* * *} \\
(0.827)\end{array}$ & $\begin{array}{l}0.208 \\
(0.188)\end{array}$ & $\begin{array}{l}-2.760^{* * * *} \\
(0.592)\end{array}$ \\
\hline $1^{\text {st }}$ year $*$ Group & $\begin{array}{l}3.200^{* * * *} \\
(0.832)\end{array}$ & $\begin{array}{l}0.112 \\
(1.120)\end{array}$ & $\begin{array}{l}-1.390^{* * * *} \\
(0.258)\end{array}$ & $\begin{array}{l}-0.293 \\
(0.811)\end{array}$ \\
\hline $2^{\text {nd }}$ year* Group & $\begin{array}{l}5.910^{* * * *} \\
(0.831)\end{array}$ & $\begin{array}{l}1.450 \\
(1.120)\end{array}$ & $\begin{array}{l}-0.720^{* * * *} \\
(0.257)\end{array}$ & $\begin{array}{l}-3.790^{* * *} \\
(0.817)\end{array}$ \\
\hline $3^{\text {rd }}$ year*Group & $\begin{array}{l}7.060^{* * * *} \\
(0.834)\end{array}$ & $\begin{array}{l}4.150^{* * * *} \\
(1.120)\end{array}$ & $\begin{array}{l}3.250^{* * * *} \\
(0.260)\end{array}$ & $\begin{array}{l}2.620^{* * * *} \\
(0.816)\end{array}$ \\
\hline $4^{\text {th }}$ year*Group & $\begin{array}{l}3.680^{* * * *} \\
(0.852)\end{array}$ & $\begin{array}{l}0.329 \\
(1.140)\end{array}$ & $\begin{array}{l}2.300^{* * * *} \\
(0.262)\end{array}$ & $\begin{array}{l}0.866 \\
(0.827)\end{array}$ \\
\hline $5^{\text {th }}$ year*Group & $\begin{array}{l}3.200^{* * * *} \\
(1.060)\end{array}$ & $\begin{array}{l}3.650^{* * * *} \\
(1.360)\end{array}$ & $\begin{array}{l}2.660^{* * * *} \\
(0.267)\end{array}$ & $\begin{array}{l}-0.204 \\
(0.840)\end{array}$ \\
\hline Constant & $\begin{array}{l}44.900^{* * * *} \\
(0.432)\end{array}$ & $\begin{array}{l}46.000^{* * *} \\
(0.574)\end{array}$ & $\begin{array}{l}55.500^{* * * *} \\
(0.133)\end{array}$ & $\begin{array}{l}47.700^{* * * *} \\
(0.420)\end{array}$ \\
\hline Observations & 2,773 & 2.833 & 2,884 & 2,922 \\
\hline $\mathrm{R}^{2}$ & 0.574 & 0.249 & 0.677 & 0.184 \\
\hline Adjusted $\mathrm{R}^{2}$ & 0.572 & 0.246 & 0.675 & 0.181 \\
\hline $\begin{array}{l}\text { Residual Std. } \\
\text { Error }\end{array}$ & $\begin{array}{l}6.580(\mathrm{df}= \\
2761)\end{array}$ & $\begin{array}{l}8.910(\mathrm{df}= \\
2821)\end{array}$ & $\begin{array}{l}2.010(\mathrm{df}= \\
2872)\end{array}$ & $\begin{array}{l}6.410(\mathrm{df}= \\
2910)\end{array}$ \\
\hline F Statistic & $\begin{array}{l}338.000^{* * * *}(\mathrm{df} \\
=11 ; 2761)\end{array}$ & $\begin{array}{l}85.000^{* * * *}(\mathrm{df} \\
=11 ; 2821)\end{array}$ & $\begin{array}{l}547.000^{* * * *}(\mathrm{df} \\
=11 ; 2872)\end{array}$ & $\begin{array}{l}59.600^{* * *}(\mathrm{df} \\
=11 ; 2910)\end{array}$ \\
\hline
\end{tabular}




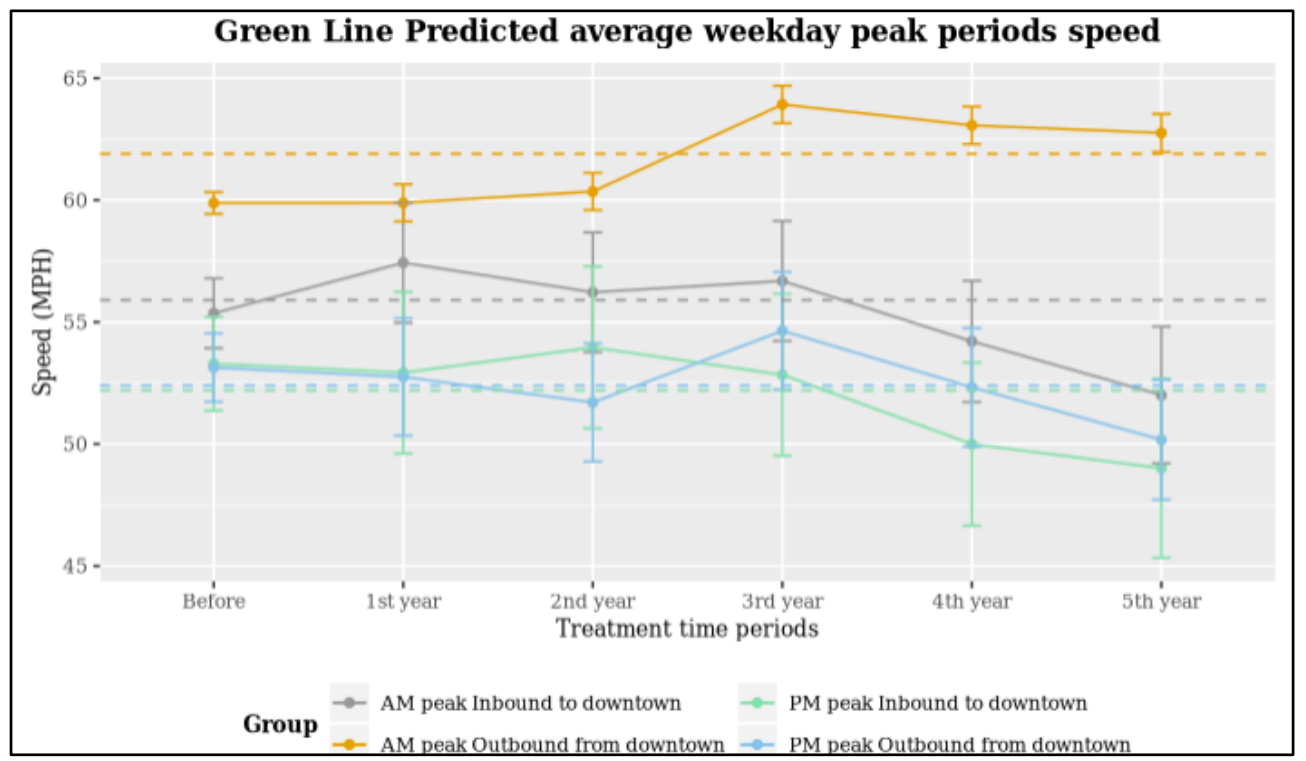

Figure 3. 17 Predicted Average Travel Speed Based on the DID models with multiple time periods for the Green Line Case

\section{Conclusion}

Although considerable research efforts have been dedicated to examining the actual or potential effects of LRT on transit ridership and traffic congestion, few studies have examined both short- and long-term effects. This study examines both the short and long-term effects of the MAX Orange and Green lines at the corridor level in Portland, Oregon by employing transit boarding data and historical high-resolution traffic information from archival databases and iPeMS. This study conducts two main analyses: (1) before and after comparisons of the LRT opening and (2) the difference-in-difference regression models to quantify the effects of new LRT service on ridership and traffic congestion and estimate the difference in effects between the two lines. 
A notable finding from the research is that the development of two LRT lines in Portland,

Oregon has led to a large increase in transit ridership and a positive impact on relieving traffic congestion. This study also finds that the effects on traffic congestion largely persist over the years -keeping improving in the case of the Orange line and lacking a clear pattern in the case of the Green line.

Specifically, the analysis on transit ridership indicates that after the opening of the new light rail transit lines, boardings within the experimental corridor increased sharply while those within the control corridor remained unchanged. The results of the ridership DID base models demonstrate that the Orange and Green Lines contributed to an increase of 6,404 and 7,225 riders on average, respectively. The crosstab of Green Line ridership suggests that ridership increase mainly occurred in the first three years after its operation. The travel speed models reveal that the new LRT lines have had a positive impact on traffic speed, with the magnitude of the effects varying by peak periods and direction. For the Orange Line, travel speed increased by between 1.35 and $2.35 \mathrm{mph}$, while for the Green Line, travel speed increased by between 1.12 and $5.12 \mathrm{mph}$. The DID models with multiple periods demonstrate that most yearly effects are positive and statistically significant and that the size of the yearly effects changes over time. For the Orange Line, the effect size on travel speed increases over time. For the Green Line, there is no clear pattern in differences in the effect size over time.

The research demonstrates how high-resolution historical data makes it possible to evaluate the impacts of transportation projects and policies. The spatial and temporal 
high-resolution data make is possible to detect impact, which cannot be captured without such dataset, on transportation system. The availability of detailed transportation data is crucial to evaluate the effects and evolution of transportation policies and projects like LRT. Such dataset makes it possible to conduct comprehensively temporal and spatial evaluation of the effect. Thus, it would help fill a research gap and explain the conflicting empirical results in previous studies because of different time frames and intervals or geographical scales. 


\section{Effect of new LRT service on transit ridership and traffic congestion at the regional level}

Many cities in the U.S. have tilted transit investments toward LRT despite the substantially higher cost, because transit with a separate right-of-way is commonly viewed to be more likely to help relieve traffic congestion (Downs, 2005; Litman, 2014). Though a considerable body of research has investigated transit ridership and congestion effect of LRT, little research has examined the long-term effect of large transit projects on transit ridership and traffic congestion at the regional level, and the causal relationship between transit and traffic congestion and transit ridership is rarely analyzed in the literature.

The New Starts program is a transit capital investment program administrated by Federal Transit Administration (FTA). It primarily funds fixed guideway systems, including light rail, commuter rail, and fixed guideway Bus Rapid Transit (BRT). To apply for funding from New Starts, the cost of the transit project should be more than $\$ 300$ million, or the total New Starts funding sought should be no less than $\$ 100$ million (Federal Transit Administration, 2015). From 1998 to 2017, 55 New Starts transit projects began operation across 27 UZAs and the total funding reached approximately $\$ 20$ billion. All projects competing for funding are selected based on their potential effects on accessibility, mobility, congestion relief, land use changes, and costeffectiveness. Although the New Starts program has funded various projects across UZAs, to my knowledge, no study has comprehensively examined the effect of these projects on transit ridership and traffic congestion. 
This study attempts to quantify the effect of new LRT service on transit ridership and traffic congestion at the regional level. This study conducts an empirical analysis of the impacts of new LRT lines on ridership and traffic congestion in three UAs that constructed New Starts LRT projects from 1982 to 2017. To capture the effect of new

LRT lines on traffic, we use a synthetic control method to construct a "synthetic" control UA that closely approximates the counterfactual ridership and traffic congestion scenario in the absence of light rail projects. Results of this study provide empirical evidence for the effect of large transit investment on traffic congestion and contribute to the ongoing debates concerning the effectiveness of LRT service to increase transit ridership and relieve traffic congestion across Urban Areas in the U.S.

\section{Methodology}

The Synthetic control method (SCM) was original proposed by Abadie and Gardeazabal (2003). The SCM circumvents two shortcomings of traditional comparative case studies (Abadie et al., 2012). First, in traditional comparative case studies, comparison cases selection largely relies on the subjective measures of affinity between treated cases and control cases in most applications, and such ambiguity of comparison cases selection is hard to eliminate. The synthetic control method constructs a "synthetic" control case to compare with the treated case with a data-driven approach. The datadriven procedures reduce the discretion of control UAs selection. Second, characteristics of the "synthetic" control case are much more similar to the characteristics of the treated UA than any single actual control case. The synthetic control method constructs a 
"synthetic" control case with weighted average of actual control cases. The synthetic counterpart reproduces what the trajectory of counterfactual outcomes of treated cases would have shown without intervention.

Let scalar $\mathrm{w}_{\mathrm{j}}(\mathrm{j}=2, \ldots, \mathrm{J}+1, \mathrm{~J}$ is the number of control UAs) be the nonnegative weight of UA in the synthetic treated UA. All $\mathrm{w}_{\mathrm{j}}$ construct the weight vector $\mathbf{W}(\mathrm{J} \times 1)$, and sum of $\mathrm{w}_{\mathrm{j}}$ is equal to one. The value of $\mathbf{W}$ represents relative contribution of control UAs, and the weighted average of control UAs, namely "synthetic" control UA, is supposed to be the most closely to the relevant transportation characteristics of the actual treated unit before the service of light rail project.

We define $\mathbf{X}_{\mathbf{0}}$ as a $(\mathrm{K} \times \mathrm{J})$ matrix which contains pre-service values of $\mathrm{K}$ transportation characteristics predictors for $\mathrm{J}$ control UAs, and $\mathbf{X}_{\mathbf{1}}$ be a $(\mathrm{K} \times 1)$ vector of values of the same predictor for the treated $\mathrm{UA}$, and $\mathbf{V}(\mathrm{K} \times \mathrm{K})$ as a symmetric matrix of nonnegative components. The values of the diagonal elements of $\mathbf{V}$ assign weights to the predictor in $\mathbf{X}_{\mathbf{0}}$ and $\mathbf{X}_{\mathbf{1}}$. To construct a synthetic control UA that best approximates the actual treated UA, the optimal choice of $\mathbf{W}$ should minimize

$$
|| X_{1}-X_{0} W \|=\sqrt{\left(X_{1}-X_{0} W\right)^{\prime} V\left(X_{1}-X_{0} W\right)}
$$

where the optimal selection of $\mathbf{V}$ should minimize the mean square error of the synthetic control estimator. In our study, $\mathbf{V}$ is chosen to reproduce the outcome variable of treated UA before service year. We define $\mathbf{Y}_{1}$ as $(\mathrm{T} \times 1)$ vector of values of out for treated UA from 1982 to 2011 , and $\mathbf{Y}_{\mathbf{0}}(\mathrm{T} \times \mathrm{J})$ as a matrix whose elements are values of 
outcome variable for treated UA. The counterfactual outcome of the treated UA in the absence of new LRT projects is the outcome of the synthetic control UA. Since synthetic counterpart is a weighted average of control units and the weight is restricted to be between zero and one and to be summed to one, avoiding extrapolation. The synthetic control method makes the contribution of each actual control unit explicit. The weights represent the relative contribution of each control unit to the counterfactual traffic congestion scenario in a treated UA. Since the values of weights are restricted to be between zero and one, the synthetic control method avoids extrapolation biases in the regression-based analysis (King \& Zeng, 2006).

$$
Y_{1}^{*}=Y_{0} W^{*}
$$

Abadie and Gardeazabal (2003) assessed the impact that terrorism has had on economic growth for the Basque County with SCM, using other Spanish regions to construct a "synthetic" Basque country without Terrorism. They estimated the effect of terrorism on the GDP and found that terrorist activity explains the GDP gap almost perfectly. In this study, the synthetic control method is applied to estimate the effects of new LRT lines on traffic congestion and transit ridership. Since the synthetic control method using a weighted average of control units to reproduce counterfactual of the treated unit in the absence of intervention, the outcomes of interest of treated units are required to lie between the range of outcomes of interest of control cases, otherwise, the synthetic control method is not applicable. 


\section{Data and sample}

This study uses annual Urban Area (UA) level panel data from 1982 to 2017. A primary data source is the Urban Mobility Report (UMR) from Texas A\&M Transportation Institute. The primary outcomes of interest are traffic congestion and transit ridership, measured as Travel Time Index (TTI) and Public Transit Annual Passenger Miles (PTAPM) respectively. TTI is the ratio of the peak-period travel time compared to the free-flow travel time. A TTI of 1.20 indicates a 10-minute free-flow trip takes 12 minutes in the peak period. In the dataset, TTI is available from 1982 to 2017; PTAPM is available from 1982 to 2011 (Schrank et al., 2012, 2019). The UMR panel dataset also includes other characteristics for each UA: population, auto travel cost, average state gasoline cost, average state diesel cost, freeway lane-miles, arterial street lane-miles, peak period travelers, commuters. Besides, this study collects employment and income data from the Bureau of Economic Analysis.

Since traffic congestion is more severe in large UAs, this study focuses on large UAs. In the UMR dataset, there are 47 UAs in the very large and large category, including 15 UAs with population over 3 million and 32 UAs with population between 1 million and 3 million.

This study attempts to estimate the effect of New Starts LRT projects on transit ridership and traffic congestion. Of these 47 UAs, 20 UAs that do not receive New Starts support are potential control UAs. After reviewing transportation systems in these 20 UAs, I find that there are 8 UAs with rail-like transit service, including light rail, heavy rail, commuter rail, monorail and automated guideway. Thus, these 8 UAs cannot be used 
as control units. Finally, 12 UAs without any types of rail-based transit service are identified as control units, listed in Table 4. 1. These 12 UAs make up the donor pool for the SCM analysis. For each treated UA, these 12 control UAs are used to construct its synthetic counterpart to examine what the transit ridership and traffic congestion would have been in the absence of light rail projects.

Table 4. 1 Control urban areas

\begin{tabular}{|l|l|l|}
\hline Urban Area & TTI in 2017 & $\begin{array}{l}\text { PTAPM (million) in } \\
\mathbf{2 0 1 1}\end{array}$ \\
\hline Cincinnati OH-KY-IN & 1.17 & 112.00 \\
\hline Columbus OH & 1.19 & 72.30 \\
\hline Detroit MI & 1.24 & 309.00 \\
\hline Indianapolis IN & 1.18 & 39.90 \\
\hline Kansas City MO-KS & 1.15 & 69.50 \\
\hline Louisville KY-IN & 1.18 & 65.90 \\
\hline Milwaukee WI & 1.17 & 154.50 \\
\hline Nashville-Davidson TN & 1.22 & 69.90 \\
\hline Providence RI-MA & 1.17 & 96.20 \\
\hline Raleigh-Durham NC & 1.17 & 100.40 \\
\hline San Antonio TX & 1.23 & 207.00 \\
\hline Tampa-St. Petersburg FL & 1.22 & 146.50 \\
\hline
\end{tabular}

The synthetic control method requires a certain period of pre-treatment data to construct the synthetic control counterpart. The existing studies generally use at least 10 years of pre-treatment data (Abadie et al., 2011). The data used in this study began in 1982. To ensure enough years in the pre-treatment period, this study selects UAs that began LRT service in and after 1992 as treated UAs. Besides, the SCM approach restricts the weights of the actual control units to be between zero and one to avoid extrapolation when constructing the "synthetic" control unit. Thus, UAs with values of outcomes of 
interest outside the range of values of outcome of interests of the control units are excluded in this analysis. Taking the Seattle UA as an example, its TTI is much higher than those of the control UAs, shown in Figure 4. 1.

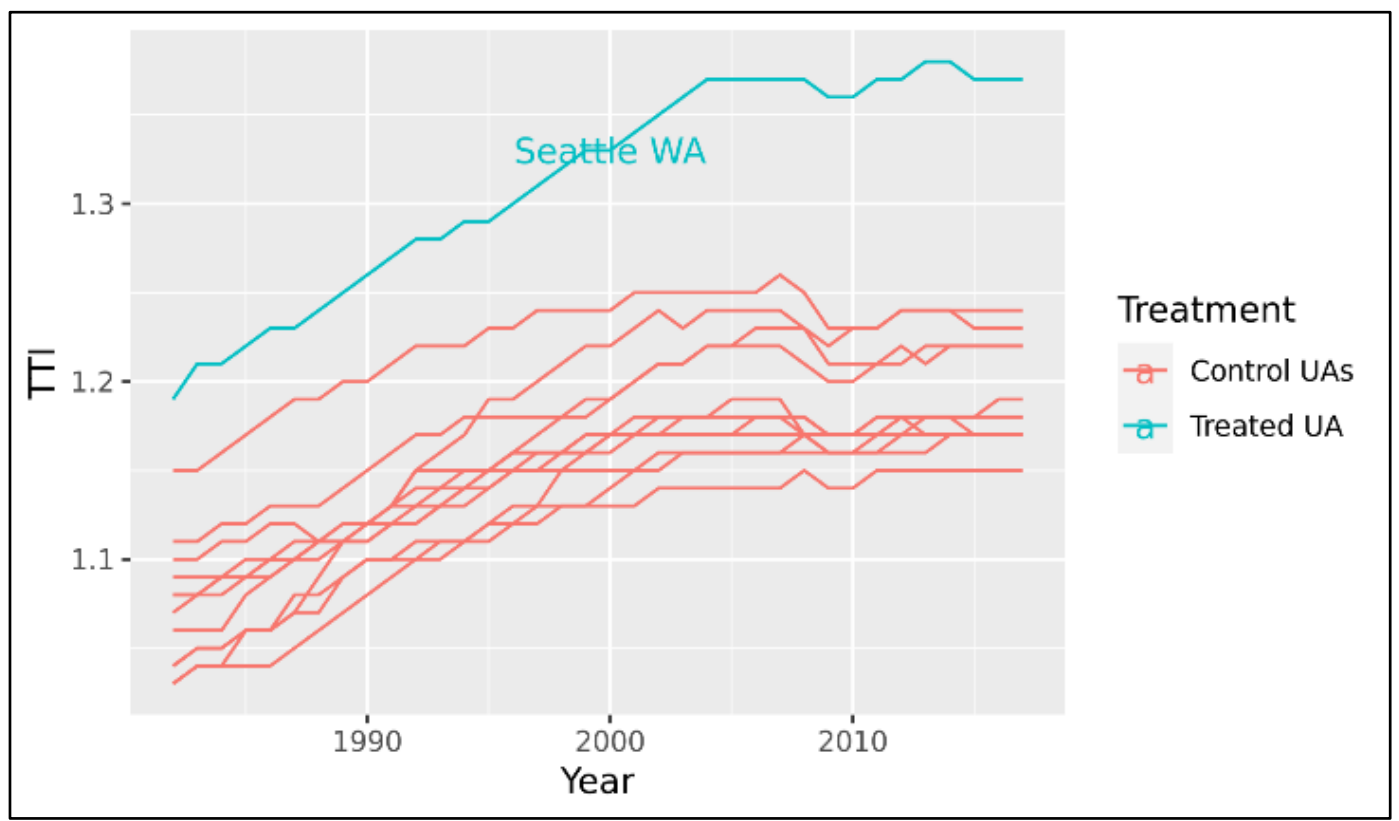

Figure 4. 1 TTI in Seattle WA and control UAs

After excluding UAs with outcomes of interest outside the range of control UAs, there are three UAs remaining, including Charlotte NC-SC and St. Louis MO-IL, and Virginia Beach VA. For each treated UA, the SCM approach is employed to examine the effect of LRT on transit ridership and traffic congestion. Because the operation year of LRT in Virginia Beach VA is 2011 and PTAPM is only available from 1982-2011, this study does not investigate the effect of LRT on transit ridership in Virginia Beach VA. 
Table 4. 2 Selected Treated UAs

\begin{tabular}{|l|l|l|l|l|l|}
\hline UA Name & LRT service & $\begin{array}{l}\text { Length } \\
(\mathbf{m i l e})\end{array}$ & $\begin{array}{l}\text { New Starts } \\
\text { LRT project } \\
\text { service year }\end{array}$ & $\begin{array}{l}\text { PTAPM } \\
\text { in 2011 }\end{array}$ & $\begin{array}{l}\text { TTI in } \\
\mathbf{2 0 1 7}\end{array}$ \\
\hline $\begin{array}{l}\text { Charlotte } \\
\text { NC-SC }\end{array}$ & Lynx Blue Line & 9.6 & 2007 & 139.00 & 1.22 \\
\hline $\begin{array}{l}\text { St. Louis } \\
\text { MO-IL }\end{array}$ & MetroLink & 46.0 & 1993 & 300.20 & 1.17 \\
\hline $\begin{array}{l}\text { Virginia } \\
\text { Beach VA }\end{array}$ & Tide light rail & 7.4 & 2011 & 122.00 & 1.17 \\
\hline
\end{tabular}

\section{Results}

\section{Charlotte NC-SC}

\section{Transit ridership}

Figure 4.2 shows the PTAPM trajectory for Charlotte NC-SC and its synthetic counterpart from 1982 to 2011. During the pre-service period, the synthetic Charlotte NC-SC closely reproduces the PTAPM trajectory for the actual Charlotte NC-SC. After the operation of the New Starts LRT, two lines gradually diverge. The PTAPM in the actual Charlotte NC-SC is higher than that in the synthetic Charlotte NC-SC. The effect of LRT project on transit ridership is measured by the difference of PTAPM between the synthetic Charlotte NC-SC and the actual Charlotte NC-SC. After the operation of the LRT project, the difference increases. The results suggest that the New Starts LRT project has an effect on transit ridership in Charlotte NC-SC. 


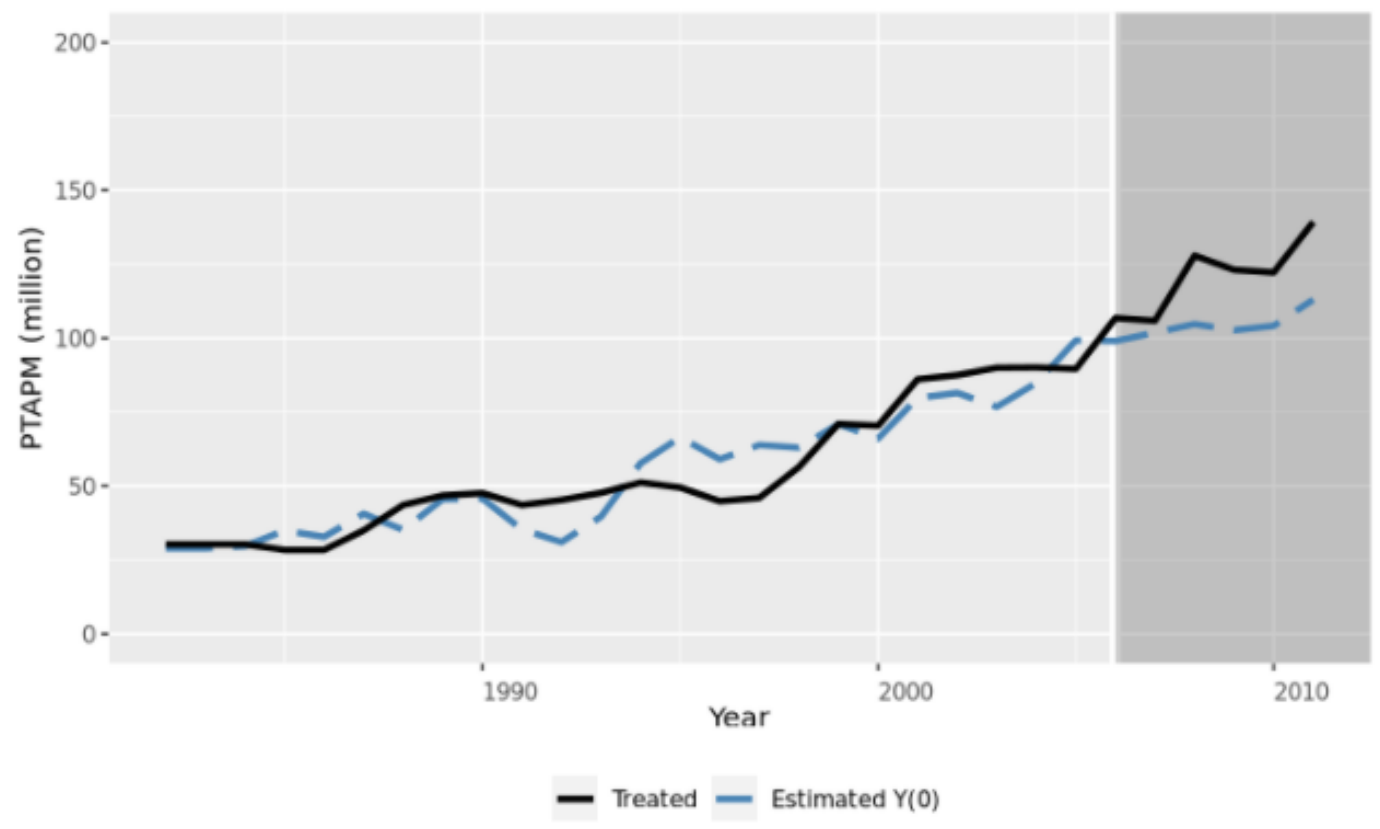

(a) Trends in PTAPM

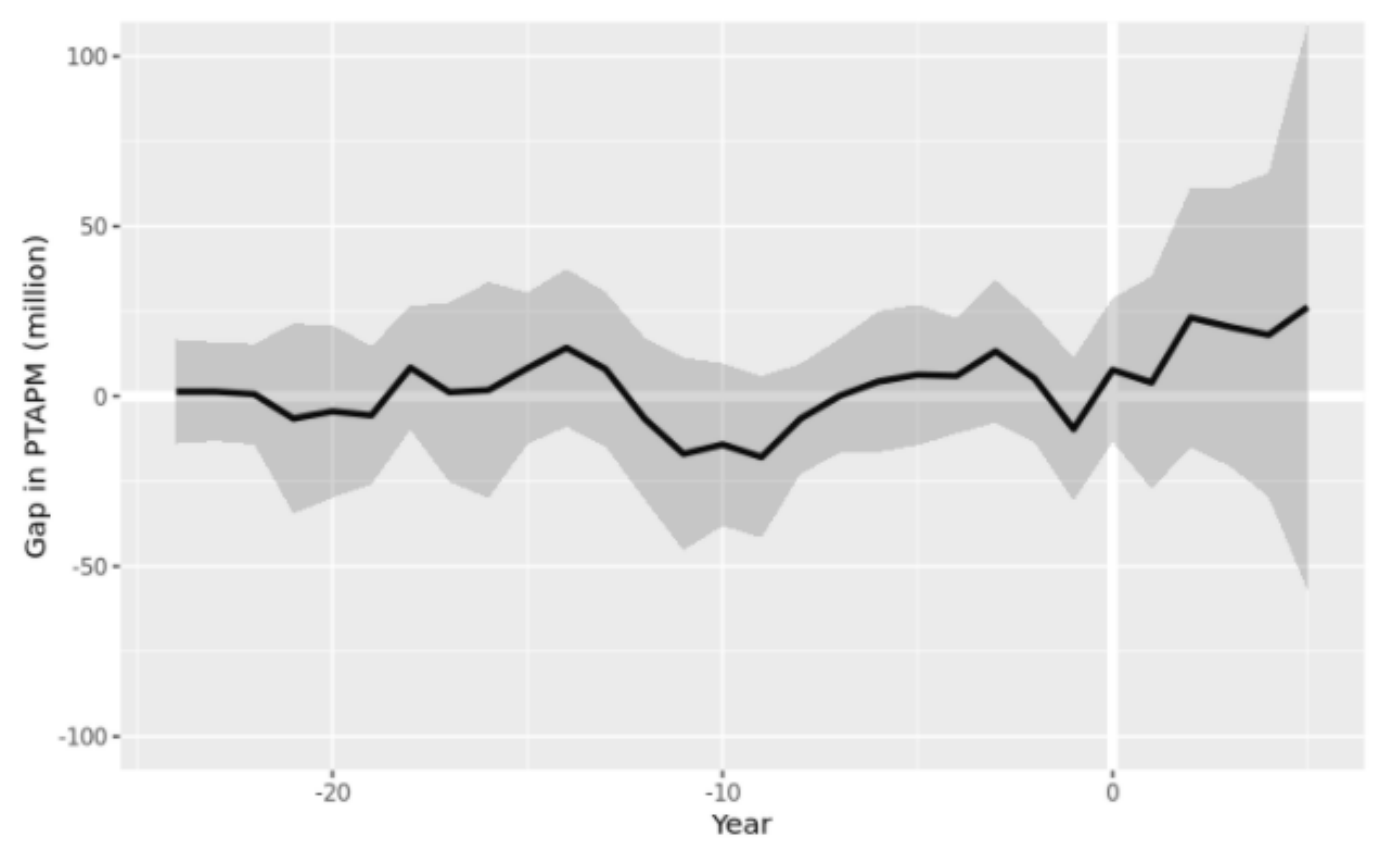

(b) Gap between Treatment and Synthetic Control

Figure 4. 2 PTAPM in Charlotte NC-SC 


\section{Traffic congestion}

Figure 4. 3 visualizes the TTI trajectory for Charlotte NC-SC and its synthetic counterpart for the 1982-2017 period. During the pre-service period, the synthetic Charlotte NC-SC almost precisely reproduces the TTI for the Charlotte NC-SC. After the operation of the LRT service, TTI in the actual Charlotte NC-SC increased in the first

year and then decreased, while TTI of the synthetic Charlotte NC-SC decreased first and then increased. Two lines intersect around 2016. 


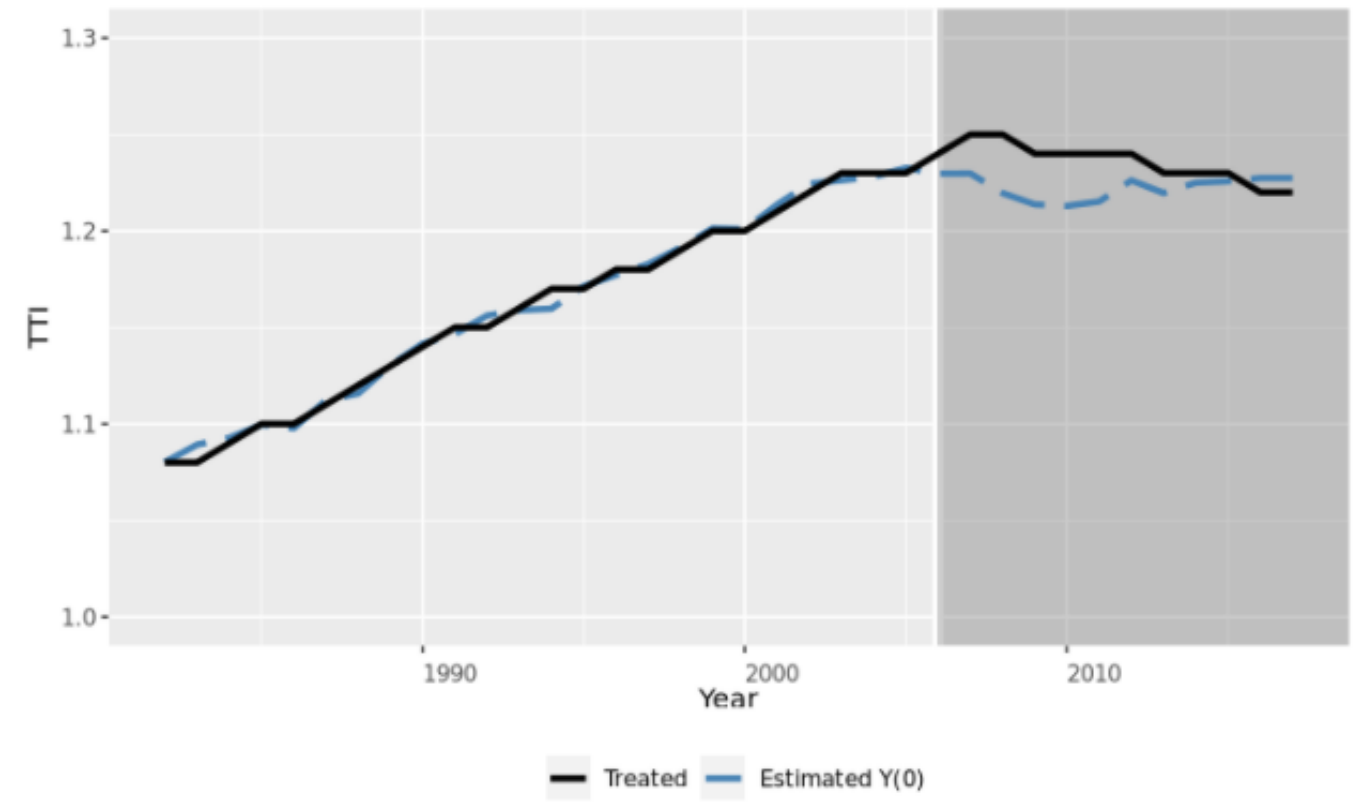

(a) Trends in TTI

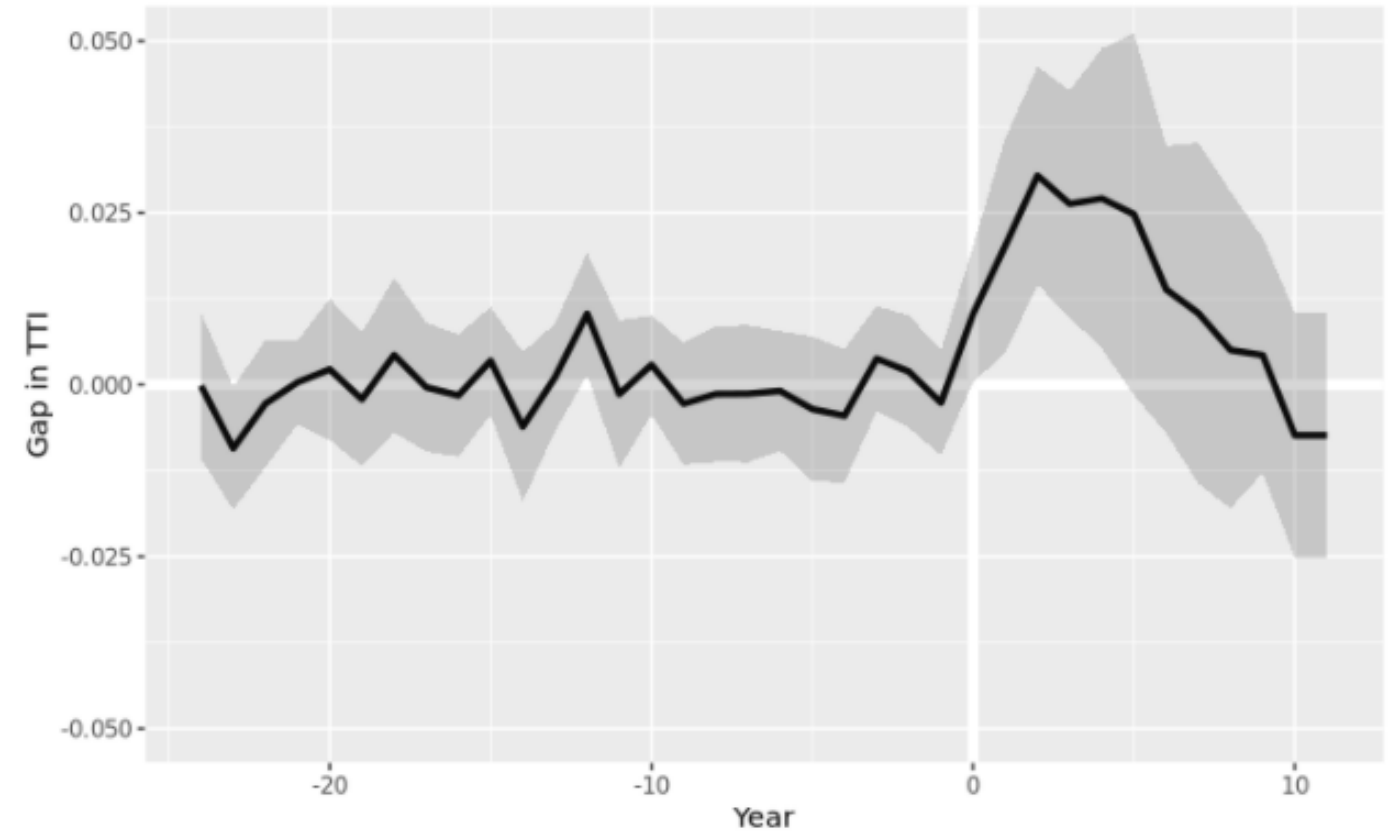

(b) Gap between Treatment and Synthetic Control

Figure 4. 3 TTI in Charlotte NC-SC 
Our estimate of the effect of new LRT service on traffic congestion is measured by the difference of TTI between the synthetic Charlotte NC-SC and the actual Charlotte NC-SC, shown in Figure 4. 3. After the operation of the LRT service, the difference first widens and then gradually narrows and becomes negative around 2016. Our results suggest that the new LRT service has had a negative effect on traffic congestion, that is, it worsens the congestion measured by TTI.

\section{St. Louis MO-IL \\ Transit ridership}

Figure 4. 4 shows the PTAPM trajectory for St. Louis MO-IL and its synthetic counterpart from 1982 to 2011, and the difference in PTAPM between the actual St. Louis MO-IL and the synthetic St. Louis MO-IL. The synthetic St. Louis MO-IL closely reproduces the PTAPM for St. Louis MO-IL during the pre-treatment period. After the operation of the LRT service, the two lines substantially diverge. After the operation of the new LRT project, the difference increases over time. The results suggest that the new LRT project has a pronounced positive effect on transit ridership in St. Louis MO-IL. 


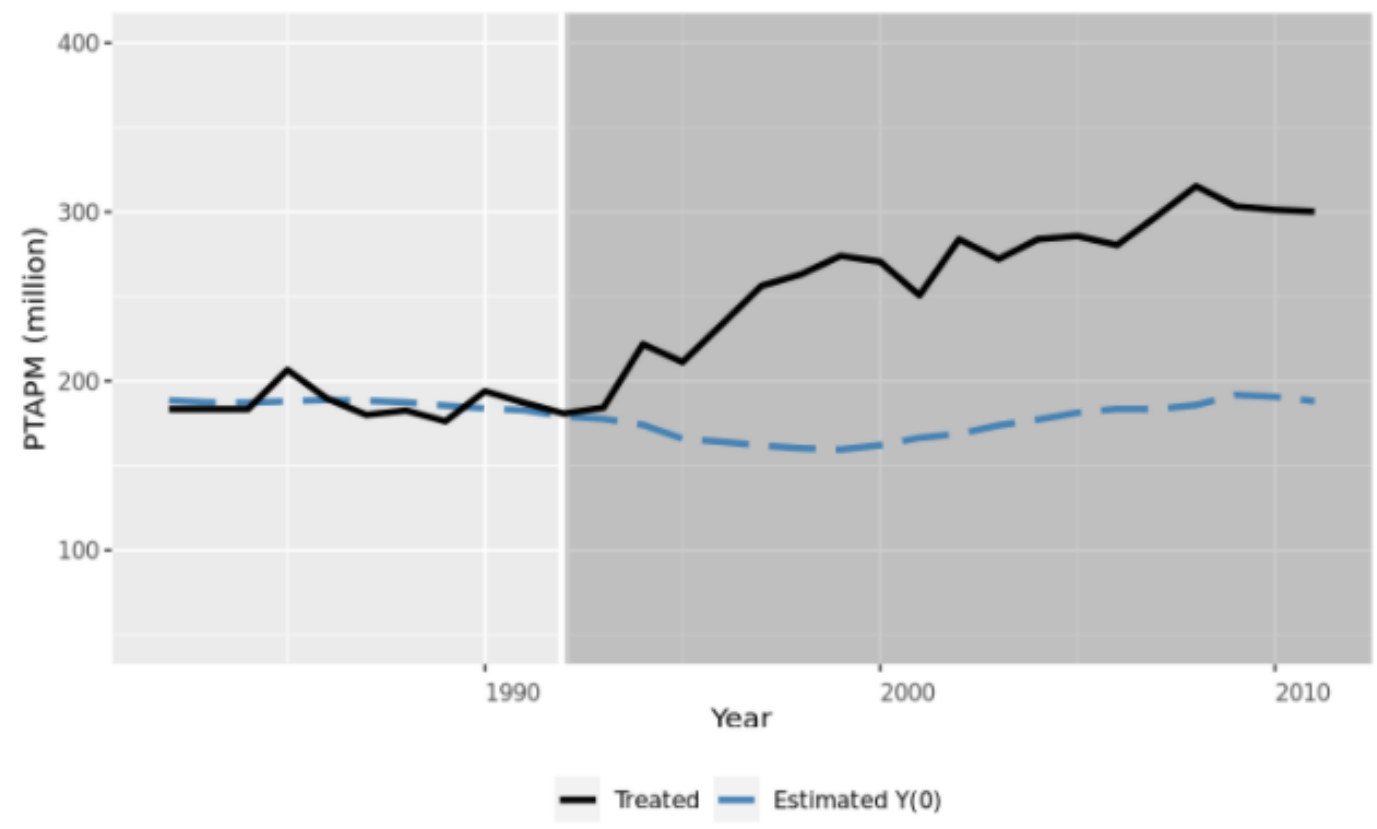

(a) Trends in PTAPM

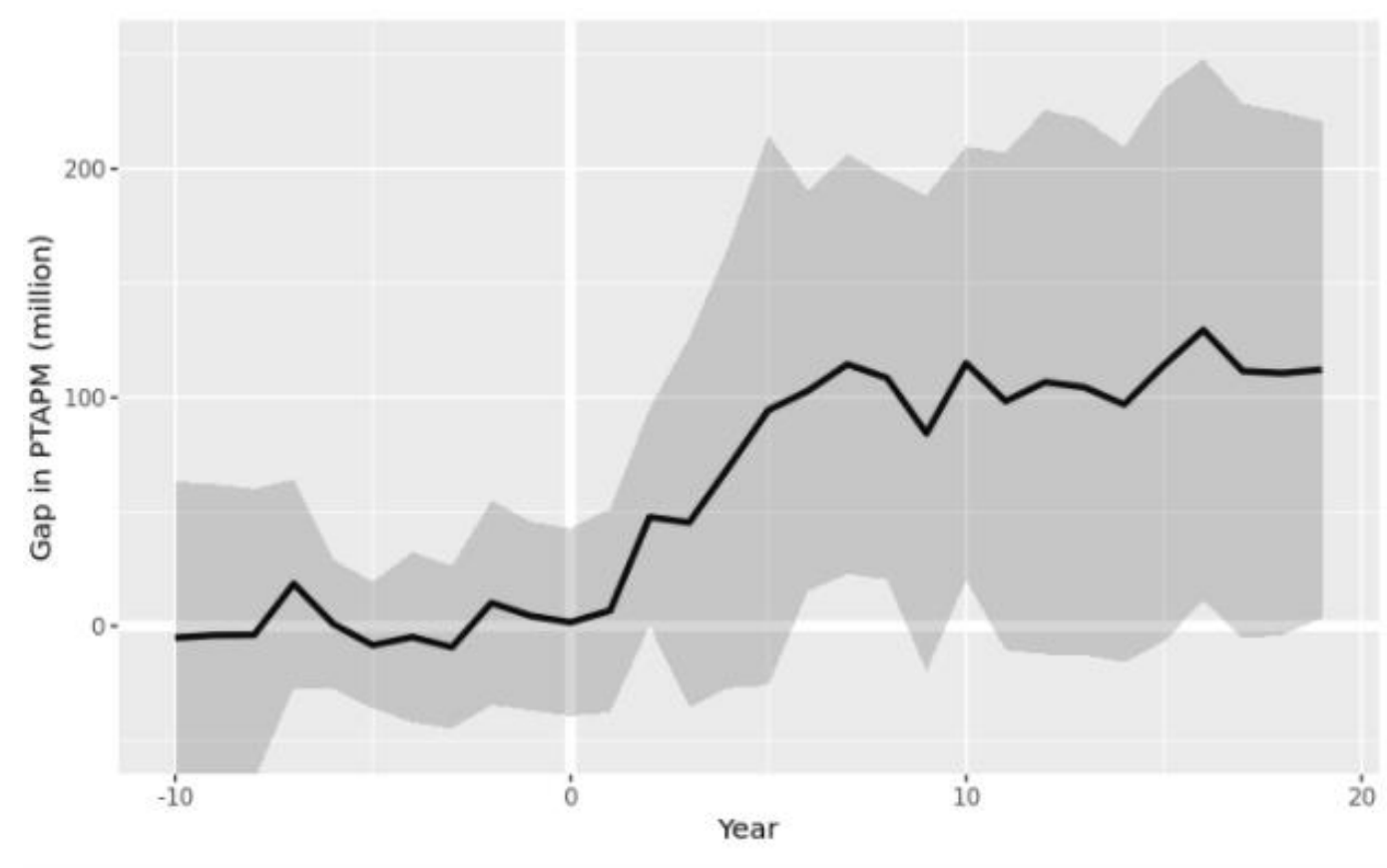

(b) Gap between Treatment and Synthetic Control

Figure 4. 4 PTAPM in St. Louis Mo-IL 


\section{Traffic congestion}

Figure 4. 5 shows the TTI trajectory of St. Louis MO-IL and its synthetic counterpart for the 1982-2017 period. During pre-treatment period, the synthetic St. Louis MO-IL closely reproduces the TTI for St. Louis MO-IL. In the first five years immediately following the operation of new LRT service, TTI in the actual St. Louis MO-IL and its synthetic counterpart is close. From 1998 onward, the gap between the two lines varies over time, but constantly stays negative, indicating an effect of the New Starts LRT projects on reducing congestion (lowering TTI) for the St. Louis MO-IL UA. 


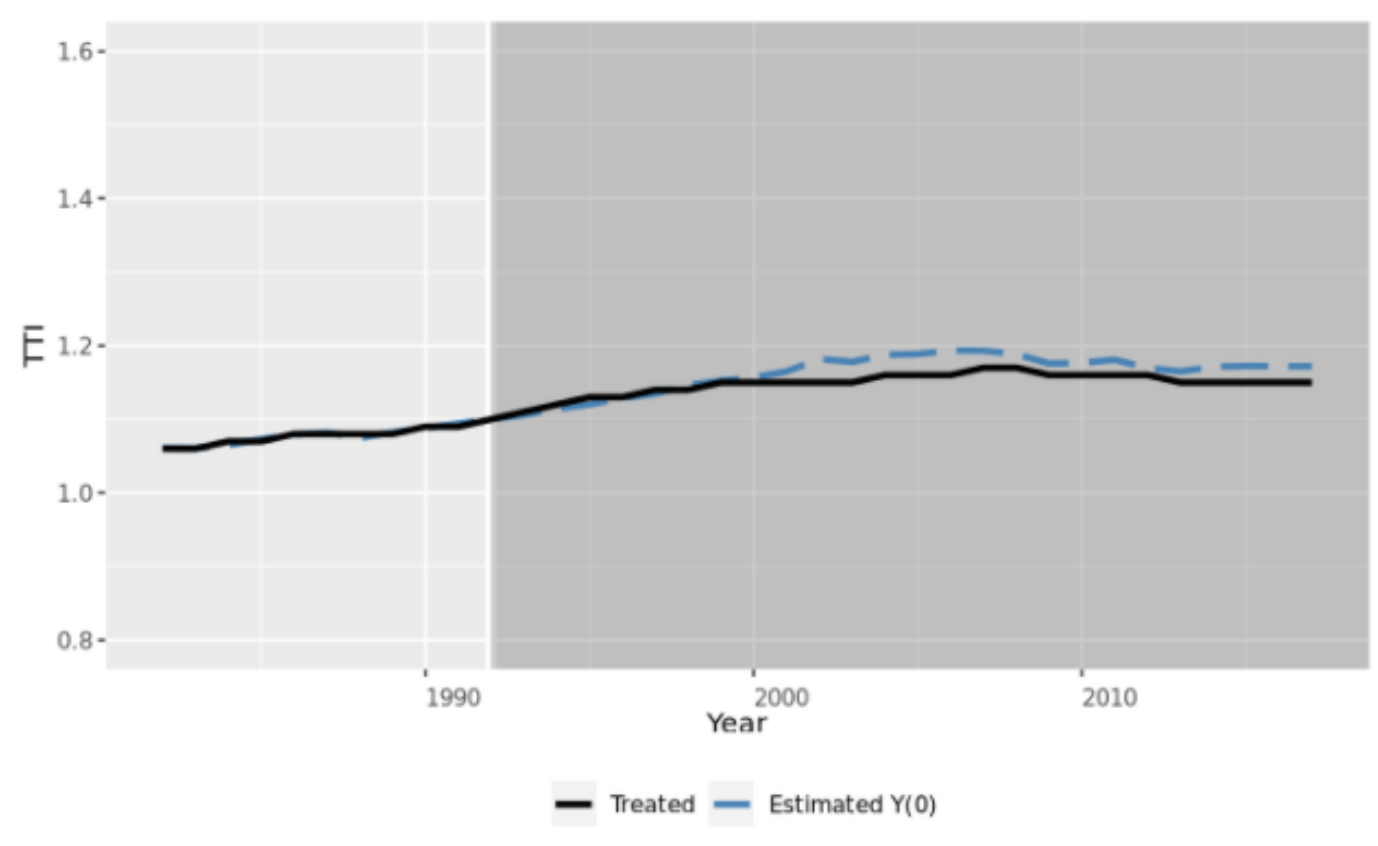

(a) Trends in TTI

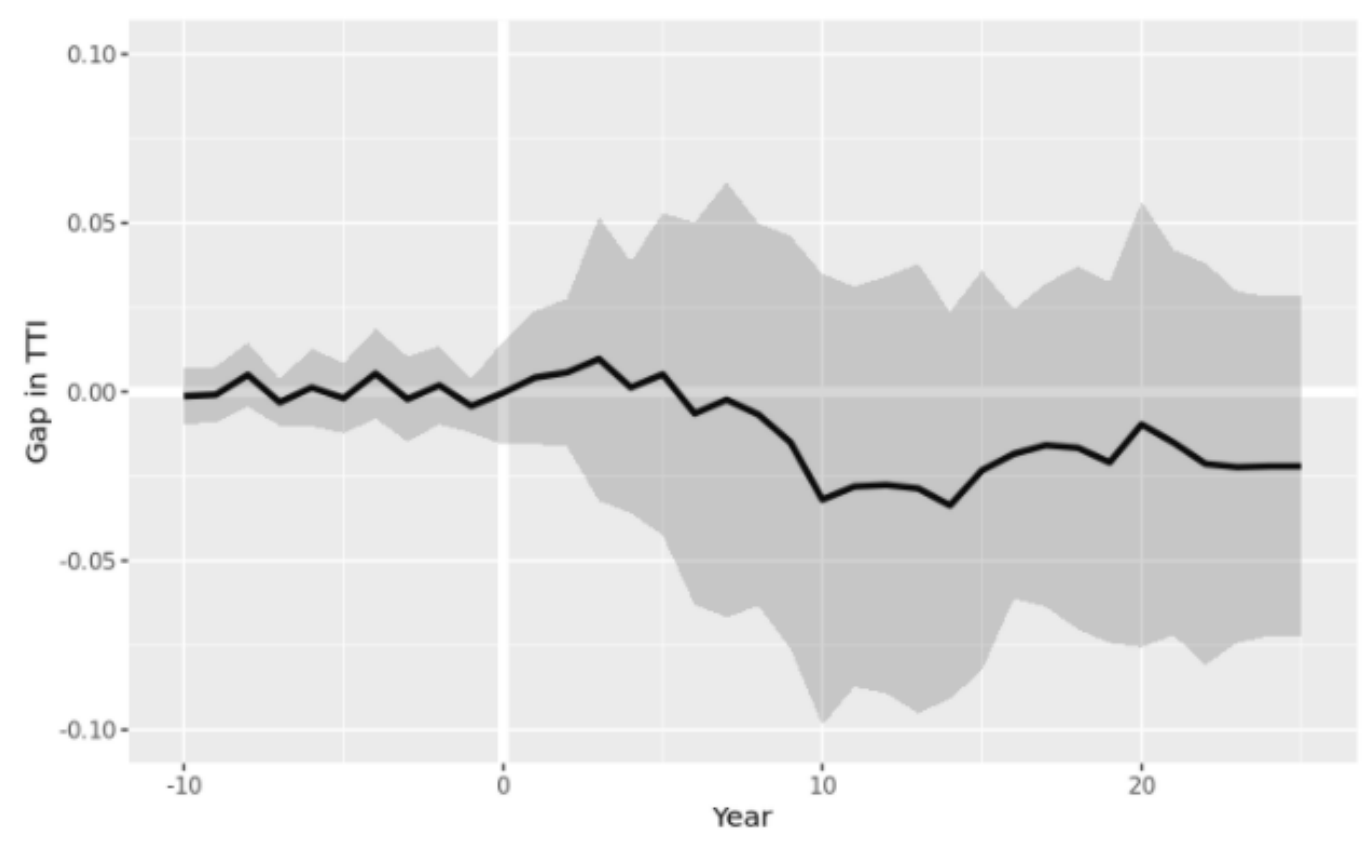

(b) Gap between Treatment and Synthetic Control

Figure 4. 5 TTI in St. Louis Mo-IL 


\section{Virginia Beach VA}

\section{Traffic congestion}

Figure 4. 6 shows the TTI for Virginia Beach VA and its synthetic counterpart from 1982 to 2017 . The synthetic Virginia Beach VA exactly reproduces the TTI for the actual Virginia Beach VA during the pre-treatment period. After the operation of LRT service, the two lines are still close. The effect of new LRT service on traffic congestion is measured by the difference between the actual Virginia Beach VA and its synthetic Virginia Beach VA. The difference is small after the operation of the new LRT service. The results suggest no effect of New Start LRT service on traffic congestion in Virginia Beach VA. 


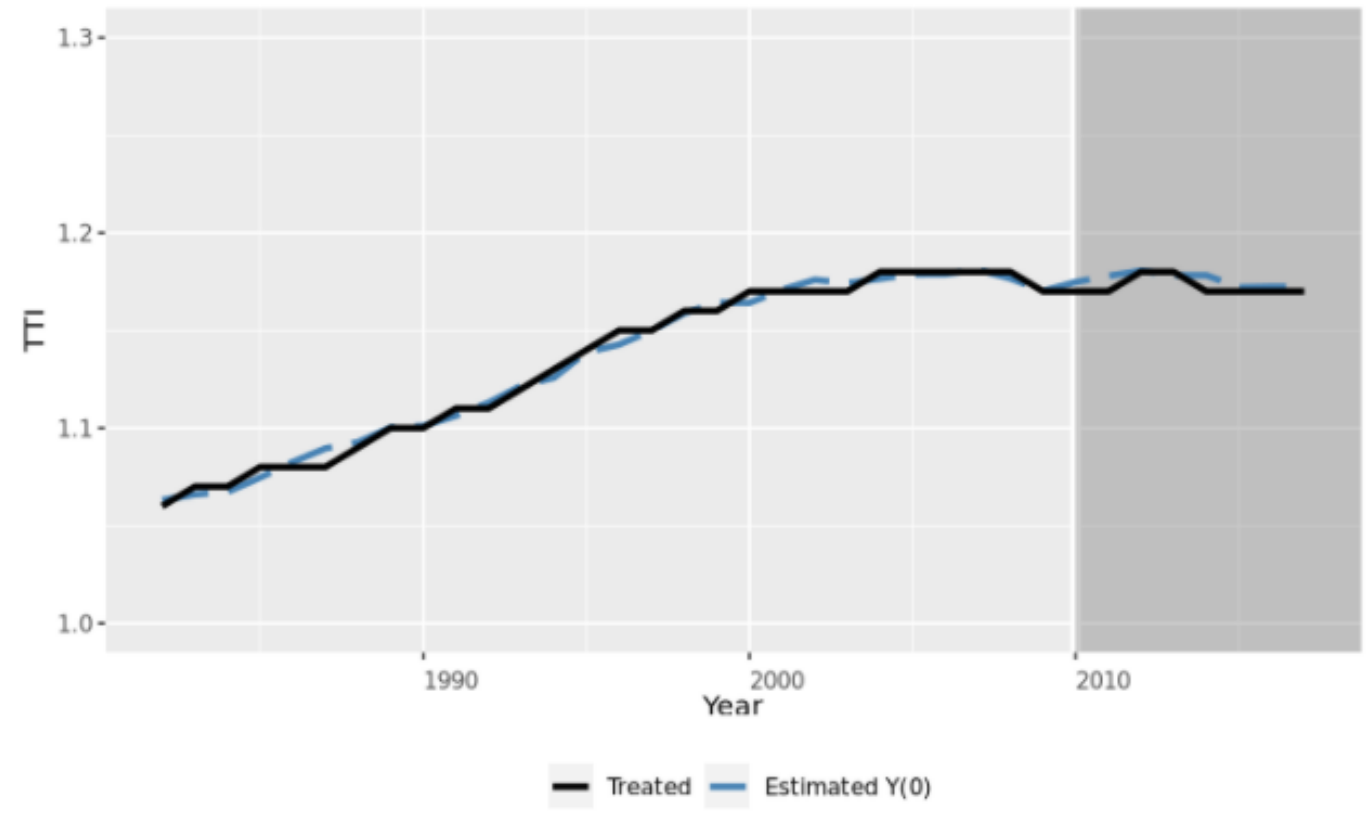

(a) Trends in TTI

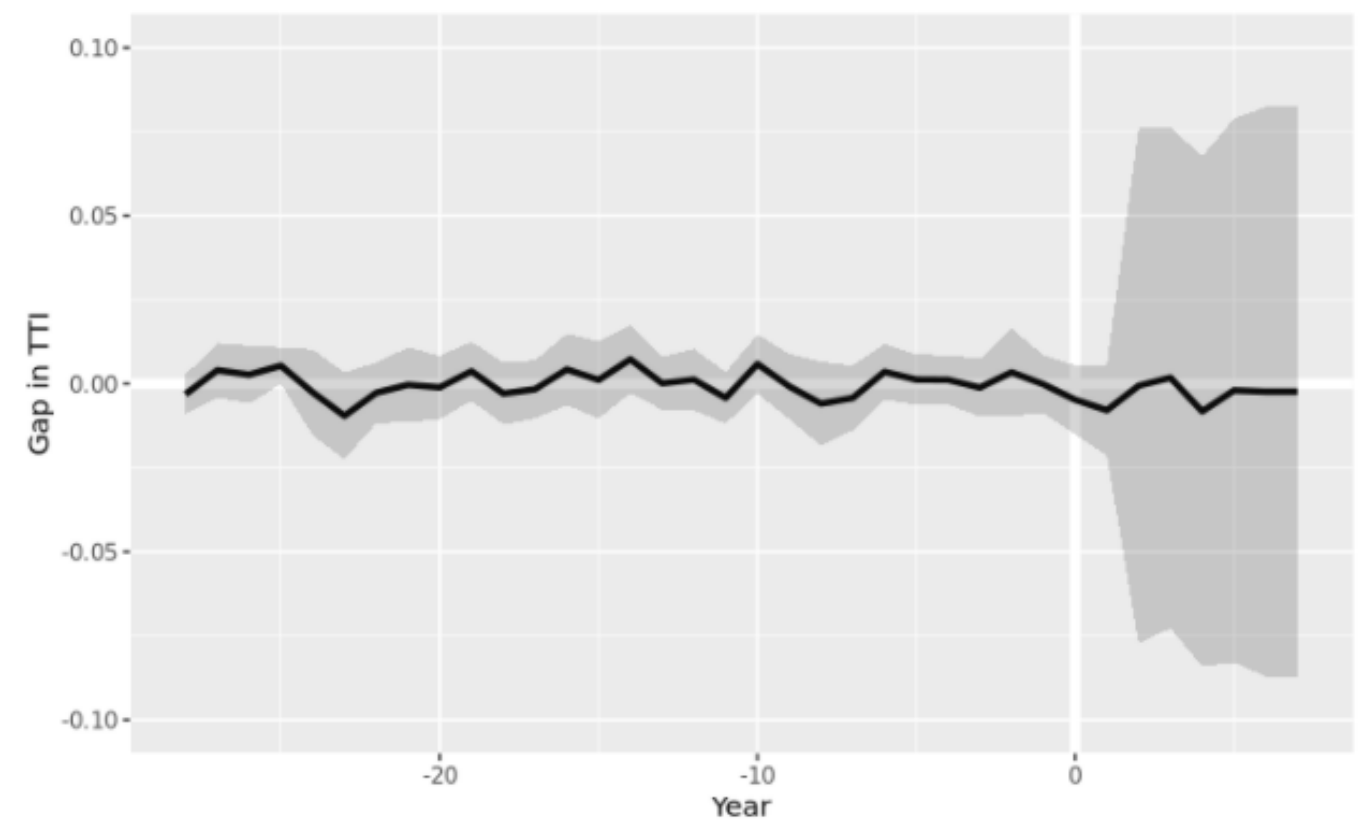

(b) Gap between Treatment and Synthetic Control

Figure 4. 6 TTI in Virginia Beach VA 
Table 4. 3 GSCM Results across UAs shows the analysis results of three UAs.

The average treated effects and p-values are calculated with the generalized synthetic control method $(\mathrm{Xu}, 2017)$. The results suggest that the effect of the new LRT projects on transit ridership and traffic congestion varies across UAs. For transit ridership, the New Starts LRT service increases transit ridership in two UAs: the effect is significant in St. Louis MO-IL and the effect is not significant in Charlotte NC-SC. This probably because the New Starts LRT project that began service in 2007 is small in Charlotte NC-SC. Though this New Starts LRT service is the first trail line in Charlotte NC-SC, it is only a 9.6-mile route line, accounting for a small proportion of transportation supply.

For traffic congestion, the effects of the new LRT service on traffic congestion are not significant, though the figures for traffic congestion show that there is a relief effect on traffic congestion. One reason may be that driving mode is the dominant mode in these UAs and transits only accounts for a limited share in daily travel.

Table 4. 3 GSCM Results across UAs

\begin{tabular}{|l|l|l|}
\hline \multirow{2}{*}{ UA Name } & \multicolumn{2}{|c|}{ Average Treated Effect } \\
\cline { 2 - 3 } & PTAPM (p value) & TTI (p value) \\
\hline Charlotte NC-SC & 18.38 million $(0.416)$ & $0.013(0.053)$ \\
\hline St. Louis MO-IL & 93.31 million $(0.0330)$ & $-0.014(0.556)$ \\
\hline Virginia Beach & & $-0.003(0.931)$ \\
\hline
\end{tabular}

\section{Conclusions}

This chapter of the dissertation focuses on the effects of New Starts LRT Projects on transit ridership and traffic congestion at the regional level. This study applies the 
SCM to quantify and compare transit ridership and traffic conditions before and after the launch of new LRT projects in three UAs.

In this study, the effects of new LRT project on transit ridership and traffic congestion are different across UAs. These are consistent with expectations (Beaudoin et al., 2015). There is regional spatial heterogeneity across UAs. The effects on transit ridership are significant, while the effects on traffic congestion are not significant. LRT only accounts for a limited share in commuting travel. Thus, the construction of new LRT service is hard to exact a pronounced relief effect at the regional level. The results also indicate that the effect of new LRT service on transit ridership and traffic congestion changes over time at the regional level.

This study illustrates the advantages of using the SCM approach. The data-driven procedures for constructing synthetic unit reduce the subjective selection of comparison units. Most synthetic control UAs reproduce the counterfactual of the treated UA in the absence of new LRT projects. This study also demonstrates the applicability of synthetic control method on studying the effects of transportation policies and investments at the UA-level and how it complements and facilitate comparative case studies in the transportation field. The SCM provides a counterfactual analysis and the results are much more intuitive to interpret than previous research results using a model-based approach or regression-based empirical analysis.

The approach, however, has some limitations. First, though the synthetic control method provides a convenient way to create a comparable control unit, the outcome of interest should be within the range of outcomes of actual control units due to positive 
weight restriction. Second, in this study, most large UAs have LRT and therefore there are a limited number of large UAs in the donor pool, which makes large UAs unable to be analyzed with the synthetic control method. Third, whether the SCM approach can construct a comparable synthetic largely depends on the donor pool. If a synthetic counterpart could not be constructed with the donor pool, a solid conclusion could not be drawn. And there are few ways to say definitively whether a counterfactual estimate is acceptable or not. 


\section{Discussions and takeaways}

This research provides a closer look at the impact of new LRT service on transit ridership and traffic congestion at different geographical levels by utilizing newer data sources. At the corridor level, using transit boarding data and high-resolution historical traffic information from archival databases and iPeMS, this study comprehensively investigates the short- and long-term effects of LRT through case studies of two LRT lines in Portland, Oregon region. Using a quasi-experimental design, this study estimated the effects of LRT on transit ridership as well as traffic congestion. In contrast to existing research, this study used high-resolution transit and travel speed data from a longer time period. Such dataset allows for comprehensively temporal and spatial evaluation. For each LRT line, transit ridership and traffic conditions before and after opening were compared and difference-in-difference (DID) regression models were estimated in order to quantify the effects. The results demonstrated that both LRT lines increased transit ridership in the short- and long-term. The Orange Line contributed to an increase of 6,404 riders on average and the Green Line 7,225, and the effect is significant especially in the first three years. Also, it is estimated that travel speed increased by $1.35 \sim 2.35 \mathrm{mph}$ for the Orange Line and 1.12 5.12 mph for the Green Line. Although LRT relieved traffic congestion in the short-term, it may have no significant effect on traffic congestion in the long-term, probably due to induced traffic demand. The effects of LRT varied by LRT lines because of various local land use and transportation systems.

Generally, at the corridor level, my work may contribute in terms of literature and data handling. In addition to contributing to the literature on the effects of transit in terms 
of travel ridership, speed and congestion, the results of this study demonstrate how highresolution archival transportation data enable analyses that had been previously impossible. The growing availability of transportation data of high temporal and spatial resolution over a long time period provides a unique opportunity to evaluate the effects and evolution of transportation policies and projects like LRT, which helps to explain the seemingly conflicting empirical results of existing studies.

However, several important points are worth exploring further. But limited to the focus and scope of this dissertation, I do not give them in-depth discussion. As mentioned earlier, "induced traffic demand" is one of the keys for traffic effect evaluation, especially for the causal inference between the launch of transit and potential traffic congestion alleviation in the long term. I find evidence that in the long term, the effect of LRT on traffic congestion will be weaker than that of the first three years, and this is probably because people adjust their behaviors (change traffic routes, move home or work location, etc.) and for high demand areas and inbound/outbound option (AM inbound or PM outbound), long term effect (three years or more) tends to be insignificant. Based on the analysis at the corridor level, I anticipate that the future research will provide more evidence and insights on the cutting point of long term from short term and LRT long term corridor traffic effect mechanism (e.g., interaction between induced traffic demand, local land use \& transportation systems, and people adjustment of mismatching).

Study conducts an empirical analysis of the impacts of new light rail transit (LRT) lines on traffic congestion in three UAs at the regional level. To capture the transit 
ridership and traffic congestion effect of new LRT lines, we use a synthetic control method to construct a "synthetic" control UA that closely approximates the counterfactual transit ridership and traffic congestion scenario in the absence of light rail projects. Results indicated that New Starts LRT projects contributed to transit ridership in most UAs but they did relieve traffic congestion in limited UAs, and that the effect changed over time and varied across UAs. The analysis of LRT miles indicates that UAs with New Starts LRT projects are more likely to build more LRT.

To quantify the regional level effect of LRT on traffic ridership and congestion, instead of applying traditional case studies, I select to use SCM method to do the comparison. Different from sampling-based inference (e.g. DID), SCM is specifically designed to facilitate the evaluation of policy intervention or events taking place at an aggregate level (e.g. school districts, cities, countries). Although SCM is an appropriate method for the regional level analysis, it has been technically difficult to draw fundamentally solid and detailed causal inference comparable to what can be done at the corridor level. In Chapter 4, SCM was used to visualize the long-term trend of LRT on traffic ridership and congestion, which provided evidence that LRT region may subject to more severe traffic congestion in the long run. Moreover, given that the 3 UAs are subject to different land use and transportation systems, further studies may be conducted to explore why LRT in different regions contributes to different traffic effects. Last but not least, although the results show some evidence that the traffic congestion has become worse after the operation of the new LRT service, LRT undoubtedly has provided local 
people with more economic opportunities and social benefits (e.g. easy accessibility and mobility).

This study provides some takeaways for the practitioners in transportation policy and planning. Not only quantifying the benefits (e.g. increase ridership and speed, relieve congestion in the short term), this research also provides evidence of the evolution of the effect of new LRT service on transit ridership and traffic congestion. These findings may help practitioners to make potential transit investment decision. The findings of this study indicate the short and long-term potential effects, including transport ridership, travel speed and traffic congestion, of new LRT service, and hence will be useful for practitioners to optimize transit system to maximize benefits.

This study also makes contributions to the transport modeling and traveler behavior research, and may help to fill the gap of existing inconsistent documents. First, this study illustrates how high-resolution archival transportation data facilitate impact analysis of transportation policies and projects previously difficult. Due to the lack of detailed travel time data, most existing studies have to use approximate measurements of traffic congestion, such as AADT and VMT. The high-resolution data make it possible to use direct measurements of congestion and trace the changes of the effect on traffic congestion. Second, this study illustrates an application of novel methods like SCM to study the effects of semi-unique policies and projects, like New Starts projects. Despite the widespread availability of data at the regional level, comparative studies with rigorous methodology at the regional level are rare. A primary reason is that it is hard to find a comparable control region. By constructing a "synthetic" control unit that closely 
approximates the counterfactual scenario in the absence of treatment with the data-driven procedure, the SCM addresses the difficulty in control unit selection in comparative studies. Another advantage of the SCM over cross-sectional and panel data analysis is that it can trace the changes of the outcomes of interest. Lastly, this study helps explain the inconsistent results of existing research and provide additional in-depth understanding of the effects of LRT. Results of the evolution of the effects over time explain the inconsistent evidence due to different time dimensions. In addition, this dissertation analyzes the effects at different levels, which could explain the inconsistency resulted from differential spatial scales. 


\section{References}

Abadie, A., Diamond, A., \& Hainmueller, J. (2011). Synth: An r package for synthetic control methods in comparative case studies. Journal of Statistical Software, 42(13). http://papers.ssrn.com/sol3/papers.cfm?abstract_id=1958891

Abadie, A., Diamond, A., \& Hainmueller, J. (2012). Synthetic control methods for comparative case studies: Estimating the effect of California's tobacco control program. Journal of the American Statistical Association. http://amstat.tandfonline.com/doi/abs/10.1198/jasa.2009.ap08746

Abadie, A., \& Gardeazabal, J. (2003). The economic costs of conflict: A case study of the Basque Country. The American Economic Review, 93(1), 113-132.

Aftabuzzaman, M., Currie, G., \& Sarvi, M. (2010). Modeling the spatial impacts of public transport on traffic congestion relief in Melbourne, Australia.

Transportation Research Record: Journal of the Transportation Research Board, 2144(1), 1-10.

Anderson, M. L. (2013). Subways, Strikes, and Slowdowns: The Impacts of Public Transit on Traffic Congestion (Working Paper No. 18757). National Bureau of Economic Research. http://www.nber.org/papers/w18757

APTA. (2017). APTA 2017 Public Transportation Fact Book. https://www.apta.com/resources/statistics/Pages/transitstats.aspx

Baum-Snow, N., \& Kahn, M. E. (2005). Effects of Urban Rail Transit Expansions: Evidence from Sixteen Cities, 1970-2000 [with Comment]. Brookings-Wharton Papers on Urban Affairs, 147-206. 
Beaudoin, J., Farzin, Y. H., \& Lin, C. Y. (2015). Evaluating public transit investment in congested cities.

http://www.des.ucdavis.edu/faculty/Lin/transit_congestion_paper.pdf

Beaudoin, J., Farzin, Y. H., \& Lin, C.-Y. C. (2014). Evaluating Public Transit Investment in Congested Cities. Working paper, University of California at Davis. http://www.des.ucdavis.edu/faculty/Lin/transit_congestion_paper.pdf

Beaudoin, J., \& Lin, C.-Y. C. (2018). The effects of public transit supply on the demand for automobile travel. Journal of Environmental Economics and Management, 88, 447-467. https://doi.org/10.1016/j.jeem.2018.01.007

Bhattacharjee, S., \& Goetz, A. R. (2012). Impact of light rail on traffic congestion in Denver. Journal of Transport Geography, 22, 262-270. https://doi.org/10.1016/j.jtrangeo.2012.01.008

Cao, X. (Jason), \& Schoner, J. (2014a). The influence of light rail transit on transit use: An exploration of station area residents along the Hiawatha line in Minneapolis. Transportation Research Part A: Policy and Practice, 59, 134-143. https://doi.org/10.1016/j.tra.2013.11.001

Cao, X. (Jason), \& Schoner, J. (2014b). The influence of light rail transit on transit use: An exploration of station area residents along the Hiawatha line in Minneapolis. Transportation Research Part A: Policy and Practice, 59, 134-143. https://doi.org/10.1016/j.tra.2013.11.001

Cervero, R. (1994). Transit-based housing in California: Evidence on ridership impacts. Transport Policy, 1(3), 174-183. https://doi.org/10.1016/0967-070X(94)90013-2 
Cervero, R. (2002). Induced Travel Demand: Research Design, Empirical Evidence, and Normative Policies. Journal of Planning Literature, 17(1), 3-20. https://doi.org/10.1177/088122017001001

Ding, C., Lin, Y., \& Liu, C. (2014). Exploring the influence of built environment on tourbased commuter mode choice: A cross-classified multilevel modeling approach. Transportation Research Part D: Transport and Environment, 32, 230-238.

Downs, A. (2005). Still stuck in traffic: Coping with peak-hour traffic congestion. Brookings Institution Press. https://books.google.com/books?hl=en\&lr=\&id=ckLcxEb5tM8C\&oi=fnd\&pg=P R7\&dq=Still+stuck+in+traffic $+\& o t s=f G n 8 H U y K 0 V \& s i g=$ n38DQDcineVOTACf PEIZI26nHmc

Ewing, R., \& Cervero, R. (2010). Travel and the Built Environment—A Meta-Analysis. Journal of the American Planning Association, 76(3), 265-294.

Ewing, R., Tian, G., Spain, A., \& Goates, J. P. (2014). Effects of Light-Rail Transit on Traffic in a Travel Corridor. Journal of Public Transportation, 17(4), 93.

Federal Transit Administration. (2015, October 2). About the Program [Text]. Federal Transit Administration. https://www.transit.dot.gov/funding/grantprograms/capital-investments/about-program

Giuliano, G. (2004). Land Use Impacts of Transportation Investments-Highway and Transit. In The Geography of Urban Transportation (Third, pp. 237-273). https://trid.trb.org/view.aspx?id=756066 
Giuliano, G., Chakrabarti, S., \& Rhoads, M. (2015). Using Regional Archived Multimodal Transportation System Data for Policy Analysis: A Case Study of the LA Metro Expo Line. Journal of Planning Education and Research, 0739456X15604444. https://doi.org/10.1177/0739456X15604444

Hansen, S., Byrd, A., Delcambre, A., Rodriguez, A., Matthews, S., \& Bertini, R. L. (2005). PORtal: An on-line regional transportation data archive with transportation system management applications. Department of Civil and Environmental Engineering, Nohad A.

King, G., \& Zeng, L. (2006). The dangers of extreme counterfactuals. Political Analysis, 14(2), 131-159.

Litman, T. (2014). Critique of "Transit Utilization and Traffic Congestion: Is There a Connection?" http://trid.trb.org/view.aspx?id=1304849

Lo, S.-C., \& Hall, R. W. (2006). Effects of the Los Angeles transit strike on highway congestion. Transportation Research Part A: Policy and Practice, 40(10), 903917.

Lund, H., Willson, R. W., \& Cervero, R. (2006). A RE-EVALUATION OF TRAVEL BEHAVIOR IN CALIFORNIA TODS. Journal of Architectural and Planning Research, 23(3), 247-263.

Nelson, P., Baglino, A., Harrington, W., Safirova, E., \& Lipman, A. (2007). Transit in Washington, DC: Current benefits and optimal level of provision. Journal of Urban Economics, 62(2), 231-251. https://doi.org/10.1016/j.jue.2007.02.001 
Noland, R. B., \& Lem, L. L. (2002). A review of the evidence for induced travel and changes in transportation and environmental policy in the US and the UK. Transportation Research Part D: Transport and Environment, 7(1), 1-26. https://doi.org/10.1016/S1361-9209(01)00009-8

NTD. (2000). 1999 National Transit Summaries and Trends [Text]. https://www.transit.dot.gov/sites/fta.dot.gov/files/docs/NTST\%20for\%20RY\%20 1999.pdf

NTD. (2018). 2017 National Transit Summaries and Trends [Text]. https://www.transit.dot.gov/sites/fta.dot.gov/files/docs/ntd/130636/2017-nationaltransit-summaries-and-trends.pdf

Pickerell, D. (2001). Induced Demand: Definition, Measurement an Significance. Working Together to Address Induced Demand, 26.

Schrank, D., Eisele, B., \& Lomax, T. (2012). TTI's 2012 urban mobility report. Texas A\&M Transportation Institute. The Texas A\&M University System. http://media2.kjrh.com/html/pdfs/2012urbanmobilityreport.pdf

Schrank, D., Eisele, B., \& Lomax, T. (2019). 2019 URBAN MOBILITY REPORT. https://static.tti.tamu.edu/tti.tamu.edu/documents/mobility-report-2019.pdf

Small, K. A., \& Verhoef, E. T. (2007). The economics of urban transportation. Routledge. https://books.google.com/books?hl=en\&lr=\&id=6HGBAgAAQBAJ\&oi=fnd\&pg $=$ PT6\&dq $=$ The + Economics + of + Urban + Transportation $. \& o t s=S 55 a 6 D 8 y$ C\&sig= qoffkZzyiSDc3DAgJMhZmlabMCk 
Sun, C., Zhang, W., Fang, X., Gao, X., \& Xu, M. (2019). Urban public transport and air quality: Empirical study of China cities. Energy Policy, 135, 110998. https://doi.org/10.1016/j.enpol.2019.110998

Winston, C., \& Langer, A. (2006). The effect of government highway spending on road users' congestion costs. Journal of Urban Economics, 60(3), 463-483. https://doi.org/10.1016/j.jue.2006.04.003

Xu, Y. (2017). Generalized synthetic control method: Causal inference with interactive fixed effects models. Political Analysis, 25(1), 57-76.

Yu, H., Wang, P., Zheng, H., Luo, J., \& Liu, J. (2020). Impacts of congestion on healthcare outcomes: An empirical observation in China. Journal of Management Analytics, 7(3), 344-366. https://doi.org/10.1080/23270012.2020.1731720 